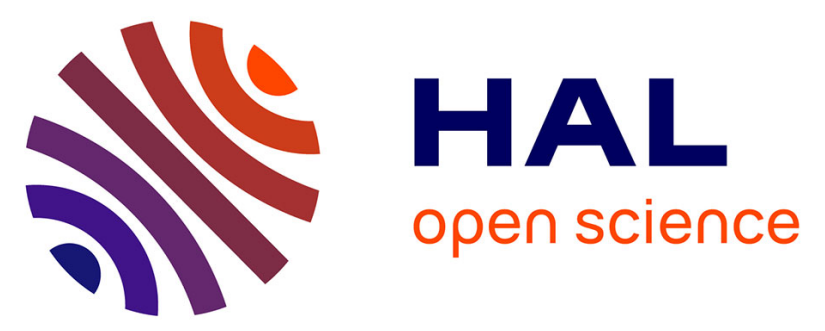

\title{
DLI-MOCVD Crx Cy coating to prevent Zr-based cladding from inner oxidation and secondary hydriding upon LOCA conditions
}

\author{
J.C. Brachet, S. Urvoy, E. Rouesne, G. Nony, M. Dumerval, Matthieu Le \\ Saux, F. Ott, A. Michau, F. Schuster, F. Maury
}

\section{To cite this version:}

J.C. Brachet, S. Urvoy, E. Rouesne, G. Nony, M. Dumerval, et al.. DLI-MOCVD Crx Cy coating to prevent Zr-based cladding from inner oxidation and secondary hydriding upon LOCA conditions. Journal of Nuclear Materials, 2021, 550, pp.152953. 10.1016/j.jnucmat.2021.152953 . hal-03212406

HAL Id: hal-03212406

https://hal-ensta-bretagne.archives-ouvertes.fr/hal-03212406

Submitted on 29 Apr 2021

HAL is a multi-disciplinary open access archive for the deposit and dissemination of scientific research documents, whether they are published or not. The documents may come from teaching and research institutions in France or abroad, or from public or private research centers.
L'archive ouverte pluridisciplinaire HAL, est destinée au dépôt et à la diffusion de documents scientifiques de niveau recherche, publiés ou non, émanant des établissements d'enseignement et de recherche français ou étrangers, des laboratoires publics ou privés. 
Title: "DLI-MOCVD $\mathrm{Cr}_{x} \mathrm{C}_{y}$ coating to prevent $\mathrm{Zr}$-based cladding from inner oxidation and secondary hydriding upon LOCA conditions"

\author{
Authors: J.C. Brachet $\left.{ }^{1}{ }^{*}\right)$, S. Urvoy ${ }^{1}$, E. Rouesne ${ }^{1}$, G. Nony ${ }^{1}$, M. Dumerval ${ }^{1}$, M. Le Saux ${ }^{1,2}$, F. Ott $^{3}$, A. \\ Michau $^{4}$, F. Schuster ${ }^{5}$, F. Maury 6 \\ 1 Université Paris-Saclay, CEA, Des - Service de Recherches Métallurgiques Appliquées, F-91191, Gif- \\ sur-Yvette, France \\ 2 Now at ENSTA Bretagne, UMR CNRS 6027, IRDL, F-29200, Brest, France \\ 3 Université Paris-Saclay, CEA-CNRS, LLB, F-91191 Gif-sur-Yvette, France \\ ${ }^{4}$ Université Paris-Saclay, CEA, Des - Service d'Etudes Analytiques et de Réactivité des Surfaces \\ (SEARS), F-91191, Gif sur Yvette, France \\ ${ }^{5}$ Université Paris-Saclay, CEA, DFP/DPg/Cross-Multidisciplinary Program on Materials Science and \\ Engineering, F-91191, Gif-sur-Yvette, France \\ ${ }^{6}$ CIRIMAT, CNRS/INPT/UPS, 4 allée E. Monso, 31030 Toulouse cedex 4, France \\ $\left({ }^{*}\right)$ corresponding author: jean-christophe.brachet@cea.fr
}

\title{
ABSTRACT:
}

Zirconium-based claddings with an outer chromium coating resistant to corrosion are studied and developed as an evolutionary Enhanced Accident Tolerant Fuel (E-ATF) concept for light water reactors. However, in hypothetical LOss-of-Coolant-Accident (LOCA) conditions, following clad ballooning and burst, the outer coating does not allow to protect the inner surface of the cladding from High Temperature $(\mathrm{HT})$ steam oxidation and associated secondary hydriding due to steam starvation occurring within the gap between the clad inner surface and the nuclear fuel pellets.

To address this issue, DLI-MOCVD (Direct Liquid Injection of Metal-Organic precursors - Chemical Vapor Deposition) $\mathrm{Cr}_{x} \mathrm{C}_{\mathrm{y}}$ coatings have been developed and successfully deposited onto the inner surface of Zr-based cladding tube prototypes. Then, preliminary two-sided oxidation tests have shown that such inner coating is able to increase the resistance to oxidation at HT of the inner clad surface.

The present study aimed at performing new steam oxidation tests at $1200^{\circ} \mathrm{C}$ on Zircaloy- 4 clad

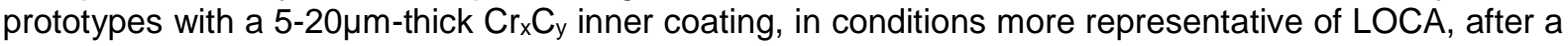
first internal pressure-induced burst step. Additionally, complementary two-sided steam oxidation tests have been carried out up to $1 \mathrm{~h}$ at $1200^{\circ} \mathrm{C}$, on short inner and/or outer-coated clad segments. Finally, Post-Quench (PQ) Ring Compression Tests (RCTs), fractographic analysis and deep metallurgical investigations including neutron-tomography have been performed to get more insights into the $P Q$ behavior of the inner-coated clad.

Among other results, it is shown that the inner $\mathrm{Cr}_{x} \mathrm{C}_{y}$ coating makes it possible to reduce significantly the oxidation and the associated secondary hydriding of the clad inner surface, after ballooning and burst. After at least $600 \mathrm{~s}$ under steam at $1200^{\circ} \mathrm{C}$, the reference uncoated clad fails upon final water quenching while the inner-coated prototype keeps its integrity. PQ RCTs showed a higher strength of the inner-coated material, related to lower oxygen and hydrogen uptakes of the substrate.

KEYWORDS: Enhanced Accident Tolerant Fuel, $\mathrm{Cr}_{x} \mathrm{C}_{y}$ DLI-MOCVD inner coating, Zircaloy-4, LOCA, high temperature steam oxidation, secondary hydriding, post-quenching strength and ductility 


\section{HIGHLIGHTS:}

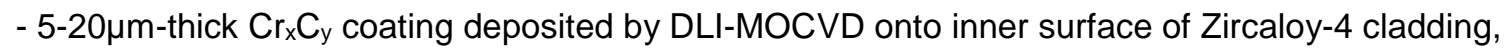

- Protection against steam oxidation at $1200^{\circ} \mathrm{C}$ comparable to outer PVD-deposited $10-15 \mu$ m-thick $\mathrm{Cr}$ coating.

- Significant reduction of secondary hydriding after clad ballooning and burst.

- Higher mechanical strength of the cladding, upon and after water quenching. 


\section{INTRODUCTION}

Zirconium-based claddings with outer corrosion resistant chromium-based coatings are studied and developed worldwide as an evolutionary Enhanced Accident Tolerant Fuel (E-ATF) concept for light water reactors, bringing additional High Temperature $(\mathrm{HT})$ oxidation resistance in hypothetical accident conditions [1]-[23]. However, in case of leaking fuel or following clad ballooning and burst upon hypothetical LOss-of-Coolant-Accident (LOCA), the outer coatings developed so far are not able to protect the clad inner surface from steam oxidation and from the associated secondary hydriding phenomena. To address this issue, DLI-MOCVD (Direct Liquid Injection of Metal-Organic precursors Chemical Vapor Deposition) $\mathrm{Cr}_{x} \mathrm{C}_{y}$ inner coating has been developed and successfully deposited on the inner surface of Zr-based cladding tube prototypes [24]-[26]. Then, preliminary oxidation tests have shown that such inner coating may increase the oxidation resistance of the clad inner surface at HT [27]-[28]. However, the preliminary two-sided HT oxidation tests carried out until now were not fully representative of LOCA situations, in which the clad inner surface is exposed to an oxidizing steam atmosphere confined into the gap between the nuclear-fuel pellets and the cladding tube. In such conditions, due to steam starvation, the cladding materials experience localized massive hydrogen uptake, characterized by "hydrogen peaks", a few centimeters from the burst opening, with hydrogen contents up to 3000-4000 parts per million in weight (wt.ppm). Such phenomena may induce cladding embrittlement and loss of clad integrity upon the final water quenching and/or in Post-Quenching (PQ) situation. Thus, they have been extensively studied at ANL [29]-[30], at JAERI/JAEA [31]-[39], at KIT [40]-[46] and at other institutes [47]-[48]. Additionally, modelling efforts have been carried out [50]-[52] and safety criteria have been proposed in some countries, to account for this clad embrittlement due to secondary hydriding, following ballooning and burst upon LOCA conditions [53]-[57].

To address this issue, the present study aimed at performing new and more LOCA-representative HT oxidation tests on the DLI-MOCVD inner $\mathrm{Cr}_{x} \mathrm{C}_{y}$-coated $\mathrm{Zr}$-based cladding prototypes [27]-[28].

Additionally, complementary HT two-sided steam oxidation tests have been carried out on inner and/or outer-coated short clad segments. Finally, PQ Ring Compression Tests (RCTs), fractographic analysis and deep metallurgical investigations (including neutron tomography to obtain 3D mapping of hydrogen) have been performed to get more insights into the $P Q$ behavior of inner-coated clad.

\section{MATERIALS AND EXPERIMENTAL PROCEDURES}

\subsection{Coated and uncoated materials}

\section{Uncoated substrate materials:}

Fully recrystallized Zircaloy-4 with high tin and oxygen contents (HSn-HO-Zirc-4), $0.6 \mathrm{~mm}$-thick, cladding tube has been used as a substrate. The contents of the main alloying chemical elements are given in Table 1. It has to be mentioned that the quality of the "old grade" Zircaloy-4 cladding material tested is not representative of modern industrial advanced cladding materials in as-received conditions. The clad inner surface exhibits a high roughness and some superficial oxidation, as shown below. Thus, in the following, this material has to be considered as having a "lower-bond quality" compared to modern nuclear fuel cladding materials, especially at its inner surface. Indeed, it is likely that this poor quality (rough and slightly oxidized) of the as-received clad inner surface negatively impact the adhesion of the inner coating.

\begin{tabular}{|c|c|c|c|c|c|c|}
\cline { 2 - 7 } \multicolumn{1}{c|}{} & \multicolumn{4}{c|}{ Wt.\% } & \multicolumn{2}{c|}{ Wt.ppm } \\
\hline Alloy & Sn & Fe & Cr & O & H & N \\
\hline HSn-HO-Zirc-4 & $\mathbf{1 . 6 2}$ & 0.20 & 0.10 & $\mathbf{0 . 1 8}$ & 12 & 60 \\
\hline
\end{tabular}

Table 1 - Contents of the main alloying chemical element of the "old grade" high tin - high oxygen Zircaloy-4 used as a substrate 


\section{Coated materials:}

$\mathrm{Cr}_{x} \mathrm{C}_{\mathrm{y}}$ coatings were deposited directly inside a bundle of 16 cladding tubes with a horizontal hot-wall CVD chamber of approximately $0.15 \mathrm{~m}$ of inner diameter and $1 \mathrm{~m}$ of length. A liquid solution of bis(ethylbenzene)chromium (precursor) and toluene (solvent) was vaporized using a Kemstream DLI system and sent to the inside of the 16 claddings segments at $670 \mathrm{~Pa}$ heated at $325^{\circ} \mathrm{C}$ by a tubular furnace. More information about the deposition chamber can be found in [25].

A schematic view of the inner-coated $1 \mathrm{~m}$-long Zircaloy-4 cladding tube prototype studied here is shown in Figure 1. In this figure, the different samples machined and tested are represented together with the as-received inner coating thicknesses measured by Optical Microscopy (OM) at different axial locations. Due to the deposition process used, there is an axial gradient of the inner coating thickness from the left end to the right end of the tube. In consequence, depending of the axial position, the inner $\mathrm{Cr}_{x} \mathrm{C}_{\mathrm{y}}$ coating thickness ranges from $\sim 20 \mu \mathrm{m}$ at the M2 location down to $\sim 6 \mu \mathrm{m}$ at the M5 location. It is nevertheless possible to inject sequentially the reactive vapor at each end of the chamber to smoothen thickness profiles, as demonstrated in [24] for a single $1 \mathrm{~m}$-long cladding segment. In the following, one has to account for the different inner coating thicknesses when analyzing the results. The different clad segment geometries tested and/or analyzed are:

- "Mi" 5mm-long rings, for as-received microstructural observation and hydrogen analysis;

- "Oi" 30mm-long clad segments for two-sided HT steam oxidation testing followed by PQ microstructural and micro-chemical analysis and RCTs. Among these samples and following the inner DLI-MOCVD deposition process, $\sim 10 \mu \mathrm{m}$-thick outer chromium coating has been deposited on two of these $30 \mathrm{~mm}$ long segments by the PVD process already used for previous CEA-Framatome-EDF studies on outer Cr-coated advanced nuclear fuel claddings [2][7][11][20][21]. Following preliminary air oxidation tests carried out at $1100^{\circ} \mathrm{C}$ on such double-coated claddings [28], the idea here was to have a deeper view of the benefits, regarding oxidation resistance and $P Q$ mechanical behavior, of double (inner + outer) coating protection in conditions more representative of LOCA, i.e. two-sided HT steam oxidation at $1200^{\circ} \mathrm{C}$ followed by direct water quenching.

- "E1" and "E2" longer segments that have been used for two-steps LOCA testing, including a first internal pressure thermal ramp test leading to cladding burst and a subsequent steam oxidation test at $1200^{\circ} \mathrm{C}$ followed by direct water quenching. So, these two particular segments have been specifically devoted to the study of secondary hydriding following burst occurrence upon LOCA. The results have been compared to those obtained in the same conditions on the uncoated clad.

\subsection{Experimental procedures}

Internal pressure burst tests, one/two-sided HT steam oxidation tests, $\mathrm{PQ}$ mechanical tests and metallurgical examination including micro-chemical analysis and neutron radiography/tomography have been carried out on several CEA's facilities already described in details in [47] and [58]-[62]. They are only briefly recalled below.

Internal pressure thermal ramp tests to burst have been carried out using the "EDGAR" facility used at CEA for more than twenty years to perform thermal-mechanical tests upon LOCA conditions on $500 \mathrm{~mm}$-long clad segments [58]. Direct Joule heating was used to be able to achieve fast enough heating rates with good circumferential temperature homogeneity. The evolution of the cladding outer diameter was measured using a non-contact laser extensometer. Temperature was monitored and controlled by pyrometers and internal thermocouples. The tests were performed under steam and stopped just after the burst. The tested clad segments were then cooled at moderate rate (a few tenths of ${ }^{\circ} \mathrm{C} / \mathrm{s}$ at the beginning of the cooling) down to RT. The internal pressure and heating rate applied here were set to 40 bars and $25^{\circ} \mathrm{C} / \mathrm{s}$ respectively. These particular values have been chosen to allow a comparison with previous data obtained on uncoated M5Framatome reference cladding segments [47]. Since the final cladding hoop strain at burst and the overall balloon size, and thus the inner gap size, may depend on the internal pressure and heating rate applied, the results obtained here should not be extrapolated directly to other testing conditions. Indeed, due to the limited ductility of the inner coating, it is likely that larger clad deformations than those experienced here promote cracking of the inner $\mathrm{CrC}$ coating, and thus influence secondary hydriding). 
- $\quad$ Following the creep and burst sequence, $150 \mathrm{~mm}$-long segments have been machined from the segments tested in "EDGAR" by localizing the burst opening at their mid-length. An alumina rod $(8.2 \mathrm{~mm}$ in diameter) has been inserted inside the tube to simulate the gap between the fuel pellets and the clad inner surface. Zircaloy- 4 end caps have been welded at both clad segment extremities. A typical macrograph of a pre-burst clad segment before the subsequent HT oxidation test is shown in Figure 2(a).

Oxidation tests in steam at $1200^{\circ} \mathrm{C}$ for different oxidation times have been carried out in the CEA's "DEZIROX 1" facility [59]-[61]. Upon the HT oxidation process, the axial temperature gradient along the $150 \mathrm{~mm}$-long clad segment is lower than $10-15^{\circ} \mathrm{C}$. Direct water quenching from $1200^{\circ} \mathrm{C}$ down to Room Temperature (RT) was applied at the end of the isothermal HT oxidation step. It must be mentioned that, compared to a direct quenching from the $\mathrm{HT} \beta \mathrm{zr}$ temperature range, when the final water quenching is applied at 600 or $700^{\circ} \mathrm{C}$ (after a first cooling at an intermediate rate, i.e., $0.1-10^{\circ} \mathrm{C} / \mathrm{s}$ ), an increase of the PQ clad ductility has been observed for Zircaloy-4 pre-hydrided at $600-700$ wt.ppm [60]. This cooling scenario effect has been attributed to the hydrogen and oxygen micro-chemical partitioning occurring upon the on-cooling $\beta_{z r} \rightarrow \alpha_{z r}$ phase transformation, and to its consequences on the local prior- $\beta z$ r hardening and embrittlement at $R T$, related to the intermediate cooling rate and the temperature from which the final water quenching is applied [62]. Thus, in the following, one has to keep in mind that the direct quenching conditions applied here are likely conservative compared to two-steps cooling. In other words, it is possible that the direct quenching applied induces higher PQ clad embrittlement compared to more LOCA-representative two-steps cooling.

- $\quad$ As already extensively used by M. Grosse et al. [41]-[46] [63] to study HT secondary hydriding, non-destructive neutron radiography/tomography has been performed to have a better view of the hydrogen redistribution, in three dimensions, in the samples that have experienced internal pressureinduced burst followed by HT oxidation and quenching. The experiments were performed on the IMAGINE radiography station connected to the experimental Orphée reactor at CEA Saclay. Compared to previous measurements [47], smaller spatial resolution was used (voxel size down to $50 \mu \mathrm{m}$ ) to be able to map the hydrogen content not only as an integrated value for a given azimuthal position but also across the thickness of the cladding wall. The hydrogen quantity in the cladding was normalized with respect to reference samples with calibrated hydrogen contents. The typical sensitivity to hydrogen content is of the order of 100 wt.ppm.

- $\quad$ Additional PQ destructive hydrogen content measurements were performed by an Inert Gas Fusion Thermal Conductivity (IGFTC) technique using a HORIBA EMGA-821 analyser. Electron Probe Micro-Analysis (EPMA) using a Cameca SX-100 microprobe was carried out to quantify the oxygen (and other alloying elements) concentration profile through the clad wall thickness.

- $\quad$ Local hardening of the quenched prior- $\beta$ zr material is sensitive to the additional oxygen resulting from oxygen diffusion induced by the HT steam oxidation process. Thus, one can roughly evaluate the local oxygen content from micro-hardness measurements by using the following equation from [60].

$$
H V(0.1) \text { Prior- } \beta \text { Zr Zircaloy-4 }=370 \times[w t . \% \text { O }]+224 \quad \text { Equation } 1
$$

where $\mathrm{HV}(0.1)$ denotes the Vickers hardness at $0.1 \mathrm{~kg}$. Alternatively, the following relationship can be derived from the data already presented and discussed in [47]. This relationship is more representative of the hardening of the quenched prior- $\beta z$ r microstructure of highly hydrided materials, i.e., up to $\sim 3000$ 4000 wt.ppm of hydrogen.

$$
H V(0.1) \text { Prior- } \beta_{Z r} \text { Highly Hydrided-Zircaloy-4 }=193 \times[w t . \% \text { O }]+301 \quad \text { Equation } 2
$$

Then, systematic PQ micro-hardness measurements have been carried out using a Buehler VH-3300 device equipped with Vickers or Knoop indenters. Up to 50 indents were performed throughout the clad wall thickness on each sample characterized after quenching, under an applied load of $0.05,0.01$ or $0.025 \mathrm{~kg}$. These low load levels have been chosen to obtain a good description of the gradient through 
the clad thickness. It has been checked that these low load levels gave results comparable to those obtained from Vickers hardness measurements performed at $0.1 \mathrm{~kg}$, as more conventionally done.

Finally, $\mathrm{PQ} R C T$ s have been carried out on $10 \mathrm{~mm}$-long clad segments machined from the samples oxidized at $\mathrm{HT}$. The tests were conducted on a universal electromechanical tensile machine at temperatures of 20 and $135^{\circ} \mathrm{C}$ (saturation temperature during reflood in the case of large break LOCA), with a cross-head displacement rate of $0.5 \mathrm{~mm} / \mathrm{min}$ (up to a maximum displacement of $6 \mathrm{~mm}$ or a maximum load of $2 \mathrm{kN}$ ). Failure of RCT samples was considered to occur at the first significant load drop of more than $30 \%$, which may indicate the formation of at least one through-wall crack. The fracture surface of the samples was examined using Scanning Electron Microscopy (SEM) to assess the PQ failure mode.

Figure 2-(b) shows the locations where the samples were machined from the tested clad segments for $P Q$ analysis.

\section{RESULTS AND DISCUSSION}

\subsection{As-received conditions}

Zr-based substrate: As already mentioned, the "old-grade" HSn-HO-Zirc-4 material used here for the substrate is not fully representative of modern advanced nuclear fuel cladding made of zirconium-based alloys. Figure 3-(a) illustrates its as-received microstructure with a homogenous distribution of equiaxed azr grains. The corresponding Vickers micro-hardness value is $200 \mathrm{HV}_{0.05}$, which is typical of fully recrystallized $\alpha z$ microstructure. Additionally, a typical (non-oxidized) quenched prior- $\beta z$ r microstructure is depicted in Figure 3-(b) showing a Vickers micro-hardness of $275 \mathrm{HV}_{0.05}$. Such microstructure has been obtained after a "flash" $\beta \mathrm{zr}$ thermal treatment at $1000^{\circ} \mathrm{C}(<30 \mathrm{~s})$ followed by water quenching down to RT to avoid significant HT oxidation. Thus, the hardness value measured seems to be higher than the typical one obtained for low-tin Zircaloy-4 prior- $\beta_{\mathrm{Zr}}\left(\sim 220 \mathrm{HV}_{0.05}\right)$. This is likely due to the higher oxygen and tin contents of HSn-HO-Zirc-4.

Outer coating: Figure 4 illustrates the typical as-received microstructure of the $\sim 10 \mu \mathrm{m}$-thick $\mathrm{Cr}$ outerPVD-coated materials. Multiscale characterizations (down to the atomic scale) of the microstructures of such PVD-deposited $\mathrm{Cr}$ coating and $\mathrm{Cr}$-Zr interface have been already reported and discussed in [11][20][64]. Just recall that, by using convenient PVD deposition parameters and process, such coatings are characterized by:

- low surface roughness and good thickness uniformity,

- very few defects/micro-cracks,

- no delamination or porosities at the $\mathrm{Cr}-\mathrm{Zr}$ interface, thus inducing high bonding strength, even after (ion) irradiation [65],

- columnar grains morphology with specific crystallographic textures,

- reduced compressive internal stresses.

Inner coating: Detailed information about the typical microstructure of DLI-MOCVD $\mathrm{Cr}_{x} \mathrm{C}_{\mathrm{y}}$ inner coating has been already published in [26] and [27]. However, it is necessary to briefly discuss the particular microstructure of the inner-coated clad segment studied here. Figure 5 shows the typical aspect of the clad wall thickness at the "M2" axial location (Figure 1), corresponding to $\sim 20 \mu$-thick inner $\mathrm{Cr}_{x} \mathrm{C}_{\mathrm{y}}$ coating. One can observe the typical fully recrystallized structure of the HSn-HO-Zirc-4 substrate and a quite uniform inner coating thickness. Recall that previous studies have shown that such coating is in an amorphous state in as-received conditions.

However, localized delamination and porosities are observed at the $\mathrm{Zr} / \mathrm{Cr}_{x} \mathrm{C}_{\mathrm{y}}$ interface. This could be partially related to the poor initial surface quality of the "old-grade" material used here as a substrate, as shown in Figure 6-(a). The SEM micrograph in Figure 6-(b) illustrates the typical morphology of the inner coating surface. The coating surface appears to have a quite smooth aspect with localized circular protrusions. Some localized cracks and delamination (not illustrated here) are also observed, indicating that an additional optimization of the deposition process and a substrate material with a smoother initial surface are necessary to further improve the inner coating adhesion properties. 
Additionally, Figure 7 shows mapping and quantitative profiles of chemical elements obtained by EPMA within the wall thickness of the as-received $20 \mu \mathrm{m}$-thick amorphous $\mathrm{Cr}_{x} \mathrm{C}_{y}$ inner coating at the "M2" axial location. The average chemical stoichiometry of the coating deduced by integrating the EPMA profiles is close to $\mathrm{Cr}_{0.58} \mathrm{C}_{0.30} \mathrm{O}_{0.12}$, which is in very good agreement with previous $\mathrm{X}$-ray Photoelectron Spectroscopy (XPS) measurements reported in [26]. However, a significant oxygen content is observed, especially near the $\mathrm{Cr}_{x} \mathrm{C}_{y}-\mathrm{Zr}$ interface. Such an oxygen pollution may be attributed to the CVD process itself but also to the poor quality of the inner surface of the substrate (i.e., with thin zirconium oxide and/or hydroxide scales initially present on its surface, before the CVD deposition process). Interestingly and neglecting the oxygen contribution, the chemical profiles in Figure 7-(b) show a continuous evolution of the $\mathrm{Cr} / \mathrm{C}$ ratio with an apparent stoichiometry going from $\mathrm{Cr}_{7} \mathrm{C}_{3}$ near the $\mathrm{Cr}_{x} \mathrm{C}_{y}-\mathrm{Zr}$ interface to $\mathrm{Cr}_{3} \mathrm{C}_{2}$ close to the outer coating surface. Between these two zones, and based on previous studies and interpretation, one can make the assumption that there are nanometric $\mathrm{C}$-free domains embedded in an amorphous $\mathrm{Cr}_{7} \mathrm{C}_{3}$ carbide matrix. Thus, in the following, this specific as-received amorphous nanocomposite structure and the existence of a gradient in $\mathrm{Cr} / \mathrm{C}$ concentration ratio along the coating wall thickness have to be kept in mind, for further interpretation of the coating microstructural evolution upon HT steam oxidation, typical of LOCA situations.

\subsection{HT two-sided steam oxidation and PQ RCT of inner/outer-coated short clad segments}

Weight gain evolution and hydrogen uptake - The HT steam oxidation conditions tested and the associated weight gains and $P Q$ hydrogen contents measured for uncoated and coated materials are summarized in Table 2. All the tested $30 \mathrm{~mm}$-long clad segments kept their integrity after the final direct water quenching down to RT, except the uncoated one oxidized for 3220 s at $1200^{\circ} \mathrm{C}$, consistently with its very high "Baker-Just" [66] "Equivalent Cladding Reacted " (ECRBJ) calculated value of $70 \%$.

The evolution of weight gain as a function of the two-sided oxidation time in steam at $1200^{\circ} \mathrm{C}$ is plotted in Figure 8 for uncoated and coated $30 \mathrm{~mm}$-long clad segments. The results are compared with onesided steam oxidation data previously obtained at CEA on uncoated low-tin Zircaloy-4 [60] and on 12$15 \mu \mathrm{m}$-thick $\mathrm{Cr}$ outer-coated M5Framatome claddings [21]. From this figure, the following observations can be made:

- Despite its non-optimized chemical composition and poor inner surface quality, the old-grade HSn-HOZirc-4 behaves more or less like modern low-tin Zircaloy-4.

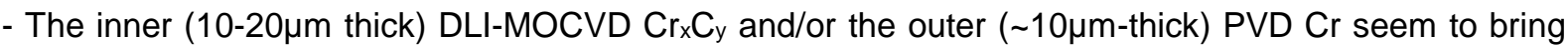
good protectiveness against steam oxidation at least up to 1500 s (two-sided ECR $\mathrm{BJ}=47.5 \%$ ) at $1200^{\circ} \mathrm{C}$. Indeed, the weight gains of inner or outer one-sided coated materials are nearly half those of the uncoated materials after two-sided oxidation for 600-1500s. This means that, for these particular cases, the measured weight gain is essentially due to the oxidation of the (outer or inner) uncoated (and thus unprotected) clad surface. This is further confirmed by the behavior of the two-sided (inner + outer) coated samples, showing a very limited overall weight gain of only $2.2 \mathrm{mg} / \mathrm{cm}^{2}$ after two-sided steam oxidation up to $1500 \mathrm{~s}$ at $1200^{\circ} \mathrm{C}$. As shown in Figure 8 , this low weight gain value is comparable to the one achieved after one-sided (outer) steam oxidation for 1500 s at $1200^{\circ} \mathrm{C}$ of $12-15 \mu \mathrm{m}$-thick (PVD) $\mathrm{Cr}$ outer-coated M5Framatome [21].

- For the higher (two-sided) oxidation time tested (3220s), the measured weight gain of the inner-coated sample is close to the uncoated reference one. This indicates that, for such a high ECRBJ value $(70 \%)$, the $10-20 \mu \mathrm{m}$ thick DLI-MOCVD $\mathrm{Cr}_{x} \mathrm{C}_{\mathrm{y}}$ coating is no more protective. Indeed, as already illustrated in [27], for such a long oxidation time, both uncoated and inner-coated samples have been almost fully transformed into zirconia and $\alpha_{\mathrm{zr}}(\mathrm{O})$ layers, thus inducing a high brittleness. However, it should be noticed that, for the same (one-sided) oxidation time at $1200^{\circ} \mathrm{C}$, a $12-15 \mu \mathrm{m}$-thick PVD Cr outer coating on a M5Framatome substrate is still protective [21].

- Additionally, as shown in Table 2, the hydrogen contents measured post-oxidation show negligible or very limited hydrogen uptake, except for the inner-coated sample tested for $3220 \mathrm{~s}$ at $1200^{\circ} \mathrm{C}$ for which the measured hydrogen concentration is close to $160 \mathrm{wt} . \mathrm{ppm}$. Such phenomena could be due to a "transient" hydrogen uptake, as already observed on 12-15 $\mu$ m-thick (PVD) Cr outer-coated M5Framatome 
for equivalent ECR values (i.e. for one-sided $E C R_{B J}$ higher than $50 \%$ at $1200-1300^{\circ} \mathrm{C}$ ) [20]. This has been attributed to the short period when the coating loses its protectiveness, thus inducing a direct access of steam molecules to the metallic zirconium-based substrate. For longer oxidation times, it was then observed that there was no more additional hydrogen uptake. It was thus assumed that, beyond this short period of transient hydrogen uptake, additional hydrogen uptake is prevented by the subsequent rapid growth of a dense and thick enough sub-coating zirconia layer. It would be interesting to check if such saturation of the hydrogen content is also operant for the present inner $\mathrm{Cr}_{x} \mathrm{C}_{\mathrm{y}}$ coating, when tested at longer oxidation times (i.e., beyond the oxidation time when the coating loses its protectiveness).

In summary, based on the measured weight gains, one may conclude that, overall, the inner $(10-20 \mu \mathrm{m}$ thick) DLI-MOCVD $\mathrm{Cr}_{x} \mathrm{C}_{\mathrm{y}}$ coating associated with an outer ( $\sim 10 \mu \mathrm{m}$ thick) PVD Cr coating brings a significant coping time upon two-sided HT steam oxidation, up to an ECRBJ value of $\sim 50 \%$ (>1500s) at $1200^{\circ} \mathrm{C}$. Such performances have been already achieved on PVD Cr-outer-coated materials, but in that case, only upon one-sided outer oxidation at HT [21].

\begin{tabular}{|c|c|c|c|c|c|c|}
\hline $\begin{array}{c}\text { Materials } \\
\text { (substrate }=\text { HSn-HO-Zirc-4) }\end{array}$ & $\begin{array}{c}\text { Initial } \\
\text { outer / } \\
\text { inner } \\
\text { coating } \\
\text { thickness } \\
(\mu \mathrm{m})\end{array}$ & $\begin{array}{c}\text { Two- } \\
\text { sided } \\
\text { steam } \\
\text { oxidation } \\
\text { time at } \\
1200^{\circ} \mathrm{C} \\
\text { (s) }\end{array}$ & $\begin{array}{c}\text { Calculated } \\
E^{E C R_{B J}(\%)} \\
\left(^{*}\right)\end{array}$ & $\begin{array}{l}\text { Measured } \\
\text { weight } \\
\text { gain } \\
\left(\mathrm{mg} / \mathrm{cm}^{2}\right)\end{array}$ & $\begin{array}{c}\text { Post- } \\
\text { oxidation } \\
\text { hydrogen } \\
\text { content } \\
\text { (wt.ppm) }\end{array}$ & $\begin{array}{l}\text { Post- } \\
\text { quenching } \\
\text { integrity }\end{array}$ \\
\hline \multirow{2}{*}{ Uncoated } & \multirow{2}{*}{$0 / 0$} & 600 & 30 & 14.88 & 27 & YES \\
\hline & & 3220 & 70 & 34.63 & 51 & $\mathrm{NO}\left({ }^{* *}\right)$ \\
\hline $\mathrm{Cr}_{x} \mathrm{C}_{y}$ inner coated "O2" & $0 / \sim 20$ & 600 & 30 & 8.3 & 37 & YES \\
\hline $\mathrm{Cr}_{x} \mathrm{C}_{\mathrm{y}}$ inner coated "O1" & $0 / \sim 20$ & 3220 & 70 & 29.22 & 164 & $\begin{array}{c}\text { YES/NO } \\
\left({ }^{\star \star \star}\right)\end{array}$ \\
\hline Cr outer coated & $9 / 0$ & 600 & 30 & 7.56 & 25 & YES \\
\hline Cr outer coated & $9 / 0$ & 1500 & 47.5 & 11.8 & 31 & YES \\
\hline $\mathrm{Cr} / \mathrm{Cr}_{x} \mathrm{C}_{y}$ two-sided-coated "O4" & $9 / 9$ & 600 & 30 & 1.05 & 35 & YES \\
\hline $\mathrm{Cr} / \mathrm{Cr}_{x} \mathrm{C}_{\mathrm{y}}$ two-sided-coated "O3" & $9 / 11$ & 1500 & 47.5 & 2.22 & 48 & YES \\
\hline
\end{tabular}

Table 2 - HT steam oxidation conditions, associated weight gains and PQ hydrogen contents of uncoated, and of inner and/or outer-coated HSn-HO-Zirc-4 (30mm-long) clad segments

(*) Equivalent Cladding Reacted (ECR) parameter calculated using the "Baker-Just" correlation for two-sided oxidation of uncoated $610 \mu m$-thick cladding tubes

$\left(^{* *}\right)$ longitudinal (through-wall) crack; high PQ embrittlement (failure upon machining/cutting)

$\left.{ }^{* \star *}\right)$ external rough protrusions, but with no apparent through-wall cracking; high $P Q$ embrittlement (failure upon machining/cutting)

$\mathrm{Cr}_{x} \underline{C}_{y}$ inner coating microstructure after steam oxidation for 600 s at $1200^{\circ} \mathrm{C}$ - Post-HT-oxidation microstructures of both outer $\mathrm{Cr}$ PVD and inner DLI-MOCVD $\mathrm{Cr}_{x} \mathrm{C}_{\mathrm{y}}$ coatings have been already described in details in [11][20][21] and Erreur ! Source du renvoi introuvable.[27], respectively. However, it seems useful to recall some Electron-Back Scattered Diffraction (EBSD) results obtained on the inner $\mathrm{Cr}_{x} \mathrm{C}_{y}$ coating, after two-sided steam oxidation for 600 s at $1200^{\circ} \mathrm{C}$, as illustrated in Figure 9 (replotted from [27]). In this figure, one can observe that preferential recrystallization and formation of $\mathrm{Cr}_{7} \mathrm{C}_{3}$ and $\mathrm{Cr}_{3} \mathrm{C}_{2}$ have occurred in the vicinities of the $\mathrm{Cr}_{x} \mathrm{C}_{y}-\mathrm{Zr}$ interface and the outer coating surface, respectively. This can be understood from the EPMA results already shown in Figure 7. Indeed, their localization coincides with the coating depth where the $\mathrm{Cr} / \mathrm{C}$ atomic fraction ratio is close to the stoichiometries of carbides, thus promoting their crystallization upon HT incursion. By contrast, at the coating mid-thickness, EBSD analysis failed to identify recrystallized carbides phases, while submicronic chromia crystallites have been identified. These last ones are likely due to the initial oxygen content (i.e., $\sim 10$ atomic\%) within the amorphous $\mathrm{Cr}_{x} \mathrm{C}_{y}$ coating layer and to potential additional oxygen diffusion from the outer oxidized coating surface which took place upon steam oxidation at $1200^{\circ} \mathrm{C}$. However, at coating mid-thickness, one can assume that the observed delay in carbides crystallization 
could be due to the local as-received particular nanocomposite structure, with some nanometric carbonfree domains embedded in an amorphous $\mathrm{Cr}_{7} \mathrm{C}_{3}$ carbide matrix [27]. It is possible that such a nonstoichiometric as-received (amorphous) microstructure, with some carbon-free submicronic areas, is less favorable to further crystallization of HT chromium carbides. As already discussed in [27], maintaining such an amorphous (crystallite free) microstructure as long as possible at HT could delay the overall oxidation kinetics of the coating, by decreasing the density of grain boundaries which can be assumed to be accelerated diffusion paths for oxygen. Additionally, in this figure, one can observe a more or less continuous, micrometer-thick, zirconium carbide layer at the $\mathrm{Cr}_{x} \mathrm{C}_{y}-\mathrm{Zr}$ interface, which has been induced by (spatially limited) $\mathrm{Zr}-\mathrm{C}$ interdiffusion phenomena at $\mathrm{HT}$.

Effects of pre-cracks/defects in the $\mathrm{Cr}_{x} \underline{C}_{y}$ coating - One important issue of coated claddings, especially upon LOCA, is the consequence of potential defects/cracks in the coating on the subsequent (localized) HT oxidation and the effect on the cladding residual strength and ductility upon quenching and postquenching situations. This is one of the fundamental reason for having chosen pure metallic chromium coating for the outer clad protection instead of ceramic ones, during the early studies carried out at CEA on several types of coatings [11]. Indeed, it has been shown that, upon LOCA transient, optimized PVD $\mathrm{Cr}$ metallic coating is able to sustain significant clad ballooning without cracking or spallation, thus preserving the protection against the subsequent HT oxidation, even at the balloon location [67]-[69]. Because of the amorphous and/or ceramic nature of the inner $\mathrm{Cr}_{x} \mathrm{C}_{\mathrm{y}}$ coating studied here, it is anticipated that this type of coating may experience significant cracking upon clad deformation (ballooning) typical of LOCA situations. Figure 10 depicts typical zones in samples with an inner $\mathrm{Cr}_{x} \mathrm{C}_{y}$ coating with preexisting cracks that have experienced HT steam oxidation and quenching. One can observe three typical (localized) oxidation behaviors at the locations of the defects/cracks in the inner coating:

- Type-1 coating crack/defect with no oxygen diffusion into the Zr substrate. This particular situation seems to be due to the coating self-healing capacity, i.e, formation of a dense and thick enough $\mathrm{Cr}_{2} \mathrm{O}_{3}$ scale inside the cracking, thus preserving the $\mathrm{Zr}$ substrate from further oxygen penetration and diffusion.

- Type-2 coating crack/defect with partial oxygen diffusion into the $Z r$-based substrate inducing $\alpha_{z r}(O)$ incursions (partial self-healing capacity). Such a situation may occur when the inward oxygen diffusion flux into the zirconium substrate is not high enough to promote zirconium oxide formation but sufficient to induce $\alpha_{z r}(O)$ formation. In fact, such a situation has also been observed, transitorily, for the outer PVD Cr-coated cladding when the $\mathrm{Cr}$ coating begins to be no more protective, upon long enough $\mathrm{HT}$ oxidation [20][21].

- Type-3 coating crack/defect with under-coating zirconia spot formation (no self-healing). In that particular case, the rapid formation of under-coating zirconia, due to a direct access of steam to the $\mathrm{Zr}$ based substrate, leads to opening of the pre-existing crack/defect due to the associated volume change (i.e., "Pilling-Bedworth" ratio). This situation has been already observed on outer PVD Cr-coated cladding when the coating loses definitely its HT oxidation protectiveness [20][21]. However, as already observed on PVD outer Cr-coated Zr-based claddings, there is no sign of local oxidation acceleration, nor of extended coating delamination and spallation at the vicinity of the cracks. Indeed, the freshly formed sub-coating zirconia spot is always thinner (or at least equivalent) than the zirconia scale formed in the same HT oxidation conditions on uncoated Zr-cladding, as already observed for PVD coated materials [11][70][75].

It must be pointed out that such defects were not so numerous on the (not deformed) clad segments tested. It is why they did not significantly affect the overall oxidation kinetics as derived from the measured weight gain evolution. However, after significant clad deformation (ballooning), the surface density of such through-wall cracks in the coating may increase and thus may affect the PQ strength and ductility of inner $\mathrm{Cr}_{x} \mathrm{C}_{\mathrm{y}}$ coated materials that have experienced ballooning and burst, followed by $\mathrm{HT}$ steam oxidation of the inner (coated) clad surface.

EPMA and micro-hardness profiles - As initially reported by Sawatzky [71] and Chung \& Kassner [72], oxygen content in the residual prior- $\beta$ zr layer is a key parameter to predict the post-quench mechanical behavior of as-received zirconium-based nuclear fuel cladding tubes, after HT steam oxidation and final water quenching typical of LOCA situations. More recently, the critical oxygen content for waterquenched prior- $\beta$ Zr structure has been reassessed for both Zircaloy-4 and Zr-Nb alloys [60][60][73][74]. 
For example, based on $\mathrm{PQ}$ impact tests, a critical oxygen content value of $0.4+/-0.1 \mathrm{wt} \%$ has been related to the Ductile-to-Brittle (DBT) failure mode transition of (as-water-quenched) prior- $\beta z$ r at RT, for both Zircaloy-4 and M5Framatome alloys [60]. Then, in the following, particular attention is paid to the PQ oxygen (but also chromium) diffusion profiles through the cladding thickness measured by EPMA, especially in the residual prior- $\beta_{z r}$ layer. Indeed, this last layer is the only residual part of the cladding able to keep significant ductility and toughness after HT steam oxidation and quenching. Then, the oxygen (and chromium) diffusion profiles can be related to the associated hardening of the as-quenched prior- $\beta$ zr structure. For this purpose, Table 3 and Figure 11 to Figure 16 summarize the oxygen and chromium diffusion profiles measured by EPMA and the associated micro-hardness profiles for the different types of coated samples, after two-sided steam oxidation up to $1500 \mathrm{~s}$ at $1200^{\circ} \mathrm{C}$ (i.e., up to an $E C R_{B J}$ value of nearly $50 \%$ ). The two uncoated / inner-coated clad segments oxidized up to 3220 s have not been considered here because, due to the very high ECRBJ achieved $(70 \%)$, these samples have been fully transformed into brittle zirconia and $\alpha z r(O)$ thick layers, as already shown and discussed in [27]. One can make the following observations:

- After two-sided oxidation for 600 s at $1200^{\circ} \mathrm{C}\left(E C R_{B J}=30 \%\right)$ : due to the quite high ECR achieved, the uncoated clad is characterized by a very limited residual prior- $\beta z$ layer thickness, with an oxygen content of $\sim 0.6 \mathrm{wt} . \%$. Such an oxygen concentration is consistent with the (maximum) oxygen solubility in the $\beta z$ phase at $1200^{\circ} \mathrm{C}$ which can be derived from the pseudo-binary oxygen-Zircaloy-4 phase diagram proposed by Chung \& Kassner (i.e., 0.57 wt.\%) [76]. This oxygen concentration is also consistent with the measurements already performed at CEA on low-tin Zircaloy-4 one-sided steam oxidized at $1200^{\circ} \mathrm{C}$ [60] and calculated using Thermocalc $®$ software associated with the CEA "Zircobase" thermodynamic database for zirconium alloys [77]. In comparison, both one-sided and two-sided coated materials are characterized by thicker residual prior- $\beta$ zr layers with lower oxygen contents due to protection from oxygen ingress provided by the inner and/or outer coating. However, probably due to surface oxidation contamination effects, it seems that EPMA measurements have overestimated the prior- $\beta z$ zr oxygen content of the two-sided-coated materials when compared to the value which can be derived from the micro-hardness measurements (using equation 1). Then, for this particular sample and by taking into account the oxygen content derived from the measured prior- $\beta z$ r hardening, one can conclude that the two-sided coatings have reduced drastically the oxygen diffusion within the metallic zirconium-based substrate upon the HT two-sided steam oxidation.

- After two-sided oxidation for 1500 s at $1200^{\circ} \mathrm{C}\left(E C R_{B J}=47.5 \%\right)$ : for such a high ECR, the one-sided outer-coated materials have experienced significant oxygen diffusion from the unprotected inner surface, inducing deep $\alpha_{\mathrm{zr}}(\mathrm{O})$ incursions. Overall, one can consider that until the $\mathrm{Cr}$ coating is protective, two-sided oxidation of one-sided (outer) coated materials is more or less comparable to one-sided oxidation of uncoated materials, as also reflected by their overall weight gain. For two-sided coated materials, one can observe that the inner coating has been more or less protective while slight oxygen diffusion has been observed at the outer $\mathrm{Cr}$-coated side. Based on the HT steam oxidation mechanism and process of outer (PVD) Cr-coated Zr-based claddings already discussed in [20], this particular oxidation time at $1200^{\circ} \mathrm{C}$ may coincide with the early beginning of oxygen intergranular diffusion through the residual metallic (sub-outer-chromia scale) Cr coating thickness. Furthermore, the Cr-coating consumption kinetics already described in [11] predict that $9 \mu \mathrm{m}$-thick $\mathrm{Cr}$ coating may be fully consumed after nearly $3000 \mathrm{~s}$ at $1200^{\circ} \mathrm{C}$, which seems to be consistent with the results obtained here.

Finally, as already reported in [11], it can be observed that, upon HT incursion, $\mathrm{Cr}$ diffusion occurred within the $\beta z$ r substrate from the Cr-coated outer surface, while no apparent $\mathrm{Cr}$ diffusion is observed from the $\mathrm{Cr}_{x} \mathrm{C}_{y}$ inner-coated surface. Indeed and as already mentioned in [27], for short oxidation times, only slight carbon diffusion has been detected by EPMA from the $\mathrm{Cr}_{x} \mathrm{C}_{\mathrm{y}}$ inner-coated surface (not represented in the figures for sake of simplicity). Additionally, for the coated samples oxidized for $600 \mathrm{~s}$, it can be observed that, on the outer $\mathrm{Cr}$-coated side, chromium diffusion has induced a significant $\mathrm{PQ}$ prior- $\beta z$ r hardening, while no hardening is observed at the vicinity of the $\mathrm{Cr}_{x} \mathrm{C}_{y}$ inner-coated surface. 


\begin{tabular}{|c|c|c|c|c|}
\hline $\begin{array}{c}\text { Materials } \\
\text { (HSn-HO-Zirc-4 substrate) }\end{array}$ & $\begin{array}{c}\text { two-sided } \\
\text { oxidation time (s) } \\
\text { at } 1200^{\circ} \mathrm{C} / E C R_{B J} \\
(\%)\end{array}$ & $\begin{array}{c}\text { wt. \% O in prior- } \\
\text { Bzr (EPMA) }\end{array}$ & $\mathrm{HV}(0.01)$ & $\begin{array}{c}\text { wt. \% O in prior- } \\
\beta z \text { (calculated } \\
\text { from HV, eq. 1) }\end{array}$ \\
\hline Uncoated & $600 / 30$ & $0.60+/-0.10$ & $\begin{array}{c}\text { not } \\
\text { measured }\end{array}$ & $\begin{array}{c}0.60 \\
\text { (from EPMA) }\end{array}$ \\
\hline $\mathrm{Cr}_{x} \mathrm{C}_{\mathrm{y}}$ one-sided inner-coated & $600 / 30$ & $0.44+/-0.10$ & $370+/-10$ & 0.39 \\
\hline Cr one-sided outer-coated & $600 / 30$ & $0.48+/-0.10$ & $405+/-10$ & 0.49 \\
\hline $\mathrm{Cr}$ one-sided outer-coated & $1500 / 47.5$ & $\sim 1.1$ & $\sim 475$ & $\sim 0.7$ \\
\hline $\begin{array}{c}\mathrm{Cr} / \mathrm{Cr}_{x} \mathrm{C}_{\mathrm{y}} \text { two-sided coated } \\
\text { "O4" }\end{array}$ & $600 / 30$ & $<0.4\left(^{*}\right)$ & $300+/-10$ & 0.21 \\
\hline $\begin{array}{c}\mathrm{Cr} / \mathrm{Cr}_{x} \mathrm{C}_{\mathrm{y}} \text { two-sided coated } \\
\text { "O3" }\end{array}$ & $1500 / 47.5$ & $<0.6\left(^{*}\right)$ & $350+/-10$ & 0.34 \\
\hline
\end{tabular}

$\left({ }^{*}\right)$ likely overestimated values by EPMA, due to surface contamination/oxidation

Table 3 - Evaluation of the oxygen contents of residual prior- $\beta$ zr layer from EPMA measurements and calculated from micro-hardness using equation 1

$P Q R C T$ - Preliminary remark: The determination of the "Residual $P Q$ clad ductility" parameter from the $R C T$ results was sometimes not obvious. Indeed, especially for the two-sided coated materials, it appeared that several RCT curves show multiple significant load drops, but with a relative amplitude lower than $30 \%$, which is the threshold value that is conventionally considered to be representative of through-wall clad cracking upon $P Q R C T$ of reference (uncoated) zirconium-based claddings ([30][80][81]]). Such $P Q R C T$ specific behaviors may be related to the more complex multilayer $P Q$ microstructure of $H T$ oxidized inner-outer coated materials, compared to reference uncoated claddings. Complementary experiments are on-going at CEA to better assess the complex mechanical behavior of multilayered materials following HT oxidation and quenching, and will need further analysis and discussion. Keeping that in mind, in the following, it was decided to consider only the maximum load measured during the RCT tests, which is assumed to be a less ambiguous parameter than the "residual ductility" one, for the particular samples tested here.

"Qualitative" evaluations of the overall $P Q$ failure mode and maximum load values derived from $P Q$

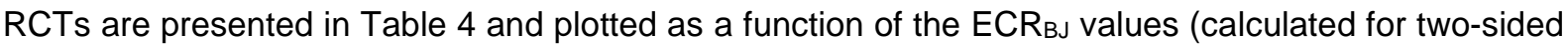
oxidation conditions) in Figure 17. They are compared to previous data obtained on reference uncoated [60] [79] and outer Cr-coated [21] cladding materials. Overall, it is interesting to note that:

- when plotted as a function of calculated ECR that have experienced $\mathrm{HT}$ two-sided steam oxidation and direct quenching is close to the one obtained for outer-Cr-coated M5Framatome materials, but in this last case after one-sided (outer) oxidation corresponding to oxidation times four times longer;

- one-sided (inner and outer) coated materials behave quite similarly and display an intermediate PQ "residual strength" evolution as a function of the calculated ECRBJ, ranging between the respective ones of uncoated and two-sided coated materials. 


\begin{tabular}{|c|c|c|c|c|c|}
\hline \multirow[b]{2}{*}{$\begin{array}{c}\text { Materials } \\
\text { (HSn-HO-Zirc-4 substrate) }\end{array}$} & \multirow[b]{2}{*}{$\begin{array}{c}\text { two-sided } \\
\text { oxidation time } \\
\text { (s) at } 1200^{\circ} \mathrm{C} \\
/ E C R_{B J}(\%)\end{array}$} & \multicolumn{2}{|c|}{ Room Temperature } & \multicolumn{2}{|c|}{$135^{\circ} \mathrm{C}$} \\
\hline & & $\begin{array}{c}\text { Overall } \\
\text { failure } \\
\text { mode } \\
\left({ }^{*}\right)\end{array}$ & $\begin{array}{l}\text { Max. load } \\
(\mathrm{N})\end{array}$ & $\begin{array}{c}\text { Overall } \\
\text { failure } \\
\text { mode } \\
\left({ }^{*}\right)\end{array}$ & $\begin{array}{l}\text { Max. load } \\
\text { (N) }\end{array}$ \\
\hline \multirow{2}{*}{ Uncoated } & $600 / 30$ & Brittle & 225 & $\begin{array}{c}\text { Low } \\
\text { ductility }\end{array}$ & 486 \\
\hline & $1500 / 47.5$ & \multicolumn{4}{|c|}{ Failed upon $Q$ or $P Q$ machining } \\
\hline $\begin{array}{c}\mathrm{Cr}_{x} \mathrm{C}_{\mathrm{y}} \text { one-sided inner-coated } \\
\text { "O2" }\end{array}$ & $600 / 30$ & $\begin{array}{c}\text { Low } \\
\text { ductility }\end{array}$ & 486 & $\begin{array}{c}\text { Low } \\
\text { ductility }\end{array}$ & 498 \\
\hline $\begin{array}{l}\mathrm{Cr}_{x} \mathrm{C}_{\mathrm{y}} \text { one-sided inner-coated } \\
\text { "O1" }\end{array}$ & $1500 / 47.5$ & \multicolumn{4}{|c|}{ Failed upon $Q$ or $P Q$ machining } \\
\hline Cr one-sided outer-coated & $600 / 30$ & $\begin{array}{c}\text { Low } \\
\text { ductility }\end{array}$ & 387 & $\begin{array}{c}\text { Low } \\
\text { ductility }\end{array}$ & 482 \\
\hline Cr one-sided outer-coated & $1500 / 47.5$ & Brittle & 165 & Brittle & 226 \\
\hline $\mathrm{Cr} / \mathrm{Cr}_{x} \mathrm{C}_{y} 2$-sides coated "O4" & $600 / 30$ & $\begin{array}{c}\text { Fully } \\
\text { Ductile }\end{array}$ & 1048 & $\begin{array}{c}\text { Fully } \\
\text { Ductile }\end{array}$ & 1098 \\
\hline $\mathrm{Cr} / \mathrm{Cr}_{x} \mathrm{C}_{y} 2$-sides coated "O3" & $1500 / 47.5$ & $\begin{array}{c}\text { Low } \\
\text { ductility }\end{array}$ & 545 & $\begin{array}{c}\text { Low } \\
\text { ductility }\end{array}$ & 371 \\
\hline
\end{tabular}

$\left(^{*}\right)$ Qualitative assessment, in some cases, "low ductility" should mean "macroscopically nearly brittle"

Table 4 - Maximum load derived from PQ RCTs obtained after two-sided steam oxidation at $1200^{\circ} \mathrm{C}$ followed by direct quenching on inner and/or outer-coated 1 cm-long clad segments

Typical fractographs showing the failure mode of the prior- $\beta z$ r layer at RT, corresponding to clad midthickness location, are presented in Figure 18. These observations are consistent with the qualitative overall failure mode given in Table 4. Thus, it can be observed that the DBT at RT of uncoated claddings occurs at an ECRBJ value close to (or lower than) $30 \%$, while one-sided coated materials show a DBT ranging between $E C R_{B J}$ values of 30 and $47 \%$ and two-sided coated materials seem to keep significant residual ductility up to at least an $E \mathrm{CR}_{\mathrm{BJ}}$ value of $47 \%$.

So, as far as the calculated ECR parameter is considered, it can be concluded that the two-sided coated cladding prototype materials studied here show comparable $\mathrm{PQ}$ residual mechanical strength after twosided steam oxidation (at $1200^{\circ} \mathrm{C}$ ) when compared to reference (outer) $\mathrm{Cr}$-coated M5Framatome materials after one-sided (outer) HT oxidation. In other words, the $10 \mu \mathrm{m}$-thick $\mathrm{Cr}_{\mathrm{x}} \mathrm{C}_{\mathrm{y}}$ inner coating studied here brings comparable protectiveness against $\mathrm{HT}$ steam oxidation when compared to outer PVD chromium coatings with comparable thicknesses.

Finally and as previously mentioned, $P Q$ mechanical properties of zirconium-based nuclear fuel claddings that have experienced $\mathrm{HT}$ steam oxidation and a final water quenching mainly rely on the residual prior- $\beta z \mathrm{zr}$ layer thickness and its oxygen content [60][71]-[74]. To address this effect, Figure 19 illustrates the evolution of the maximum load derived from PQ RCTs as a function of the prior- $\beta$ zr oxygen content (derived from micro-hardness measurements - equation 1). The observed PQ "residual strength" and the associated evolution of the residual ductility of $\mathrm{HT}$ oxidized inner and/or outer coated Zircaloy4 appear to be consistent with previous data obtained on uncoated [60][79] and outer $\mathrm{Cr}$-coated [12][21] cladding materials.

\subsection{Inner steam oxidation and secondary hydriding following clad ballooning and burst, and consequences on the residual strength derived from RCT}

Let us recall that four tests consisting in a first temperature ramp test under internal pressure up to burst, followed by steam oxidation at $1200^{\circ} \mathrm{C}$ and final direct water quenching, have been carried out on both uncoated and inner-coated HSn-HO-Zirc-4 clad segments (with internal alumina rods to simulate the gap between clad inner surface and fuel oxide pellets). The tests conditions and the associated measured burst temperatures and circumferential strains are given in Table 5. As already observed for outer $\mathrm{Cr}$-coated low-tin Zircaloy-4 and M5Framatome claddings [67]-[69], the presence of the coating tends 
to decrease clad ballooning when compared to uncoated materials tested in the same conditions. Let us recall that such behavior may have positive consequences on flow blockage and potential fuel pellets fragments relocalisation in the balloon upon LOCA transient. Moreover, the thicker inner coating tested (i.e., with a thickness ranging between 11 and $19 \mu \mathrm{m}$ ) has induced a significant increase of the burst temperature, indicating that such inner coating may have a clad strengthening effect at $\mathrm{HT}$, as already observed for outer 12-15 $\mu \mathrm{m}$ Cr-coated materials [67]-[69].

\begin{tabular}{|c|c|c|c|c|c|c|c|}
\hline & \multicolumn{5}{|c|}{ Internal pressure "EDGAR" thermal ramp tests } & \multicolumn{2}{|c|}{ HT steam oxidation tests } \\
\hline Materials & $\begin{array}{l}\text { Heating } \\
\text { rate } \\
\left({ }^{\circ} \mathrm{C} / \mathrm{s}\right)\end{array}$ & $\begin{array}{l}\text { Internal } \\
\text { pressure } \\
\text { (bar) }\end{array}$ & $\begin{array}{c}\text { Burst } \\
\text { temperature } \\
\left({ }^{\circ} \mathrm{C}\right)\end{array}$ & $\begin{array}{l}\text { Total hoop } \\
\text { strain at } \\
\text { burst } \\
\text { location (\%) }\end{array}$ & $\begin{array}{c}\text { Hoop strain at } \\
+/-20 \mathrm{~mm} \text { from } \\
\text { burst location } \\
(\%)\end{array}$ & $\begin{array}{c}\text { Steam } \\
\text { oxidation } \\
\text { time at } \\
1200^{\circ} \mathrm{C}(\mathrm{s})\end{array}$ & $\begin{array}{c}\text { ECRBJ } \\
(\%)\end{array}$ \\
\hline $\begin{array}{c}\text { Uncoated } \\
\text { HSn-HO-Zirc-4 }\end{array}$ & 25 & 40 & 981 & 13 & 3.5 & 600 & $30-35\left(^{\star}\right)$ \\
\hline $\begin{array}{c}11-19 \mu m \text { thick } \\
\mathrm{Cr}_{x} \mathrm{C}_{\mathrm{y}} \text { inner coated } \\
\text { HSn-HO-Zirc-4 }\end{array}$ & 25 & 40 & 1045 & 6,3 & 0.7 & 600 & $30-32\left(^{*}\right)$ \\
\hline $\begin{array}{c}\text { Uncoated } \\
\text { HSn-HO-Zirc-4 }\end{array}$ & 25 & 40 & 979 & 13,4 & 2.7 & 1500 & $47.5-55\left(^{*}\right)$ \\
\hline $\begin{array}{c}\text { 6-9um thick } \mathrm{Cr}_{x} \mathrm{C}_{y} \\
\text { inner coated } \\
\text { HSn-HO-Zirc-4 }\end{array}$ & 25 & 40 & 977 & 4,6 & 1.8 & 1500 & $47.5-50\left({ }^{*}\right)$ \\
\hline
\end{tabular}

$\left(^{*}\right)$ Max. ECR $R_{B J}$ values calculated by taking into account the wall clad thinning at burst location

Table 5 - Internal pressure temperature ramp tests and associated burst temperatures and mean circumferential strains, and corresponding subsequent HT steam oxidation test conditions followed by direct water quenching

Figure 20 depicts the macroscopic aspects of the four uncoated and inner-coated HSn-HO-Zirc-4 clad segments that have experienced ballooning and burst tests then subsequent $\mathrm{HT}$ steam oxidation and direct water quenching. After oxidation for $600 \mathrm{~s}$ at $1200^{\circ} \mathrm{C}$ corresponding to an ECRBJ value of at least $30 \%$, the inner-coated clad survived to the final quenching while the uncoated materials did not. After oxidation for 1500 s at $1200^{\circ} \mathrm{C}\left(E C R_{B J}\right.$ of at least $\left.47.5 \%\right)$, both materials failed upon quenching but the uncoated one has broken in much more fragments than the inner-coated one. For this last one it must be also kept in mind that the initial inner coating thickness was limited to 6-9um, thus likely inducing a lower protectiveness of the inner clad surface upon the HT steam oxidation step, when compared to the one tested for $600 \mathrm{~s}$ at $1200^{\circ} \mathrm{C}$, with inner coating thickness ranging from 11 to $19 \mu \mathrm{m}$. However, these preliminary macroscopic results show encouraging behavior of inner-coated claddings, with indications of a significant additional coping time before failure upon quenching, when compared to reference uncoated materials.

In the following, we will focus on samples tested for 600 s at $1200^{\circ} \mathrm{C}\left(\mathrm{ECR}_{\mathrm{BJ}}=30-35 \%\right)$ only, because multi-fragmentation of clad segments that have experienced HT steam oxidation up to ECRBJ values of nearly $50 \%$ makes more complicated the accurate $P Q$ metallurgical examinations and hydrogen measurements as a function of the $P Q$ clad segment location. Additionally, for such fragmented PQ clad segments, it was obviously not possible to perform PQ RCTs.

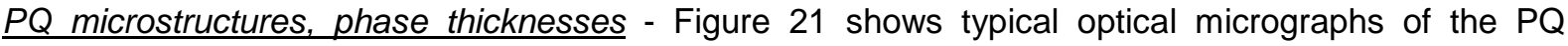
uncoated and inner-coated microstructures of HSn-HO-Zirc-4 clad segments that have experienced internal pressure ballooning and burst temperature ramp tests then subsequent $\mathrm{HT}$ steam oxidation for $600 \mathrm{~s}$ at $1200^{\circ} \mathrm{C}$ followed by direct water quenching down to RT, for different axial locations from the burst. The corresponding oxide and metallic sub-layers thicknesses are plotted in Figure 22. In this last figure, the results are compared to the results of previous tests carried out on (uncoated) M5Framatome tested using the same methodology, but for a shorter $\mathrm{HT}$ oxidation time at $1200^{\circ} \mathrm{C}$, that is $160 \mathrm{~s}$, which corresponds to a two-sided ECR B $_{\text {J }}$ value of nearly $17 \%$ [47].

One can make the following observations: 
- For the outer part of the claddings : The respective thicknesses of the $\mathrm{ZrO}_{2}$ and $\mathrm{azr}_{\mathrm{r}}(\mathrm{O})$ layers are very close to the ones already measured on low-tin Zircaloy- 4 after one-sided (outer) steam oxidation for $600 \mathrm{~s}$ at $1200^{\circ} \mathrm{C}[60]$, thus confirming the consistency and the good reproducibility of the HT steam oxidation tests performed so far on uncoated reference materials. Moreover, the $\mathrm{ZrO}_{2}$ and $\alpha_{\mathrm{zr}}(\mathrm{O})$ thicknesses achieved after $600 \mathrm{~s}$ at $1200^{\circ} \mathrm{C}$ are twice the values measured on (uncoated) tested M5 Framatome after $160 \mathrm{~s}$ at $1200^{\circ} \mathrm{C}$ [47]. This is fully consistent with the ECR $\mathrm{BJ}_{\mathrm{BJ}}$ value here achieved, after 600 s of oxidation, being twice the value achieved after 160 s oxidation, thanks to the parabolic oxidation kinetics of the materials when tested at $1200^{\circ} \mathrm{C}$.

- For the inner part of the claddings : On the one hand, the thicknesses of the $\mathrm{ZrO}_{2}$ and $\mathrm{\alpha zr}(\mathrm{O})$ layers in uncoated $\mathrm{HSn}$-HO-Zirc-4 oxidized for $600 \mathrm{~s}$ at $1200^{\circ} \mathrm{C}$ are comparable to those of M5Framatome oxidized for $160 \mathrm{~s}$ at $1200^{\circ} \mathrm{C}$, with, close to the burst, comparable values to the ones measured at the outer surface. This is likely due to the easy steam access through the burst opening inducing locally two-sided oxidation conditions. Close to the sample ends and as already discussed in details in [47], there is no more inner oxide scale and the $\alpha \mathrm{zr}(\mathrm{O})$ sub-layer is no more circumferentially homogeneous (Figure 21). This can be related to steam starvation conditions that prevail within the gap between the inner rod (simulating fuels pellets) and the inner clad surface, close to the end caps. Such a behavior is believed to be responsible for the localized massive (secondary) hydrogen uptake, due to: (i) gaseous hydrogen enrichment (and associated oxygen depletion) in the gap and (ii) the absence of continuous and dense zirconia scale which could acts as an efficient hydrogen permeation barrier.

For the inner-coated clad segment, most of the inner surface has been protected from significant oxidation and oxygen ingress. However, localized $\alpha_{z r}(\mathrm{O})$ areas can be observed (Figure 21-b), likely due to localized inner coating cracking and/or spallation. It is worth noting that the localized $\alpha_{z r}(\mathrm{O})$ growth is preferentially observed at the vicinity of the burst opening. This is likely due to higher localized strain promoting steam/oxygen access due to larger (localized) inner coating cracks opening and/or density.

Secondary hydriding and associated quenched prior- $\beta z$ z hardening - Figure 23 depicts the hydrogen distribution derived from non-destructive neutron tomography and from post-mortem IGFTC measurements. It is worth noticing that the two types of hydrogen measurements give fully consistent results. Consistently with the numerous previous studies dealing with secondary hydriding phenomena upon LOCA [30]-[52], the uncoated clad segment shows typical secondary hydrogen peaks with maximum values reaching $\sim 2500$ wt.ppm, close to the sample ends. While, for the inner-coated clad segment, the uptake of hydrogen appears to be much lower, thus demonstrating the overall capacity of the inner DLI-MOCVD $\mathrm{Cr}_{x} \mathrm{C}_{\mathrm{y}}$ coating to prevent from rapid hydrogen uptake (from the inner clad surface).

However, Figure 23-(b) shows an apparent axial gradient of the hydrogen content within the PQ innercoated clad segment. In other words, upon HT inner clad oxidation, it appears that the inner coating protectiveness has not be the same at each end of the tested clad segment. Such behavior should be due to:

(i) the axial gradient in thickness of the as-received $\mathrm{Cr}_{x} \mathrm{C}_{\mathrm{y}}$ inner coating, decreasing from $\sim 19 \mu \mathrm{m}$ to $\sim 11 \mu \mathrm{m}$, with a lower $\mathrm{HT}$ oxidation/hydriding protectiveness of the thinner part of the inner coating at one end of the clad segment;

(ii) larger local "damage" of the inner coating (i.e., higher surface density of cracks and/or spallation inducing locally an easier steam/hydrogen access to the Zircaloy substrate) at one end of the PQ clad segment, as qualitatively observed in Figure 21-(b) in some parts of the PQ clad segment.

However, at that point, it is not possible to conclude if the $\mathrm{Cr}_{x} \mathrm{C}_{y}$ coating acts as an intrinsic efficient hydrogen permeation barrier and/or if the lower hydrogen uptake observed is simply due to the lower generation of gaseous hydrogen within the gap, related to the overall slower oxidation of the inner clad surface.

Additionally, through-thickness micro-hardness profiles measured at different axial locations of the two clad segments tested are plotted in Figure 24. One can observe in the mid part of the claddings corresponding to the residual prior- $\beta z$ r layer that the $P Q$ hardening is significantly higher within the uncoated materials than in the inner-coated one. As already discussed in [47] and recalled below, this is likely due to an indirect effect of the hydrogen uptake, leading to an increase of the PQ prior- $\beta$ zr oxygen content. Indeed, local PQ hydrogen contents, prior- $\beta z$ r micro-hardness and associated estimated oxygen contents are listed in Table 6 as a function of the axial distance from the burst. Then, the oxygen content 
derived from prior- $\beta z$ micro-hardness can be compared to "Thermocal + Zircobase" [84][85] predicted values (assuming local thermodynamic equilibrium). It is worth noticing that, even if the thermodynamic calculations sometimes overestimate the oxygen value (potentially due to not fully at equilibrium conditions), the present results and calculations confirm the thermodynamic hydrogen effect, inducing a significant increase of the oxygen solubility in the HT $\beta z$ r phase, and thus, of the PQ prior- $\beta z$ r hardness, as already discussed in more details in [47] and [60].

\begin{tabular}{|c|c|c|c|c|c|c|c|c|}
\hline \multirow[t]{2}{*}{$\begin{array}{l}\text { Axial } \\
\text { distance } \\
\text { from } \\
\text { burst } \\
\text { location } \\
(\mathrm{mm})\end{array}$} & \multicolumn{2}{|c|}{$\begin{array}{l}\text { Wt.ppm H (from } \\
\text { IGFTC } \\
\text { measurements) }\end{array}$} & \multicolumn{2}{|c|}{$\begin{array}{c}\text { Mid-wall clad prior- } \beta \\
\text { HV }(0.01) \\
(+ \text { standard } \\
\text { deviation })\end{array}$} & \multicolumn{2}{|c|}{$\begin{array}{c}\text { Prior- } \beta \text { oxygen } \\
\text { content derived } \\
\text { from } \mathrm{HV}(0.01) \\
\text { using eq. } 2 \\
\text { (wt.\%) }\end{array}$} & \multicolumn{2}{|c|}{$\begin{array}{l}\text { Max. prior- } \beta \text { oxygen } \\
\text { content from } \\
\text { thermodynamic } \\
\text { calculations at } \\
1200^{\circ} \mathrm{C} \text { vs. measured } \\
\text { hydrogen content } \\
\text { (averaged value in } \\
\text { wt.\%) } \\
\end{array}$} \\
\hline & Uncoated & $\begin{array}{l}\text { Inner } \\
\text { coated }\end{array}$ & Uncoated & $\begin{array}{l}\text { Inner } \\
\text { coated }\end{array}$ & Uncoated & $\begin{array}{l}\text { Inner } \\
\text { coated }\end{array}$ & Uncoated & $\begin{array}{l}\text { Inner } \\
\text { coated }\end{array}$ \\
\hline \multirow{3}{*}{-65} & 2099 & 219 & \multirow{3}{*}{$640(45)$} & \multirow{3}{*}{$405(45)$} & \multirow{3}{*}{1.76} & \multirow{3}{*}{0.54} & \multirow{3}{*}{2.03} & \multirow{3}{*}{0.61} \\
\hline & 2148 & 192 & & & & & & \\
\hline & 2303 & 201 & & & & & & \\
\hline \multirow{3}{*}{-40} & 2539 & 230 & \multirow{3}{*}{$525(45)$} & \multirow{3}{*}{$420(45)$} & \multirow{3}{*}{1.16} & \multirow{3}{*}{0.62} & \multirow{3}{*}{1.78} & \multirow{3}{*}{0.63} \\
\hline & 1726 & 218 & & & & & & \\
\hline & 1420 & 231 & & & & & & \\
\hline \multirow{3}{*}{-15} & 51 & 209 & \multirow{3}{*}{$615(40)\left(^{*}\right)$} & \multirow{3}{*}{$405(45)$} & \multirow{3}{*}{$1.63\left(^{*}\right)$} & \multirow{3}{*}{0.54} & \multirow{3}{*}{0.53} & \multirow{3}{*}{0.61} \\
\hline & 58 & 178 & & & & & & \\
\hline & 49 & 223 & & & & & & \\
\hline \multirow{3}{*}{15} & 42 & 347 & \multirow{3}{*}{$470(50)$} & \multirow{3}{*}{480 (27) } & \multirow{3}{*}{0.88} & \multirow{3}{*}{0.93} & \multirow{3}{*}{0.53} & \multirow{3}{*}{0.69} \\
\hline & 36 & 410 & & & & & & \\
\hline & 38 & 290 & & & & & & \\
\hline \multirow{3}{*}{40} & 2483 & 387 & \multirow{3}{*}{$490(45)$} & & & & & \\
\hline & 1899 & 491 & & 445 (35) & 0.98 & 0.75 & 2.01 & 0.76 \\
\hline & 2089 & 520 & & & & & & \\
\hline & 2738 & 1008 & & & & & & \\
\hline 65 & $\begin{array}{c}\text { not } \\
\text { measured }\end{array}$ & 775 & $570(50)$ & $470(25)$ & 1.39 & 0.88 & 2.25 & 1.02 \\
\hline & $\begin{array}{c}\text { not } \\
\text { measured }\end{array}$ & 847 & & & & & & \\
\hline
\end{tabular}

$\left.{ }^{*}\right)$ not fully representative prior- $\beta_{z r}$ values due to localized clad thinning inducing additional hardening due to $\alpha_{z r}(O)$ incursions

Table 6 - $P Q$ hydrogen contents, prior- $\beta$ zr micro-hardness and associated estimated oxygen contents compared to "Thermocalc + Zircobase" predicted values, of uncoated and inner coated HSn-HO-Zirc-4 clad segments that have experienced internal pressure ballooning and burst temperature ramp tests, and then subsequent HT steam oxidation for 600 s at $1200^{\circ} \mathrm{C}+$ direct water quenching down to RT

PQ RCT behaviors - Table 7 gives the maximum loads derived from PQ RCTs carried out at $135^{\circ} \mathrm{C}$ on uncoated and inner-coated HSn-HO-Zirc-4 clad segments that have experienced internal pressure ballooning and burst tests, then HT steam oxidation for $600 \mathrm{~s}$ at $1200^{\circ} \mathrm{C}$. These values correspond to different axial locations of the tested rings along the $P Q$ clad segments. Even if, for all the ring samples tested, the overall RCT behavior seems to be macroscopically nearly brittle with very limited or negligible residual ductility, the inner-coated materials show higher strength values. For the uncoated one, the samples located at the vicinity of the clad segment ends display negligible residual strength. In this last case, this can be related to the localized high hydrogen and associated oxygen contents, typical of secondary hydrogen peaks. 


\begin{tabular}{|c|c|c|c|c|c|}
\cline { 3 - 6 } \multicolumn{1}{c|}{} & \multicolumn{4}{c|}{ Max load from RCTs at $135^{\circ} \mathbf{C}(\mathbf{N})$} \\
\cline { 2 - 6 } \multicolumn{1}{c|}{} & \multicolumn{3}{c|}{ approximate distance from burst opening $(\mathrm{mm})$} \\
\cline { 2 - 6 } \multicolumn{1}{c|}{} & ECR $_{\text {BJ }}(\%)\left(^{*}\right)$ & -57 to -47 & -22 to -32 & +22 to +32 & +47 to +57 \\
\hline Uncoated & $30-35$ & $\sim 20\left(^{* *}\right)$ & 183 & 183 & $<20\left(^{* * *}\right)$ \\
\hline Inner-coated & $30-32$ & 287 & 296 & 258 & 155 \\
\hline
\end{tabular}

$\left.{ }^{*}\right) E C R_{B J}$ range estimated by taking into account the localized clad thinning due to ballooning

$\left({ }^{* *}\right)$ failed upon $R C T$ pre-loading

$\left({ }^{* * *}\right)$ failed upon machining

Table 7 - Maximum load derived from PQ RCTs carried out on $1 \mathrm{~cm}$-long ring samples at $135^{\circ} \mathrm{C}$ of uncoated and inner coated $\mathrm{HSn}$-HO-Zirc-4 clad segments that have experienced internal pressure ballooning and burst thermal ramp tests, and then subsequent HT steam oxidation for 600 s at $1200^{\circ} \mathrm{C}$

Figure 25 is an attempt to relate the residual $P Q$ clad segments strength derived from RCT to the localized (circumferentially averaged) hydrogen and oxygen contents. As already discussed in [47] and as can be observed in Table 6 , the localized prior- $\beta$ zr oxygen and hydrogen concentrations are more or less linearly correlated. It is thus not surprising that plotting the strength measured during RCT vs. the concentration of each type of chemical elements gives the same overall trend. One can observe that beyond respectively 2000-3000 wt.ppm of hydrogen corresponding to oxygen contents ranging between $\sim 1.1$ and $\sim 1.4$ wt.\%, the quenched prior- $\beta z$ structure is fully brittle, with negligible residual strength. Such hydrogen/oxygen concentrations in prior- $\beta z$ r are believed to correspond to a fully brittle $P Q$ behavior. Moreover, in Figure 25-(a), the PQ strength measured here from RCT are compared with some previous IRSN PQ tensile data [82] obtained on pre-hydrided Zircaloy-4 samples that have been two-sided steam oxidized at $1200^{\circ} \mathrm{C}$ up to an $E C R_{B J}=16 \%$, and water quenched. Even if the $P Q$ mechanical tests are not the same, the results seem to be quite consistent.

Finally, to go further, let us consider the recent work carried out by Le Hong et al. by using Zircaloy-4 clad samples homogenously pre-charged in hydrogen and/or oxygen [86] [87]. Among other results, after applying $\mathrm{HT}$ incursion in the $\beta \mathrm{zr}$ temperature range and then cooling down to $\mathrm{RT}$, the authors were able to derive laws for the produced prior- $\beta z$ " model structures", describing the evolution of mechanical data as a function of both oxygen and hydrogen contents in $\beta z$ r. For PQ macroscopically "brittle" materials, Le Hong et al. derived the equation below (eq. 3), which can be used to predict the residual PQ Ultimate Tensile Strength (UTS) in uniaxial tension of the prior- $\beta$ zr structure at low temperature (here at RT), as a function of both the oxygen and the hydrogen concentrations, up to thousands of wt.ppm:

$$
\mathrm{UTS}_{\text {Brittle }}(\mathrm{MPa})=684.0 \times\left(1-1.32910^{-4} \mathrm{C}_{H}\right) \times\left(1-0.760 \mathrm{C}_{0}\right) \quad \text { equation } 3
$$

where $\mathrm{C}_{\mathrm{H}}$ and $\mathrm{Co}$ correspond to prior- $\beta_{\mathrm{zr}}$ hydrogen concentration in wt.ppm and oxygen concentration in wt.\%, respectively.

The $P Q$ tensile strength values calculated using eq. 3 are plotted in Figure 26 as a function of the experimental ones derived from PQ RCTs. Both two-sided oxidized short clad segments (with quite negligible hydrogen pick-up) and the two longer clad segments that have experienced steam oxidation following burst occurrence (with localized high hydrogen contents) have been considered. It can be concluded that, even if the mechanical tests are not the same, Le Hong et al.' correlation gives a reasonable prediction of the $P Q$ residual strength and confirm that both oxygen and hydrogen contribute to the post-LOCA localized embrittlement of the fuel cladding. 


\section{CONCLUSIONS AND FURTHER WORK}

To further improve the properties of coated claddings as E-ATF, DLI-MOCVD $\mathrm{Cr}_{x} \mathrm{C}_{y}$ coating has been developed and successfully deposited onto the inner surface of an old-grade high-tin Zircaloy-4 cladding tube prototype. Then, one-sided and two-sided steam oxidation tests have been carried out at $1200^{\circ} \mathrm{C}$ on outer PVD Cr-coated and/or inner $\mathrm{Cr}_{x} \mathrm{C}_{y}$-coated clad segments, with a final direct water quenching down to RT. Some of the HT oxidation tests have been performed after a first internal pressure-induced burst step to address inner oxidation and associated secondary hydriding, typical of (semi-)integral LOCA transients.

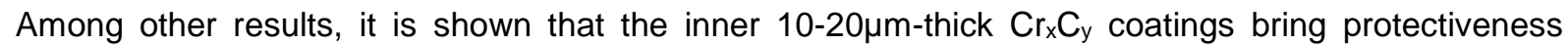
against steam oxidation at $1200^{\circ} \mathrm{C}$ comparable to that of outer PVD $10-15 \mu \mathrm{m}$-thick $\mathrm{Cr}$ coating, as well as a significant reduction of secondary hydriding after clad ballooning and burst. Then, when compared to the reference uncoated claddings, DLI-MOCVD $\mathrm{Cr}_{x} \mathrm{C}_{\mathrm{y}}$ inner coated materials show a higher strength, upon and after final water quenching, related to lower oxygen and/or hydrogen uptake in the zirconium substrate, at least up to an ECR $\mathrm{BJ}_{\mathrm{J}}$ value of $30 \%$.

Further experiments on advanced nuclear zirconium-based fuel cladding two-sided coated are planned, to confirm these preliminary encouraging results. In addition, it is planned to assess the performances of the inner coating under more representative in-service conditions and for more demanding accidental situations, including for example pellet-cladding mechanical interaction issues and chemical compatibility with the uranium oxide fuel pellets at $\mathrm{HT}$.

\section{AKNOWLEDGEMENTS}

Special thanks to:

- $\quad$ R. Boichot and M. Pons from SIMAP-CNRS (Grenoble, France) for their inputs into the R\&D and fabrication of DLI-MOCVD inner clad coatings;

Y. Gazal from CIRIMAT (Toulouse, France) for the growth of $\mathrm{CrC}_{\mathrm{x}}$ inner coatings using a DLIMOCVD pilot;

- $\quad$ E. Monsifrot and J. Runser from DEPHIS society (Etupes, France) for PVD (outer) Cr-coated materials fabrication;

- $\quad$ D. Hamon and A. Lequien from CEA/SRMA/LA2M, for the EPMA measurements and C. Miton for PQ hydrogen (IGFTC) analysis;

J. Henry, L. Vincent and L. Portier from CEA/SRMA and H. Palancher from CEA/DEC for their advising and organizing support. 


\section{REFERENCES}

[1] C. Tang, M. Stueber, H.J. Seifert, M. Steinbrueck, "Protective coatings on zirconium-based alloys as accident tolerant fuel (ATF) claddings", Corros. Rev. 35 (2017) 141-165

[2] I. Idarraga-trujillo, M. Le Flem, J.C. Brachet, M. Le Saux, D. Hamon, S. Muller, V. Vandenberghe, M. Tupin, E. Papin, A. Billard, E. Monsifrot, F. Schuster, "Assessment at CEA of Coated Nuclear Fuel Cladding for LWRs with Increased Margins in LOCA and beyond LOCA Conditions", Proceedings of 2013 LWR Fuel Performance Meeting/TopFuel, Charlotte, NC, USA, Sept. 15-19, (2013)

[3] H.-G. Kim, I.-H. Kim, Y.-I. Jung, D.-J. Park, J.-Y. Park, Y.-H. Koo, "Adhesion property and hightemperature oxidation behavior of Cr-coated Zircaloy-4 cladding tube prepared by 3D laser coating", JNM 465 (2015) 531-539

[4] A.S. Kuprin, V.A. Belous, V.N. Voyevodin, V.V. Bryk, R.L. Vasilenko, V.D. Ovcharenko, et al., "Vacuum-arc chromium-based coatings for protection of zirconium alloys from the high-temperature oxidation in air", JNM 465 (2015) 400-406

[5] J.H. Park, H.-G. Kim, J. Park, Y.-I. Jung, D.-J. Park, Y.-H. Koo, "High temperature steamoxidation behavior of arc ion plated $\mathrm{Cr}$ coatings for accident tolerant fuel claddings", Surf. Coatings Technol. 280 (2015) 256-259

[6] D.J. Park, H.G. Kim, Y. II Jung, J.H. Park, J.H. Yang, Y.H. Koo, "Behavior of an improved Zr fuel cladding with oxidation resistant coating under loss-of-coolant accident conditions", JNM 482 (2016) 75-82

[7] J. Bischoff, C. Delafoy, C. Vauglin, P. Barberis, C. Roubeyrie, D. Perche, D. Duthoo, F. Schuster, J-C. Brachet, E.W. Schweitzer, K. Nimishakavi, "AREVA NP's Enhanced Accident Tolerant Fuel Developments: Focus on Cr-coated M5 Cladding", Nuclear Engineering and Technology 50 (2018) 223-228

[8] W. Zhong, P.A. Mouche, B.J. Heuser, "Response of $\mathrm{Cr}$ and $\mathrm{Cr}-\mathrm{Al}$ coatings on Zircaloy-2 to high temperature steam", JNM 498 (2018) 137-148

[9] M. Sevecek, A. Gurgen, A. Seshadri, Y. Che, M. Wagih, B. Phillips, V. Champagne, K. Shirvan, "Development of $\mathrm{Cr}$ cold spray-coated fuel cladding with enhanced accident tolerance", Nuclear Engineering and Technology, Volume 50, Issue 2, (March 2018), 229-236

[10] Y. Wang, W. Zhou, Q. Wen, X. Ruan, F. Luo, G. Bai, Y. Qing, D. Zhu, Z. Huang, Y. Zhang, T. $\mathrm{Liu}, \mathrm{R}$. Li, "Behavior of plasma sprayed $\mathrm{Cr}$ coatings and FeCrAl coatings on $\mathrm{Zr}$ fuel cladding under loss-of-coolant accident conditions", Surface \& Coatings Technology 344 (2018) 141-148

[11] J.C. Brachet, I. Idarraga-Trujillo, M. Le Flem, M. Le Saux, V. Vandenberghe, S. Urvoy, E. Rouesne, T. Guilbert, C. Toffolon-Masclet, M. Tupin, C. Phalippou, F. Lomello, F. Schuster, A. Billard, G. Velisa, C. Ducros, F. Sanchette, "Early studies on Cr-Coated Zircaloy-4 as Enhanced Accident Tolerant Nuclear Fuel Claddings for Light Water Reactors", JNM 517 (2019) 268-285

[12] J. Krejcí, J. Kabatova, F. Manoch, J. Kocí, L. Cvrcek, J. Malek, S. Krum, P. Sutta, P. Bublíkova, P. Halodova, H.K. Namburi M. Sevecek, "Development and testing of multicomponent fuel cladding with enhanced accidental performance", Nuclear Eng. and Tech. 52, (2020), pp. 597-609

[13] H. Yeom, T. Dabney, G. Johnson, B. Maier, M. Lenling, K. Sridharan, "Improving deposition efficiency in cold spraying chromium coatings by powder annealing", The International Journal of Advanced Manufacturing Technology 100 (2019) 1373-1382

[14] X. Hana, J. Xueb, S. Penga, H. Zhang, "An interesting oxidation phenomenon of $\mathrm{Cr}$ coatings on Zry-4 substrates in high temperature steam environment", Corrosion Science 156 (2019) 117-124

[15] X. Hu, C. Dong, Q. Wang, B. Chen, H. Yang, T. Wei, R. Zhang, W. Gu, D. Chen, "Hightemperature oxidation of thick $\mathrm{Cr}$ coating prepared by arc deposition for accident tolerant fuel claddings", JNM 519 (2019) 145-156

[16] B. Maier, H. Yeom, G. Johnson, T. Dabney, J. Walters, P. Xu, J. Romero, H. Shah, K. Sridharan, "Development of cold spray chromium coatings for improved accident tolerant zirconium-alloy cladding", JNM 519 (2019) 247-254 
[17] T. Wei, R. Zhang, H. Yang, H. Liu, S. Qiu, Y. Wang, P. Du, K. He, X. Hu, C. Dong, "Microstructure, corrosion resistance and oxidation behavior of Cr-coatings on Zircaloy-4 prepared by vacuum arc plasma deposition" Corrosion Science 158 (2019) 108077, https://doi.org/10.1016/j.corsci.2019.06.029.

[18] Y.H. Lee, J.H. Park, I.H. Kim, D.J. Park, Y.I. Jung, B.K. Choi, H.G. Kim, "Enhanced wear resistance of CrAl-coated cladding for accident tolerant fuel", JNM 523 (2019) 223-230

[19] KG. Geelhood, WG. Luscher, "Degradation and Failure Phenomena of Accident Tolerant Fuel Concepts Chromium Coated Zirconium Alloy Cladding”, PNNL Report n²8437,(June 2019)

[20] JC. Brachet, E. Rouesne, T. Guilbert, J. Ribis, M. Le Saux, G. Nony, H. Palancher, A. David, J. Bischoff, J. Augereau, E. Pouillier, "High Temperature Steam Oxidation of Chromium-Coated Zirconium-Based Alloys: Kinetics and Process", Corrosion Science 167 (2020) 108537, doi: https://doi.org/10.1016/j.corsci.2020.108537

[21] J.C. Brachet, M. Le Saux, J. Bischoff, H. Palancher, R. Chosson, E. Pouillier, T. Guilbert, S. Urvoy, G. Nony, T. Vandenberghe, A. Lequien, C. Miton, P. Bossis, "Evaluation of Equivalent Cladding Reacted parameters of $\mathrm{Cr}$-coated claddings oxidized in steam at $1200^{\circ} \mathrm{C}$ in relation with oxygen diffusion/partitioning and post-quench ductility", JNM 533 (2020) 152106, https://doi.org/10.1016/j.jnucmat.2020.152106

[22] Q.S. Chen, C.H. Liua, R.Q. Zhang, H.Y. Yang, T.G. Wei, Y. Wang, Z. Li, L.X. He, J. Wang, L. Wang, J.P. Long, H. Chang, "Microstructure and high-temperature steam oxidation properties of thick $\mathrm{Cr}$ coatings prepared by magnetron sputtering for accident tolerant fuel claddings: The role of bias in the deposition process", Corrosion Science 165 (2020) 108378, https://doi.org/10.1016/j.corsci.2019.108378

[23] E.B. Kashkarov, D.V. Sidelev, M. Rombaeva, M.S. Syrtanov, G.A. Bleykher, "Chromium coatings deposited by cooled and hot target magnetron sputtering for accident tolerant nuclear fuel claddings", Surface \& Coatings Technology 389 (2020) 125618

[24] A. Michau et al., "Chromium Carbide Growth by Direct Liquid Injection Chemical Vapor Deposition in Long and Narrow Tubes, Experiments, Modeling and Simulation," Coatings 8 (2018) 2020; https://doi.org/10.3390/coatings8060220.

[25] A. Michau, Y. Gazal, F. Addou, F. Maury, T. Duguet, R. Boichot, M. Pons, E. Monsifrot, H. Maskrot, F. Schuster, "Scale up of a DLI-MOCVD process for the internal treatment of a batch of 16 nuclear fuel cladding segments with a $\mathrm{CrCx}$ protective coating", Surface \& Coatings Technology 375 (2019), 894-902, https://doi.org/10.1016/j.surfcoat.2019.06.101

[26] A. Michau et al., "Chromium carbide growth at low temperature by a highly efficient DLI-MOCVD process in effluent recycling mode," Surface and Coatings Technology 332 (2017) 96-104, https://doi.org/10.1016/j.surfcoat.2017.06.077

[27] A. Michau, F. Maury, F. Schuster, F. Lomello, J.-C. Brachet, E. Rouesne, M. Le Saux, R. Boichot, M. Pons, "High-temperature oxidation resistance of chromium-based coatings deposited by DLI-MOCVD for enhanced protection of the inner surface of long tubes", Surface and Coatings Technology 349 (2018) 1048-1057; https://doi.org/10.1016/j.surfcoat.2018.05.088

[28] F. Addou, A. Michau, H. Maskrot, Y. Gazal, F. Maury, T. Duguet, E. Monsifrot, F. Schuster, "Two-sided protection for zirconium-based nuclear fuel cladding", Proceedings of Topfuel-2019, Seattle, US

[29] H.M. Chung and T.F. Kassner, "Embrittlement Criteria for Zircaloy Fuel Cladding Applicable to Accident Situations in Light-Water Reactors", Summary Report, NUREG/CR-1344, ANL-7948, (1980)

[30] M. Billone, Y. Yan, T. Burtseva and R. Daum, "Cladding Embrittlement during Postulated Lossof-Coolant Accidents", NUREG/CR-6967 / ANL-07/04 report, (June 30, 2008)

[31] H. Uetsuka, T. Furuta and S. Kawasaki, "Failure-Bearing Capability of Oxidized Zircaloy-4 Cladding under Simulated Loss-of-Coolant Condition", Journal of Nuclear Science and Technology 20(11) (1983) 941-950

[32] F. Nagase and T. Fuketa, "Effect of Pre-Hydriding on Thermal Shock Resistance of Zircaloy-4 Cladding under Simulated Loss-of-Coolant Accident Conditions". Journal of Nuclear Science and Technology 41(7) (2004) 723-730 
[33] F. Nagase and T. Fuketa, "Behavior of Pre-hydrided Zircaloy Cladding under Simulated LOCA Conditions", Journal of Nuclear Science and Technology 42(2) (2005) 209-218

[34] F. Nagase and T. Fuketa, "Fracture Behavior of Irradiated Zircaloy-4 Cladding under Simulated LOCA Conditions", Journal of Nuclear Science and Technology 43(9) (2006) 1114-1119

[35] F. Nagase, T. Chuto and T. Fuketa, Behavior of High Burn-up Fuel Cladding under LOCA Conditions. Journal of Nuclear Science and Technology 46(7) (2009) 763-769

[36] M. Yamato, F. Nagase, M. Amaya, "Evaluation of fracture resistance of ruptured, oxidized, and quenched Zircaloy cladding by four-point-bend tests", Journal of Nuclear Science and Technology 51, (2014) 1125-1132, http://dx.doi.org/10.1080/00223131.2014.912968

[37] T. Narukawa, A. Yamaguchi, S. Jang, M. Amaya, "Experimental and statistical study on fracture boundary of non-irradiated Zircaloy-4 cladding tube under LOCA conditions", JNM 499 (2018) 528538, doi: 10.1016/j.jnucmat.2017.11.049

[38] T. Narukawa, M. Amaya, "Fracture limit of high-burnup advanced fuel cladding tubes under lossof-coolant accident conditions", Journal of Nuclear Science and Technology, 57 (2020) 68-78, DOI: 10.1080/00223131.2019.1659873

[39] T. Narukawa \& M. Amaya, "Four-point-bend tests on high burnup advanced fuel cladding tubes after exposure to simulated LOCA conditions", Journal of Nuclear Science and Technology 57 (2020) 782-791, DOI: 10.1080/00223131.2020.1724207

[40] J. Stuckert, M. Grosse, C. Rössger, M. Klimenkov, M. Steinbrück and M. Walter, "QUENCHLOCA program at KIT on secondary hydriding and results of the commissioning bundle test QUENCHLO", Nuclear Engineering and Design 255 (2013) 185-201

[41] M. Grosse, E. Lehmann, P. Vontobel, M. Steinbrück, "Quantitative determination of absorbed hydrogen in oxidised Zircaloy by means of neutron radiography", Nuclear Instruments \& Methods in Physics Research A 566 (2006) 739-745

[42] M. Grosse, G. Kuehne, M. Steinbrueck, E. Lehmann, J. Stuckert and P Vontobel, "Quantification of hydrogen uptake of steam-oxidized zirconium alloys by means of neutron radiography", Journal of Physics: Condensed Matter 20 (2008) 104263, doi:10.1088/0953-8984/20/10/104263

[43] M. Grosse, "Neutron Radiography: A Powerful Tool for Fast, Quantitative and Non-Destructive Determination of Hydrogen Concentration and Distribution in Zirconium Alloys", Journal of ASTM International, Vol. 8, No. 4, (2011), Paper ID JAl103251

[44] M. Grosse, J. Stuckert, M. Steinbrück and A. Kaestner, "Secondary hydriding during LOCA Results from the QUENCH-L0 test", JNM 420 (2012) 575-582

[45] M. Grosse, J. Stuckert, C. Roessger, M. Steinbrück, W. Mario and A. Kaestner, "Analysis of the secondary cladding hydrogenation during QUENCH-LOCA tests and its influence on the cladding embrittlement", 17th International Symposium on Zirconium in Nuclear Industries, Hyderabad (India), (February $03-07,2013)$, STP 1543, (2014)

[46] M. Grosse, C. Roessger, J. Stuckert, M. Steinbrueck, A. Kaestner, N. Kardjilov, B. Schillinger, "Neutron Imaging Investigations of the Secondary Hydriding of Nuclear Fuel Cladding Alloys during Loss of Coolant Accidents", Physics Procedia 69 (2015) 436-444

[47] JC. Brachet, D. Hamon, M. Le Saux,V. Vandenberghe, C. Toffolon-Masclet, E. Rouesne, S. Urvoy, JL. Béchade, C. Raepsaet, JL. Lacour, G. Bayon, F. Ott, "Study of secondary hydriding at high temperature in zirconium based nuclear fuel cladding tubes by coupling information from neutron radiography/tomography, electron probe micro analysis, micro elastic recoil detection analysis and laser induced breakdown spectroscopy microprobe", JNM 488 (2017) 267-286

[48] Z. Hozer, I. Nagy, A. Vimi, M. Kunstar, P. Szabo, T. Novotny, E. Perez-Fero, Z. Kis, L. Szentmiklosi, M. Horvath, A. Pinter-Csordas, E. Barsy, K. Kulacsy, M. Grosse, "High-temperature secondary hydriding experiments with E110 and E110G cladding", ASTM STP1597, ASTM International, West Conshohocken, PA, (2018), pp. 1093-1113. https://doi.org/10.1520/ STP159720160031

[49] R. Thieurmel, J. Besson, E. Pouillier, A. Parrot, A. Ambard, AF. Gourgues-Lorenzon, "Contribution to the understanding of brittle fracture conditions of zirconium alloy fuel cladding tubes during LOCA transient", JNM 527 (2019) 151815, doi: https://doi.org/10.1016/j.jnucmat.2019.151815. 
[50] M. Grosse, "Modeling of the hydrogen distribution in cladding tubes after LOCA", in: Proceedings of the 19th International QUENCH-workshop, Karlsruhe, Germany, Nov. 19-21, 2013.

[51] M.S. Veshchunov, V.E. Shestak, "Modelling of $\mathrm{Zr}$ alloy burst cladding internal oxidation and secondary hydriding under LOCA conditions", JNM 461 (2015) 129-142.

[52] V.E. Shestak, B.C. Oberländer, M.S. Veshchunov, "Analysis of fuel clad double-side oxidation and secondary hydriding under LOCA conditions in IFA-650.2 test", Final Report of a Coordinated Research Project (CRP) (2014-2018), FUMAC, IAEA TECDOC - 1889 (2019)

[53] The Nuclear Safety Commission of Japan, "Acceptance criteria for emergency core cooling systems for light-water-reactors", (1981), in Japanese.

[54] Y. Mishima, "Thirty-five years of nuclear reactor safety in Japan", J Nucl Sci Technol. 27 (1990) 205-214

[55] OECD/NEA, "Nuclear fuel behaviour in loss-of-coolant accident (LOCA) conditions: state-of-theart report", Paris (France): Organisation for economic co-operation and development nuclear energy agency, (2009) (up-dated version to be published by OECD/NEA)

[56] A. Cabrera, N. Waeckel, "A strength based approach to define LOCA limits", Proc. TopFuel 2015, Sep.14-16 2015, Zurich ,Switzerland

[57] S. Graff, S. Boutin, A. Foucher-Taisne, O. Dubois, "New LOCA and RIA fuel safety criteria in France", Proceedings of WRFPM Conference, Jeju, Republic of South Korea, (September 2017)

[58] T. Forgeron, J.C. Brachet, F. Barcelo, A. Castaing, J. Hivroz, J.P. Mardon, C. Bernaudat, "Experiment and modelling of advanced fuel rod behaviour under LOCA conditions : $\alpha \leftrightarrow \beta$ phase transformation kinetics and EDGAR methodology", ASTM STP 1354, (2000), pp. 256-278

[59] J.C. Brachet, J. Pelchat, D. Hamon, R. Maury, P. Jacques, J.P. Mardon, "Mechanical behavior at Room Temperature and Metallurgical study of Low-Tin Zy-4 and M5 ${ }^{\mathrm{TM}}$ alloys after oxidation at $1100^{\circ} \mathrm{C}$ and quenching", Proceedings of the Technical Committee Meeting on Fuel Behavior Under Transient and LOCA Conditions, IAEA-TECDOC-1320, Halden, Norway, (Sept 10-14, 2001), pp. 139158

[60] J.C. Brachet, V. Maillot, L. Portier, D. Gilbon, A. Lesbros, N. Waeckel and J.P. Mardon, "Hydrogen Content, Pre Oxidation and Cooling Scenario Influences on Post-Quench Mechanical Properties of Zy-4 and M5TM Alloys in LOCA Conditions - Relationship with the Post-Quench Microstructure", Journal of ASTM International, Vol. 5, No. 4 (2008) Paper JAl101116

[61] M. Le Saux, J.C. Brachet, V. Vandenberghe, E. Rouesne, S. Urvoy, A. Ambard, R. Chosson, "Effect of a pre-oxide on the high temperature steam oxidation of Zircaloy-4 and M5Framatome alloys", Journal of Nuclear Materials 518 (2019) 386-399.

[62] J.C. Brachet, D. Hamon, J.L. Béchade, P. Forget, C. Toffolon-Masclet, C. Raepsaet, J.P. Mardon and B. Sebbari, "Quantification of the chemical elements partitioning within pre-hydrided Zircaloy-4 after high temperature steam oxidation as a function of the final cooling scenario (LOCA conditions) and consequences on the (local) materials hardening", IAEA-TECDOC-CD-1709 (2013) 253-265

[63] W. Gong, P. Trtik, A.W. Colldeweih, L.I. Duarte, M. Grosse, E. Lehmann, J. Bertsch, "Hydrogen diffusion and precipitation in duplex zirconium nuclear fuel cladding quantified by high-resolution neutron imaging", JNM 526 (2019) 151757

[64] J. Ribis, A. Wu, J.C. Brachet, F. Barcelo, B. Arnal, "Atomic-scale interface structure of a Crcoated Zircaloy-4 material", J. Mat. Sci. 53 (2018) 9879-9895, https://doi.org/10.1007/s10853-0182333-1

[65] A. Wu, J. Ribis, J.C. Brachet, E. Clouet, F. Leprêtre, E. Bordas, B. Arnal, "HRTEM and chemical study of an ion-irradiated chromium/Zircaloy-4 Interface", JNM 504 (2018) 289-299, https://doi.org/10.1016/j.jnucmat.2018.01.029

[66] L. Baker and L.C. Just, "Studies of metal-water reactions at high temperatures. III. Experimental and theoretical studies of the zirconium-water reaction", ANL-6548, ML050550198, (May 1962)

[67] J.C. Brachet, M. Le Saux, V. Lezaud-Chaillioux, M. Dumerval, Q. Houmaire, F. Lomello, F. Schuster, E. Monsifrot, J. Bischoff, E. Pouillier, "Behavior under LOCA conditions of enhanced 
accident tolerant chromium coated Zircaloy-4 claddings", in: Proceedings of TopFuel 2016 Conference, Boise, ID, USA, September 2016.

[68] J.C. Brachet, M. Dumerval, V. Lezaud-Chaillioux, M. Le Saux, E. Rouesne, D. Hamon, S. Urvoy, T. Guilbert, Q. Houmaire, C. Cobac, G. Nony, J. Rousselot, F. Lomello, F. Schuster, H. Palancher, J. Bischoff, E. Pouillier, "Behavior of chromium coated M5 claddings under LOCA conditions", in: Proceedings of WRFPM Conference, Jeju, Republic of South Korea, September 2017.

[69] M. Dumerval, Q. Houmaire, J.C. Brachet, H. Palancher J. Bischoff, E. Pouillier, "behavior of chromium coated M5 claddings upon thermal ramp tests under internal pressure (LOss-of-Coolant accident conditions)", Proceedings of WRFPM/TOPFUEL 2018, (30 Sept. - 04 Oct. 2018), Prague, Czech Republic.

[70] J.C. Brachet, M. Le Saux, M. Le Flem, S. Urvoy, E. Rouesne, T. Guilbert, C. Cobac, F. Lahogue, J. Rousselot, M. Tupin, P. Billaud, C. Hossepied, F. Schuster, F. Lomello, A. Billard, G. Velisa, E. Monsifrot, J. Bischoff, A. Ambard, "On-going studies at CEA on chromium coated zirconium based nuclear fuel claddings for enhanced accident tolerant LWR fuel", in: Proceedings of TopFuel Conference 2015, Zurich, Switzerland, September 2015

[71] A. Sawatzky, "A Proposed Criterion for the Oxygen Embrittlement of Zircaloy-4 Fuel Cladding," Zirconium in the Nuclear Industry (4th Conference), ASTM STP 681, ASTM International, West Conshohocken, PA, (1979), pp. 479-496

[72] H.M. Chung and T.F. Kassner, "Embrittlement Criteria for Zircaloy Fuel Cladding Applicable to Accident Situations in Light-Water Reactors. Summary Report", NUREG/CR-1344, ANL-7948, (1980)

[73] M. Négyesi, L. Novotný, J. Kabátová, S. Linhart, V. Klouček, J. Lorinčík, V. Vrtílková, "UJP LOCA Oxidation Criteria "K" and "Oß"', IAEA-TECDOC-CD-1709, (2013)

[74] A. Stern, J.C. Brachet, V. Maillot, D. Hamon, F. Barcelo, S. Poissonnet, A. Pineau, J.P. Mardon, A. Mesbros, "Investigations of the microstructure and mechanical properties of prior- $\beta$ zr structure as function of the oxygen content (up to $0.9 \mathrm{wt} \%$ ) in two zirconium alloys" ASTM 15th International Symposium on Zirconium in the Nuclear Industry, June 24-28, 2007, Sunriver, Oregon, USA, Journal of ASTM International, Vol. 5, No. 4, Paper ID JAl101119, (2008)

[75] K.K. Mandapaka, R.S. Cahyadi, S. Yalisove, W. Kuang, K. Sickafus, M.K. Patel, G.S. Was, "Corrosion behavior of ceramic-coated ZIRLO' ${ }^{\text {TM }}$ exposed to supercritical water", JNM 498 (2018) 495504.

[76] H. M. Chung, and T. F. Kassner, "Pseudo Binary Zircaloy-oxygen Diagram," JNM 84 (1979) 327-339

[77] N. Dupin, I. Ansara, C. Servant, C. Toffolon, C. Lemaignan, J.C. Brachet, "A Thermodynamic Database for Zirconium Alloys", J. Nucl. Mater. 275 (1999), pp. 287-295

[78] H. K. Yueh, R. J. Comstock, B. Dunn, M. Le Saux, Y. P. Lin, D. Lutz, D. J. Park, E. Perez-Fero, Y. Yan, "Loss of Coolant Accident Testing Round Robin", Proceedings of TopFuel 2013, Charlotte, North Carolina, USA, September 15-19, 2013, pp. 550-556

[79] L. Portier, T. Bredel, JC. Brachet, V. Maillot, JP. Mardon, A. Lesbros, "Influence of Long Service Exposures on the Thermal-Mechanical Behavior of Zy-4 and M5 Alloys in LOCA Conditions," Journal of ASTM International, Vol. 2, No. 2 (2005) Paper JAl12468

[80] M.C. Billone, "Assessment of Current Test Methods for Post-LOCA Cladding Behavior", NUREG/CR-7139, ML12226A182, (August 2012)

[81] USNRC, "Testing For Post-quench Ductility", RG 1.223, ML15238B079, (2016)

[82] J. Desquines, D. Drouan, S. Guilbert, P. Lacote, "Embrittlement of pre-hydrided Zircaloy-4 by steam oxidation under simulated LOCA transients", Journal of Nuclear Materials 469 (2016) 20-31

[83] B. Sundman, B. Jansson, J.-O. Anderson, "The thermo-calc databank system", Calphad 9 (2) (1985) 153-190.

[84] N. Dupin, I. Ansara, C. Servant, C. Toffolon, C. Lemaignan, J.C. Brachet, "A thermodynamic database for zirconium alloys", JNM 275 (1999) 287-295

[85] P. Lafaye, "Développement d'outils de modélisation thermodynamique pour la prédiction de l'état métallurgique d'alliages à base de zirconium", PhD Thesis, Paris-Est Univ., in French, (2017) 
[86] T. Le Hong, "Effets de l'oxygène et de l'hydrogène sur la microstructure et le comportement mécanique d'alliages de zirconium après incursion à haute température", PhD Thesis, PSL Research University, in french, (2020)

[87] T. Le Hong, J.-C. Brachet, J. Crépin, M. Le Saux, "Combined effects of temperature and of high hydrogen and oxygen contents on the mechanical behavior of a zirconium alloy upon cooling from the $\beta z$ r phase temperature range", submitted to Journal of Nuclear Materials (Feb. 2021) 


\section{FIGURE CAPTIONS:}

Figure 1 - Schematic view of the DLI-MOCVD inner-coated clad segment and associated evolution of the $\mathrm{Cr}_{x} \mathrm{C}_{\mathrm{y}}$ inner coating thickness as a function of the axial distance from the precursor + solvent injection location

Figure 2 - Macrograph of a clad segment after burst, before the HT steam oxidation test (a) and scheme of the locations where the samples were machined from the tested clad segments for the $P Q$ testing and analysis (b) ....

Figure 3 - Optical micrograph (polarized light) of the wall thickness of uncoated HSn-HO-Zirc4 clads and corresponding Vickers micro-hardness mean values: in as-received conditions (a), and after a "flash" $\beta_{z r}$ thermal treatment at $1000^{\circ} \mathrm{C}(<30 \mathrm{~s})$ followed by water quenching down to RT (b)...

Figure 4 - Optical micrograph of the clad wall thickness of a $10 \mu \mathrm{m}$-thick PVD Cr outercoated clad in as-received condition.

Figure 5 - Optical micrograph (polarized light) (a), and SEM micrograph (higher

magnification, backscattered electron (BSE) mode) of the clad wall thickness of the $20 \mu \mathrm{m}$ thick inner-coated clad corresponding to the axial "M2" location.

Figure 6 - SEM micrographs of the inner surface of (a) uncoated and (b) inner-coated claddings in as-received conditions

Figure 7 - EPMA chemical elements mapping (a) and quantitative profiles (b) in the wall thickness of the amorphous $\mathrm{Cr}_{x} \mathrm{C}_{y}$ inner coating in as-received conditions ("M2" axial location)

Figure 8 - Weight gain evolution as a function of two-sided steam oxidation time at $1200^{\circ} \mathrm{C}$ of uncoated/coated 30mm-long clad segments (HSn-HO-Zirc-4 clad substrate); comparison with previous CEA's one-sided steam oxidation data obtained on uncoated low-tin Zircaloy-4 [60] and on 12-15 $\mu$ m-thick $\mathrm{Cr}$ (PVD) outer-coated M5 $5_{\text {Framatome }}$ claddings [21] .... 30 Figure 9 - SEM-EBSD map in phase contrast imaging mode of the inner $\mathrm{Cr}_{x} \mathrm{C}_{y}$ coating, after steam oxidation for 600 s at $1200^{\circ} \mathrm{C}$, replotted from [27] ....

Figure 10 - EPMA chemical element mappings (a), optical micrograph (b) and SEM-BSE electron micrograph (c) of different types of defects/cracks in the inner DLI-MOCVD $\mathrm{Cr}_{x} \mathrm{C}_{\mathrm{y}}$ coating, as locally observed after steam oxidation for 600 s at $1200^{\circ} \mathrm{C}$.

Figure 11 - Optical micrograph and through-thickness (from the outer diameter) oxygen (and chromium) diffusion profiles from EPMA and $\mu$-hardness profiles of uncoated HSn-HO-Zirc-4 after two-sided steam oxidation at $1200^{\circ} \mathrm{C}$ for $600 \mathrm{~s}$

Figure 12 - Optical micrograph and through-thickness (from the outer diameter) oxygen (and chromium) diffusion profiles from EPMA and $\mu$-hardness profiles of inner-coated HSn-HOZirc-4 after two-sided steam oxidation at $1200^{\circ} \mathrm{C}$ for $600 \mathrm{~s}$

Figure 13 - Optical micrograph and through-thickness (from the outer diameter) oxygen (and chromium) diffusion profiles from EPMA and $\mu$-hardness profiles of outer-coated HSn-HOZirc-4 after two-sided steam oxidation at $1200^{\circ} \mathrm{C}$ for $600 \mathrm{~s}$

Figure 14 - Optical micrograph and through-thickness (from the outer diameter) oxygen (and chromium) diffusion profiles from EPMA and $\mu$-hardness profiles of two-sided coated HSn-

$\mathrm{HO}-$ Zirc-4 after two-sided steam oxidation at $1200^{\circ} \mathrm{C}$ for $600 \mathrm{~s}$..

Figure 15 - Optical micrograph and through-thickness (from the outer diameter) oxygen (and chromium) diffusion profiles from EPMA and $\mu$-hardness profiles of outer-coated $\mathrm{HSn}$-HOZirc-4 after two-sided steam oxidation at $1200^{\circ} \mathrm{C}$ for $1500 \mathrm{~s}$ 35 Figure 16 - Optical micrograph and through-thickness (from the outer diameter) oxygen (and chromium) diffusion profiles from EPMA and $\mu$-hardness profiles of two-sided coated HSn$\mathrm{HO}-$ Zirc-4 after two-sided steam oxidation at $1200^{\circ} \mathrm{C}$ for $1500 \mathrm{~s}$ 
Figure 17 - Maximum load values derived from PQ RCTs after steam oxidation at $1200^{\circ} \mathrm{C}$ followed by direct quenching down to RT (on $1 \mathrm{~cm}$-long clad segments), plotted as a function of the Baker-Just ECR and compared with previous data obtained on uncoated [60] [79] and outer Cr-coated [21] cladding materials 36

Figure 18 - Typical fractographs showing the prior- $\beta_{z r}$ failure mode at mid clad thickness location, after PQ RCTs carried out at RT.

Figure 19 - Maximum load values derived from PQ RCTs after steam oxidation at $1200^{\circ} \mathrm{C}$ followed by direct quenching down to RT, plotted as a function of prior- $\beta_{z r}$ oxygen content derived from micro-hardness measurements (equation 1) and compared with previous data obtained on uncoated Low-Tin Zirc-4 [60] [79] and outer Cr-coated M5Framatome [21] cladding materials.

Figure 20 - Visual aspects of uncoated and inner-coated HSn-HO-Zirc-4 clad segments that have experienced internal pressure ballooning and burst temperature ramp tests and then subsequent HT steam oxidation and direct water quenching down to RT

Figure 21 - Optical micrograph showing the PQ microstructures of uncoated (a) and innercoated (b) HSn-HO-Zirc-4 clad segments that have experienced internal pressure ballooning and burst thermal ramp tests, and then subsequent HT steam oxidation for 600 s at $1200^{\circ} \mathrm{C} 39$ Figure 22 - Circumferentially averaged values of the thicknesses of the inner/outer $\mathrm{ZrO}_{2}$ and $\alpha_{\mathrm{zr}}(\mathrm{O})$ for uncoated and inner-coated $\mathrm{HSn}-\mathrm{HO}$-Zirc-4 clad segments that have experienced internal pressure ballooning and burst thermal ramp tests, and then subsequent HT steam oxidation for $600 \mathrm{~s}$ at $1200^{\circ} \mathrm{C}$ - Comparison with previous results obtained after one-sided steam oxidation of uncoated low-tin Zircaloy-4 [60] and using the same experimental methodology on uncoated M5Framatome [47].

Figure 23 - PQ hydrogen contents measured by neutron tomography (3D-maps and results plotted every $10^{\circ}$ over the clad circumference) and by post-mortem IGFTC analysis of HSn$\mathrm{HO}-$ Zirc-4 clad segments that have experienced internal pressure ballooning and burst thermal ramp tests, and then subsequent $\mathrm{HT}$ steam oxidation for $600 \mathrm{~s}$ at $1200^{\circ} \mathrm{C}$ followed by direct water quenching down to RT....

Figure 24 - Through-thickness micro-hardness profiles measured at different axial locations of uncoated and inner coated HSn-HO-Zirc-4 clad segments that have experienced internal pressure ballooning and burst thermal ramp tests, and then subsequent HT steam oxidation for 600 s at $1200^{\circ} \mathrm{C}+$ direct water quenching down to RT

Figure 25 - Relationships between maximum loads derived from $P Q R C T s$ at $135^{\circ} \mathrm{C}$ and $P Q$ tensile data from IRSN obtained on pre-hydrided Zirc-4 [82]), and: (a) circumferentially averaged measured (interpolated) hydrogen concentrations (b) interpolated prior- $\beta_{\mathrm{Zr}}$ microhardness and corresponding oxygen contents derived from equation 2

Figure 26 - Calculated PQ maximum tensile strength of prior- $\beta_{z r}$ at $R T$, using Le Hong et al.' correlation [86] for low-tin Zirc-4 vs. oxygen $\left({ }^{*}\right)$ and hydrogen $\left({ }^{* *}\right)$ respective contents, plotted as a function of the maximum load derived from PQ RCTs carried out at RT or at $135^{\circ} \mathrm{C}$ on uncoated/coated HSn-HO-Zirc-4 $\left(^{*}\right)$ derived from prior- $\beta_{\mathrm{zr}} \mathrm{HV}(0.01)$ measurements $\left({ }^{* *}\right)$ interpolated (averaged) values from IGFTC measurements 

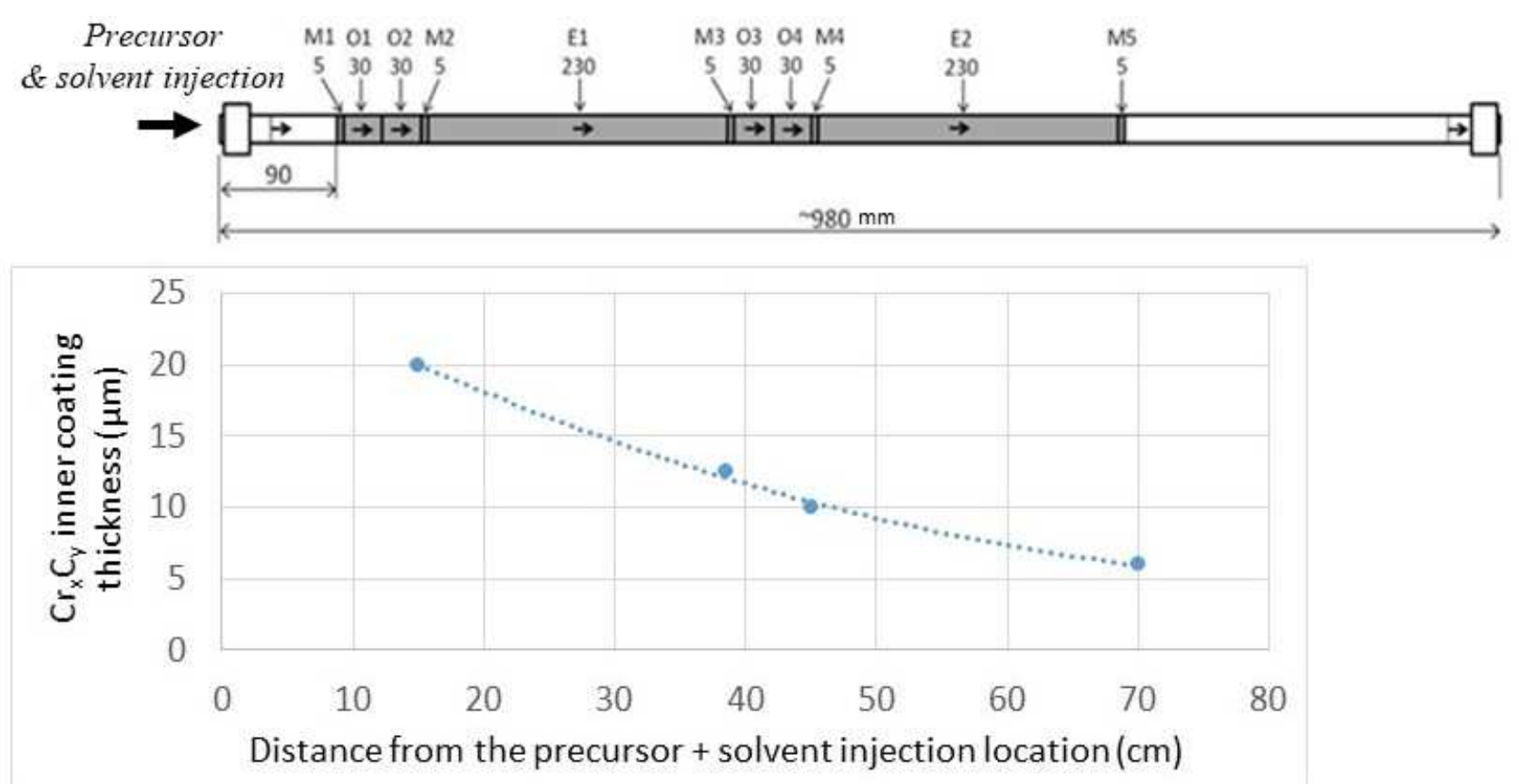

Figure 1 - Schematic view of the DLI-MOCVD inner-coated clad segment and associated evolution of the $\mathrm{Cr}_{x} \mathrm{C}_{y}$ inner coating thickness as a function of the axial distance from the precursor + solvent injection location

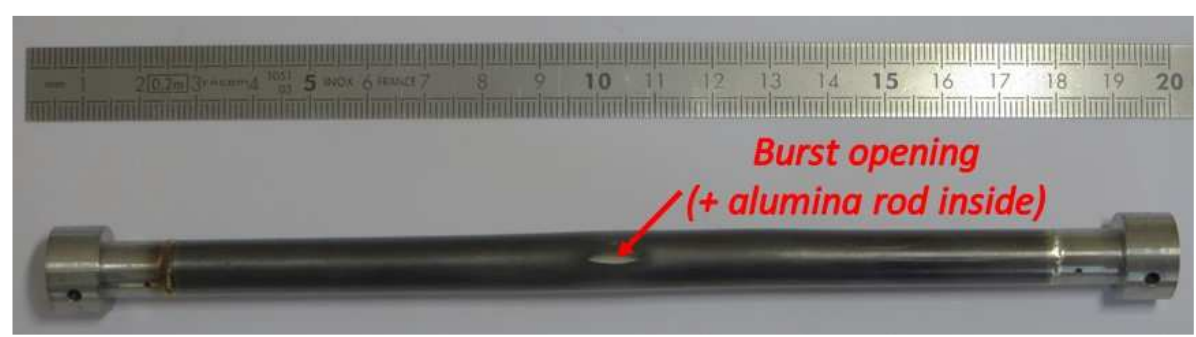

(a)

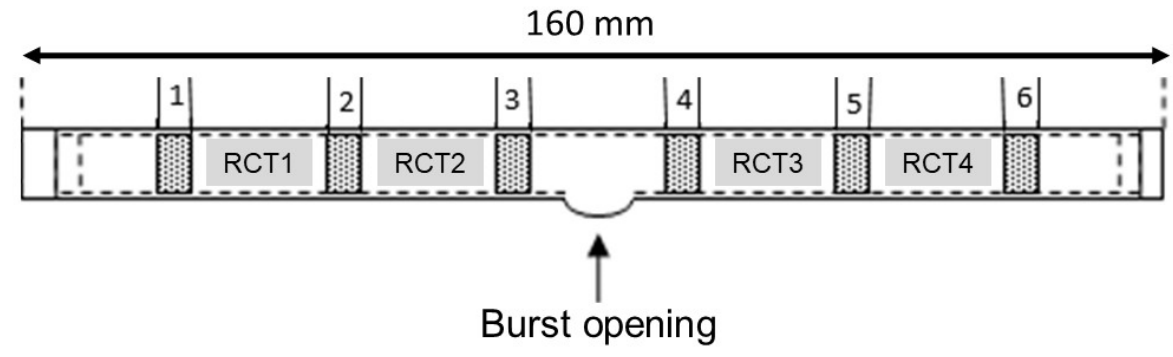

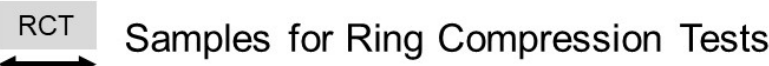

$\stackrel{\longrightarrow}{\longrightarrow m m}$

Samples for $\mu$ structural examinations, hydrogen analysis and $\mu$ hardness measurements

(b)

Figure 2 - Macrograph of a clad segment after burst, before the HT steam oxidation test (a) and scheme of the locations where the samples were machined from the tested clad segments for the $P Q$ testing and analysis (b) 


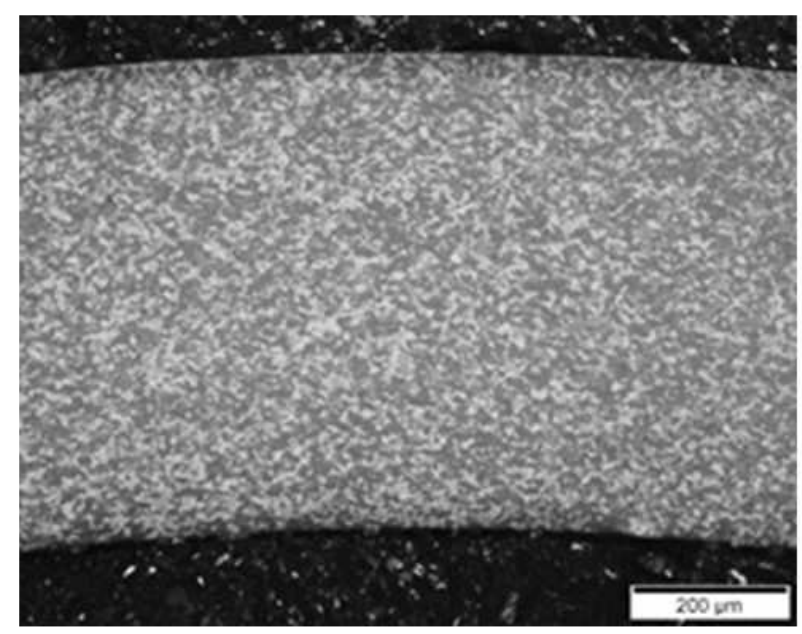

(a) $\mathrm{HV}_{0.05}=200 \pm 5$

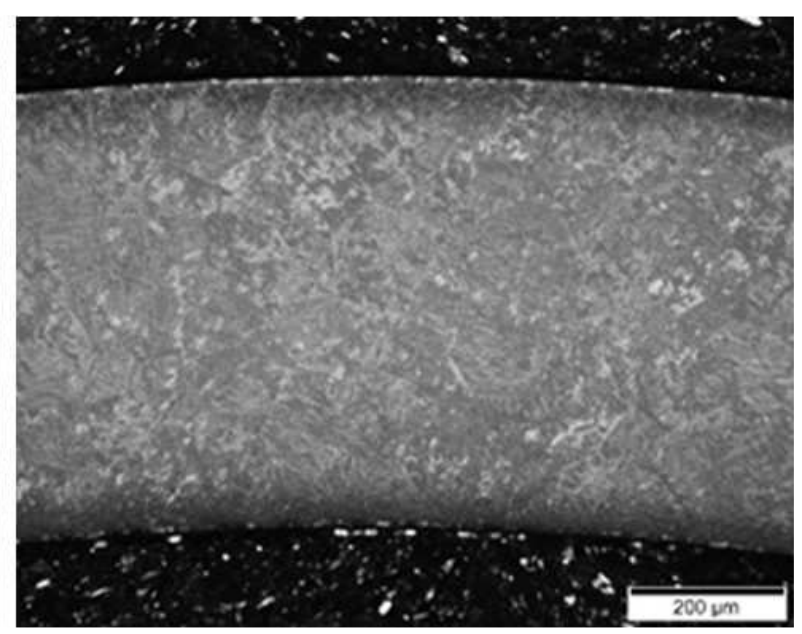

(b) $\mathrm{HV}_{0.05}=275 \pm 5$

Figure 3 - Optical micrograph (polarized light) of the wall thickness of uncoated HSn-HO-Zirc-4 clads and corresponding Vickers micro-hardness mean values: in as-received conditions (a), and after a "flash" $\beta_{z r}$ thermal treatment at $1000^{\circ} \mathrm{C}(<30$ s) followed by water quenching down to RT (b)
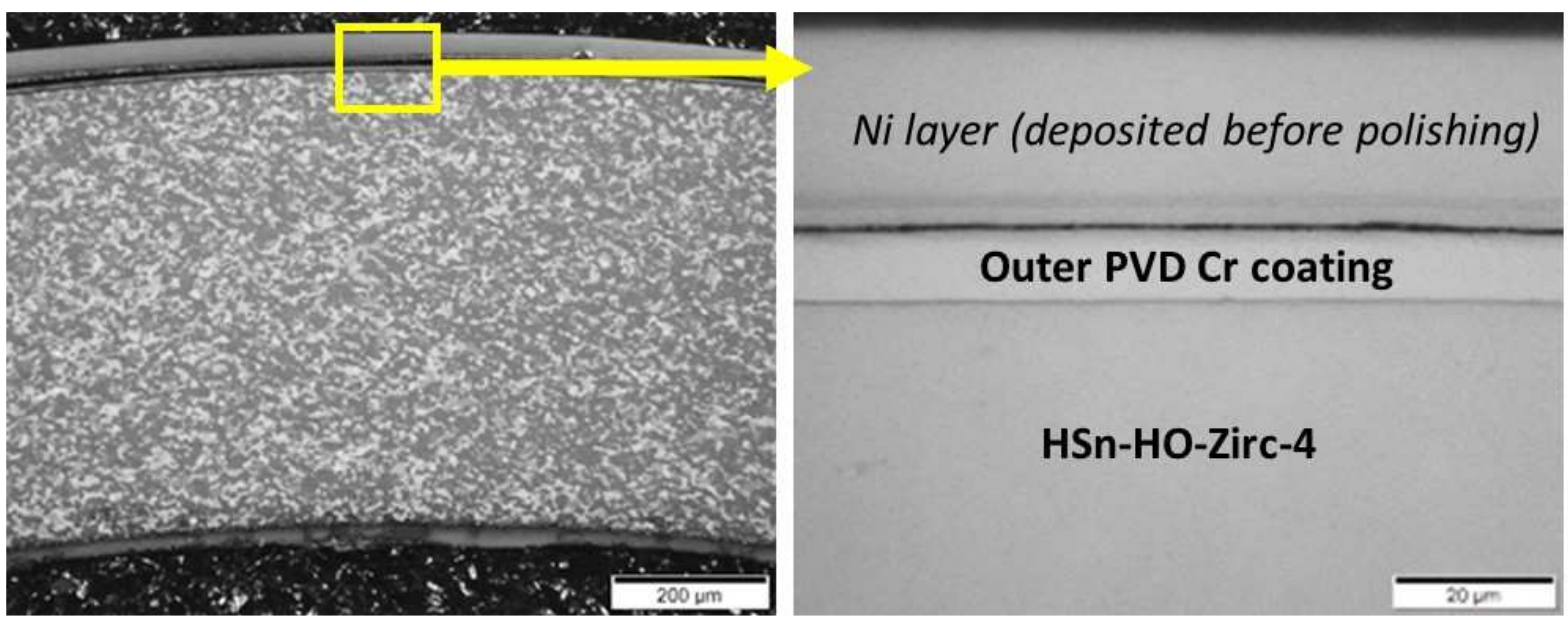

Figure 4 - Optical micrograph of the clad wall thickness of a $10 \mu$ m-thick PVD Cr outer-coated clad in as-received condition

- the apparent inner layer observed on the left micrograph is nickel deposited before polishing 


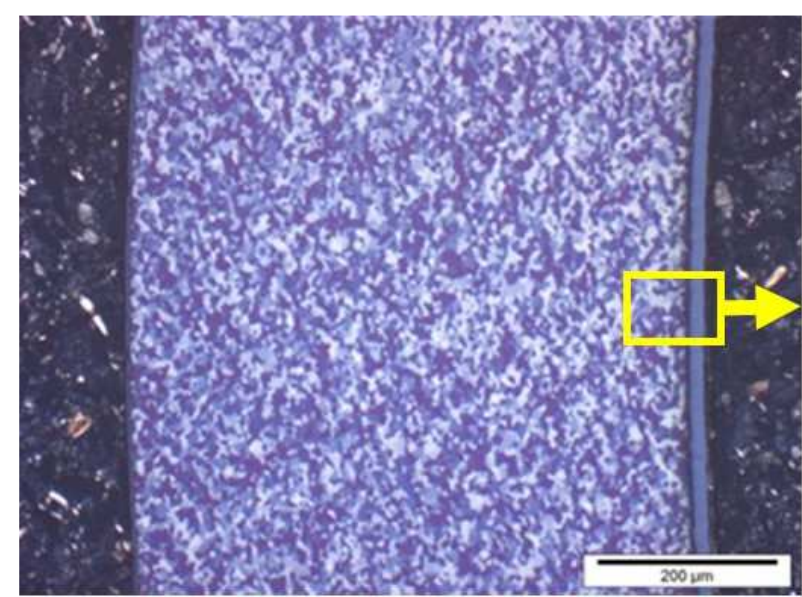

(a)

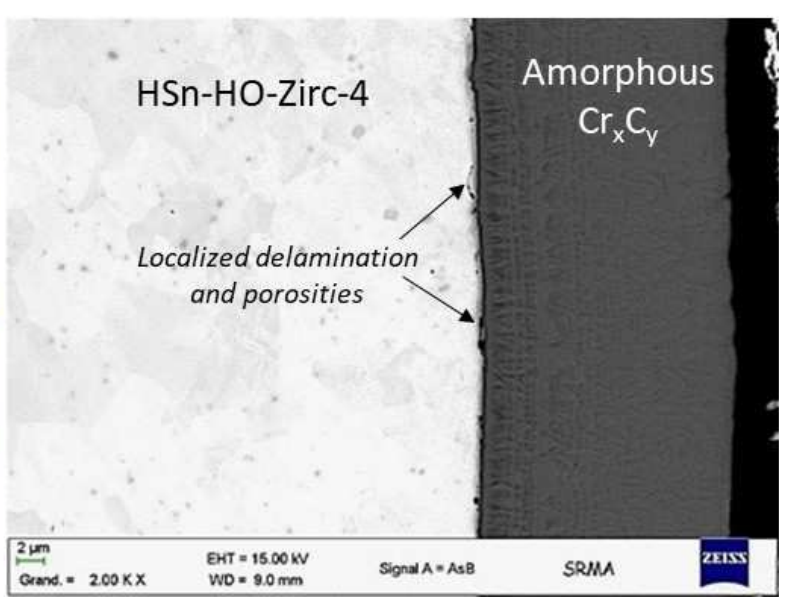

(b)

Figure 5 - Optical micrograph (polarized light) (a), and SEM micrograph (higher magnification, backscattered electron (BSE) mode) of the clad wall thickness of the $20 \mu$ m-thick inner-coated clad corresponding to the axial "M2" location

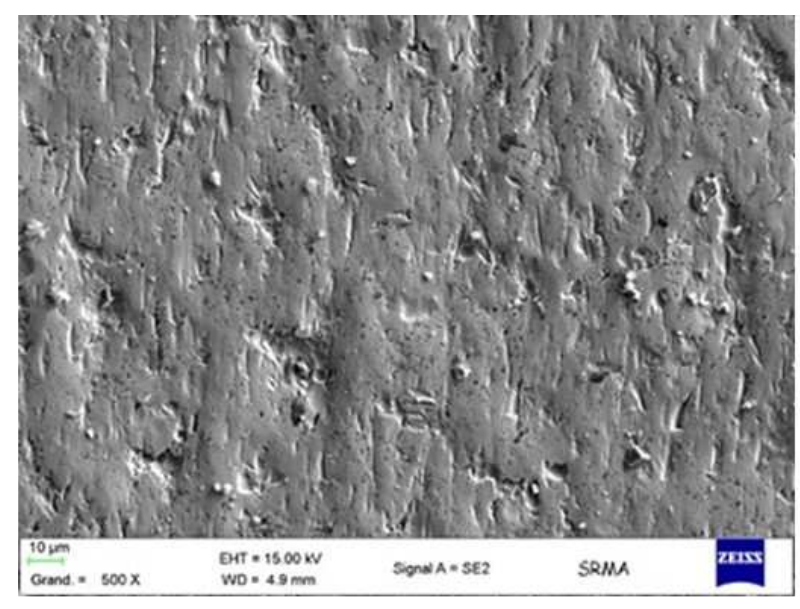

(a)

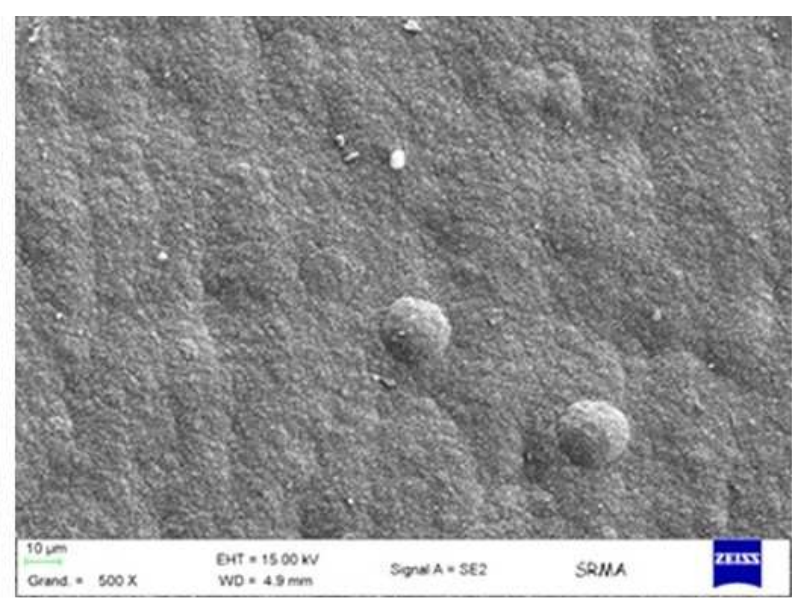

(b)

Figure 6 - SEM micrographs of the inner surface of (a) uncoated and (b) inner-coated claddings in as-received conditions 

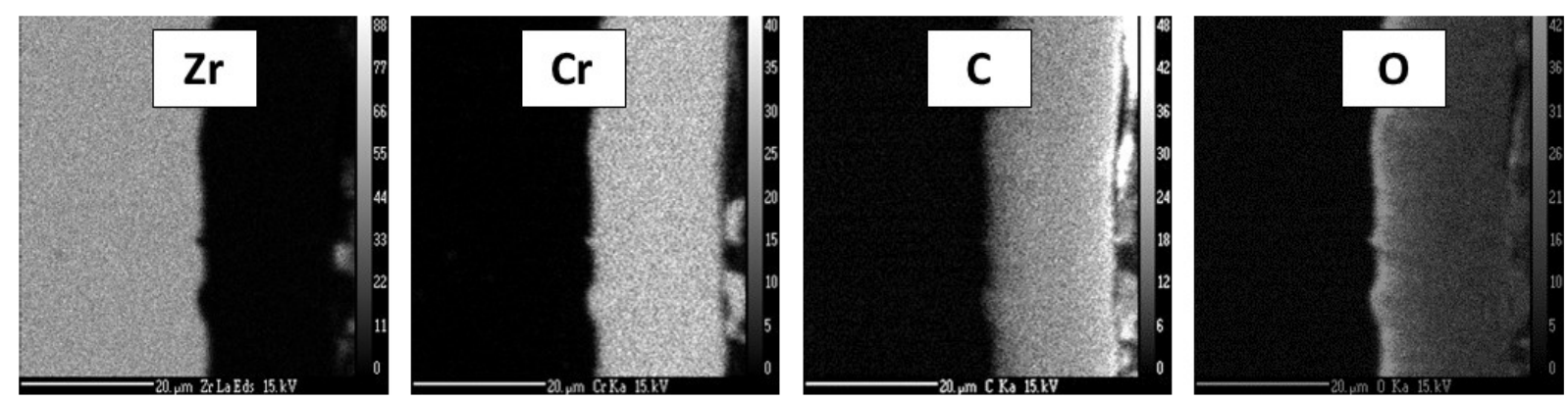

(a)

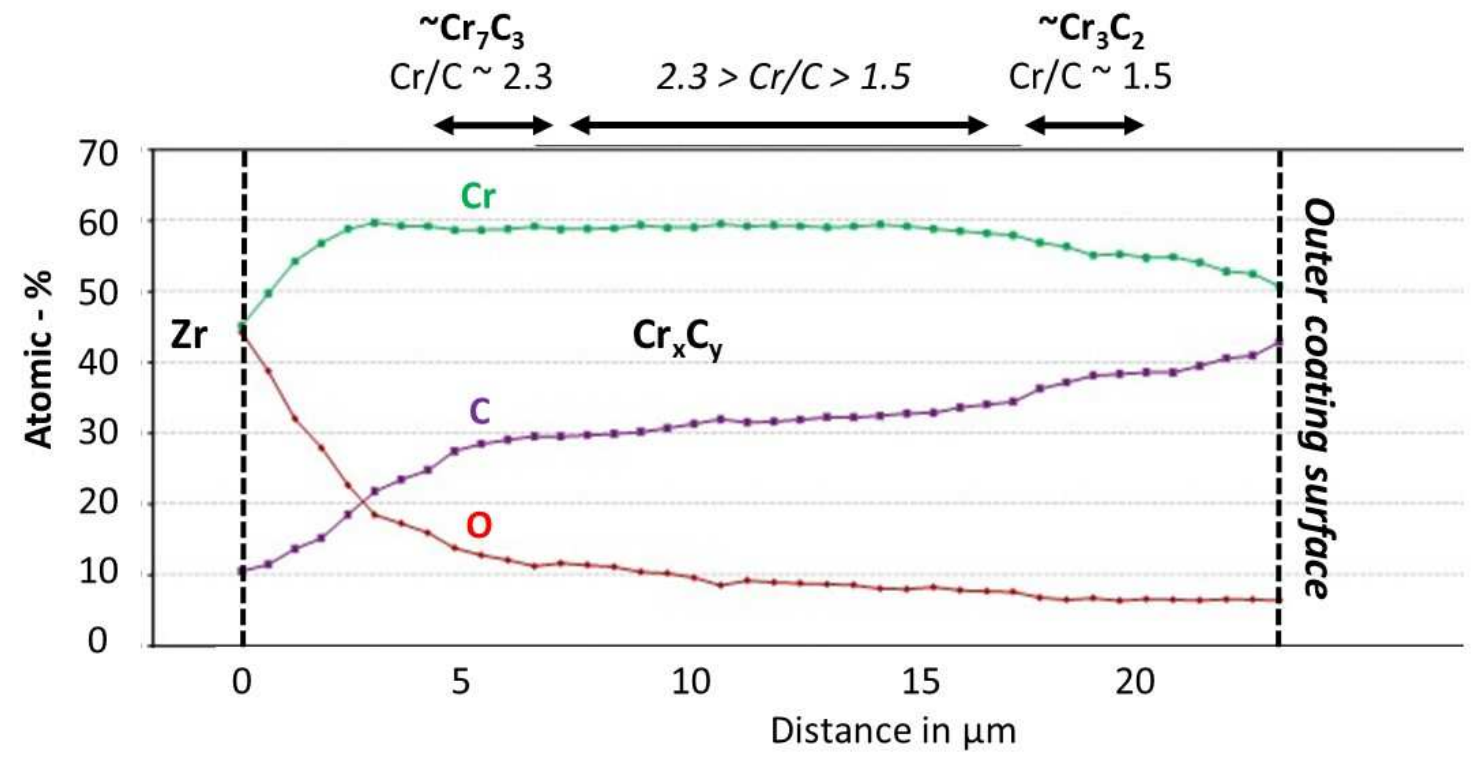

(b)

Figure 7 - EPMA chemical elements mapping (a) and quantitative profiles (b) in the wall thickness of the amorphous $\mathrm{Cr}_{x} C_{y}$ inner coating in as-received conditions ("M2" axial location) 


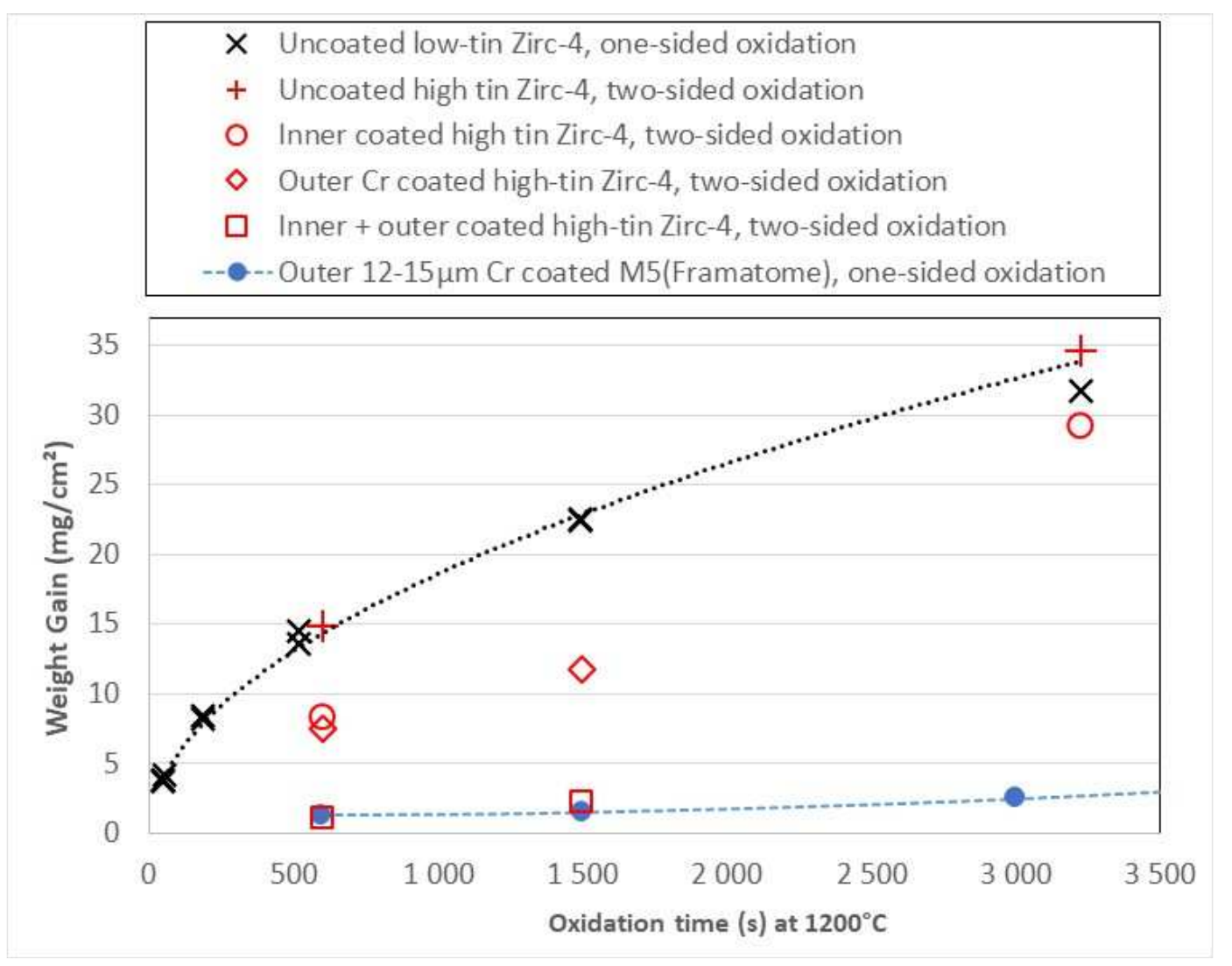

Figure 8 - Weight gain evolution as a function of two-sided steam oxidation time at $1200^{\circ} \mathrm{C}$ of uncoated/coated $30 \mathrm{~mm}$-long clad segments (HSn-HO-Zirc-4 clad substrate); comparison with previous CEA's one-sided steam oxidation data obtained on uncoated low-tin Zircaloy-4 [60] and on 12-15umthick $\operatorname{Cr}(P V D)$ outer-coated M5 Framatome claddings [21] 


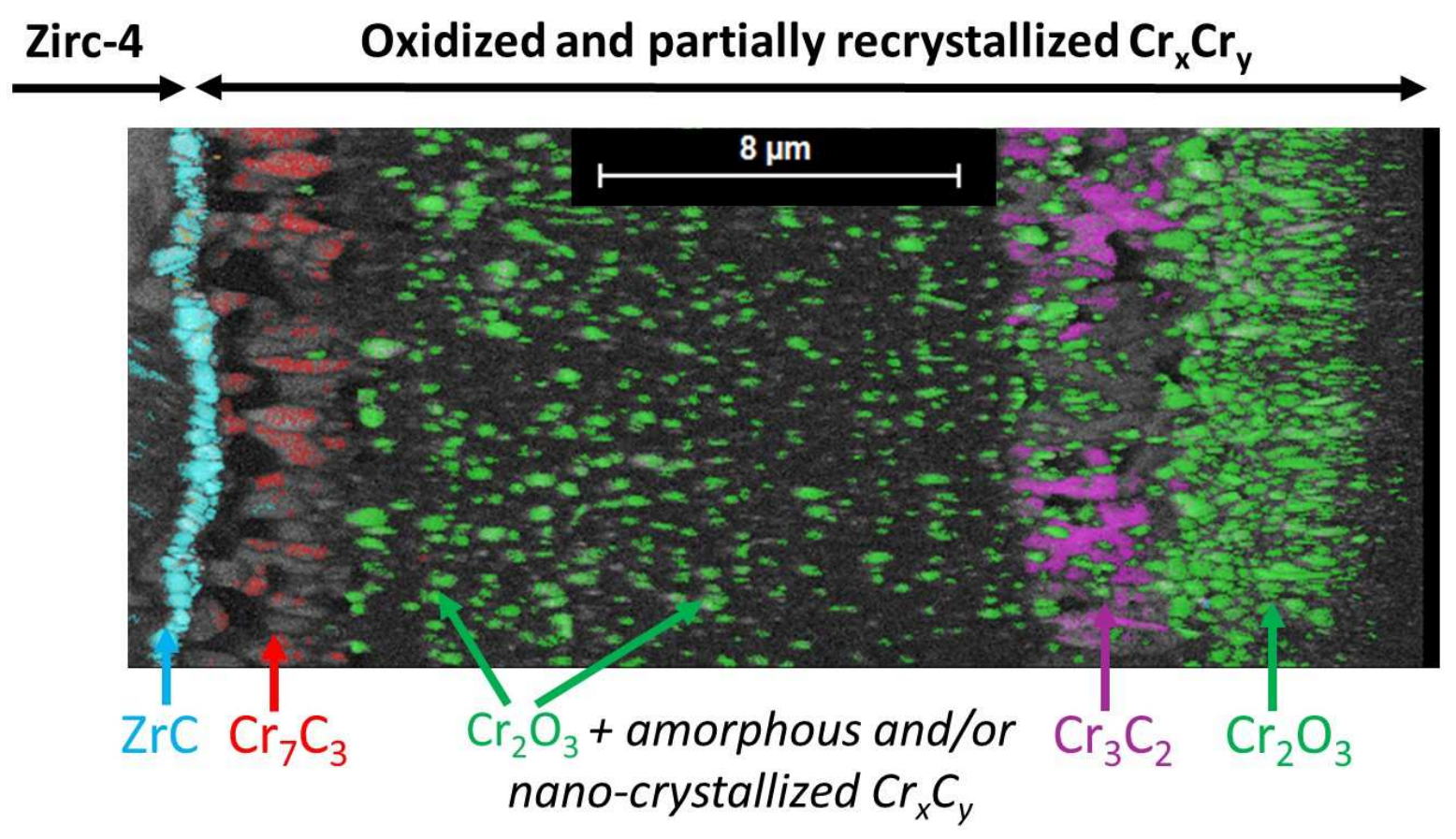

Figure 9 - SEM-EBSD map in phase contrast imaging mode of the inner $\mathrm{Cr}_{x} \mathrm{C}_{y}$ coating, after steam oxidation for 600 s at $1200^{\circ} \mathrm{C}$, replotted from [27] 

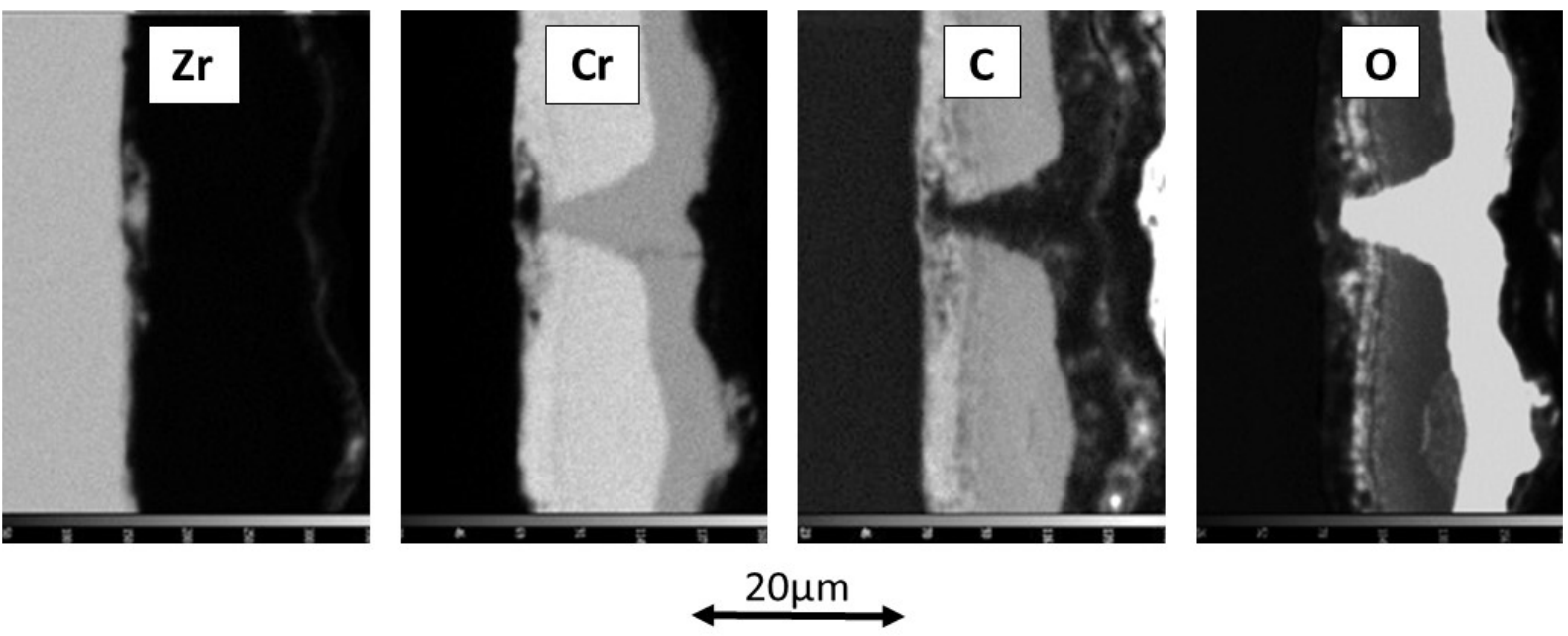

(a) Type-1 coating crack/defect with no oxygen diffusion into the Zr substrate (full self-healing capacity)

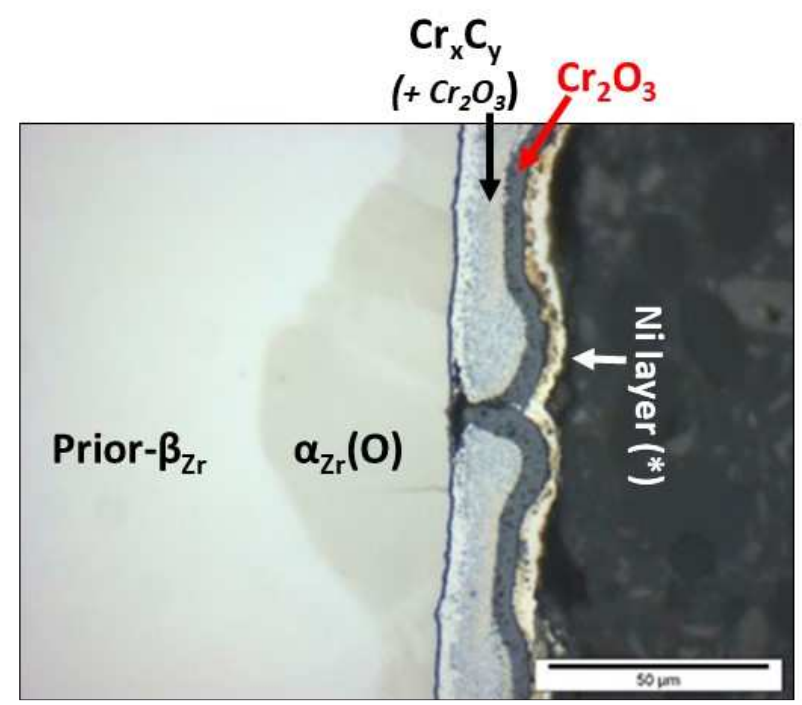

(b) Type-2 coating crack/defect with partial oxygen diffusion into the $\mathrm{Zr}$ substrate inducing $\mathrm{azr}_{\mathrm{z}}(\mathrm{O})$ incursions into the Zr-based substrate (partial selfhealing capacity)

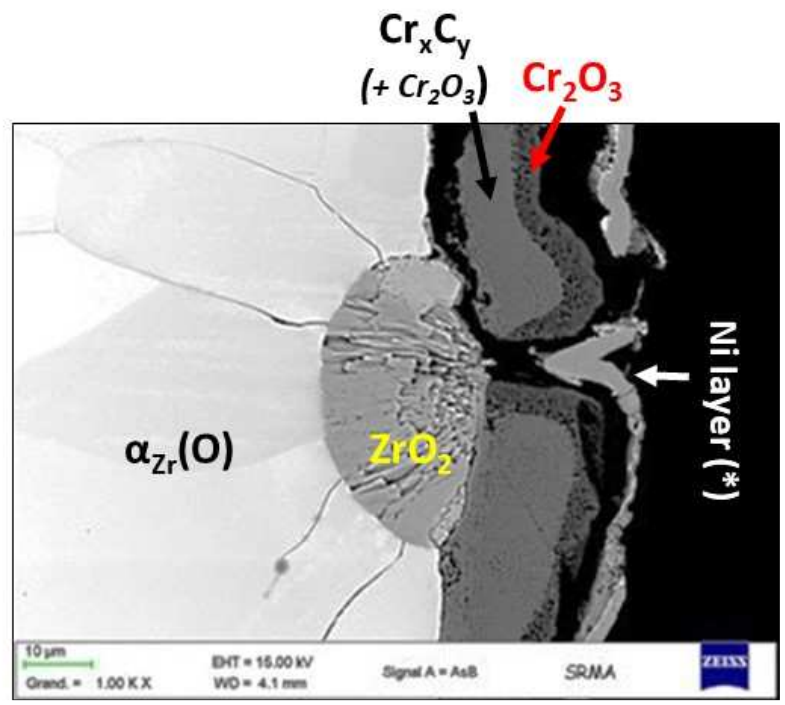

(c) Type-3 coating crack/defect with under-coating zirconia spot formation (no self-healing)

(*) Outer Ni layer deposited before sample polishing to preserve the oxide and coating scales

Figure 10 - EPMA chemical element mappings (a), optical micrograph (b) and SEM-BSE electron micrograph (c) of different types of defects/cracks in the inner DLI-MOCVD $\mathrm{Cr}_{x} \mathrm{C}_{y}$ coating, as locally observed after steam oxidation for 600 s at $1200^{\circ} \mathrm{C}$ 

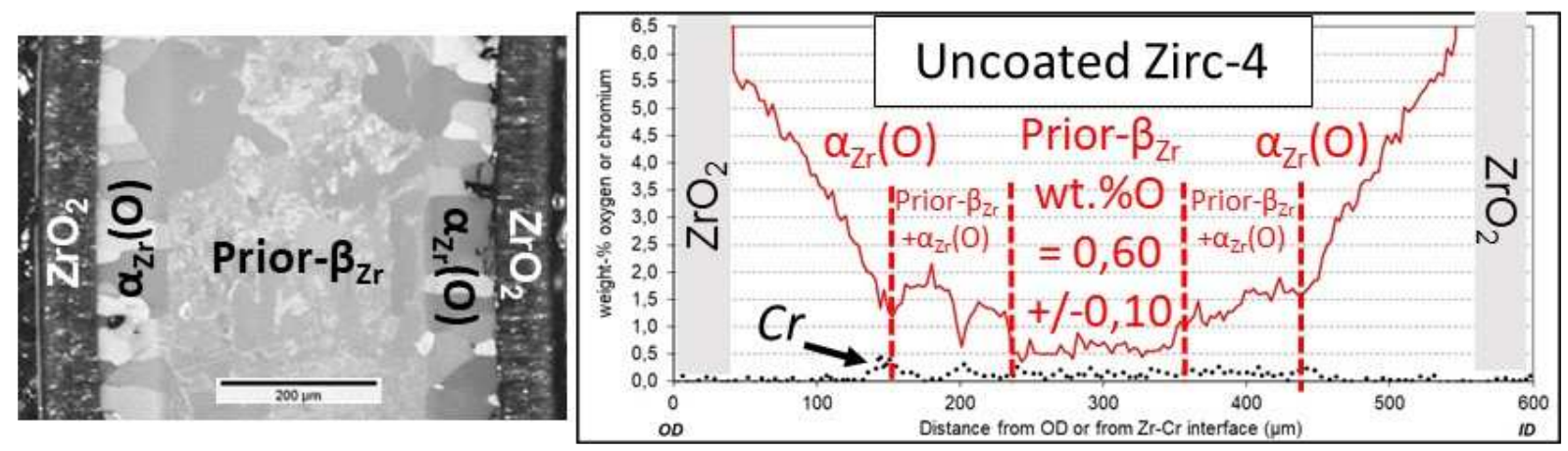

Figure 11 - Optical micrograph and through-thickness (from the outer diameter) oxygen (and chromium) diffusion profiles from EPMA and $\mu$-hardness profiles of uncoated HSn-HO-Zirc-4 after twosided steam oxidation at $1200^{\circ} \mathrm{C}$ for $600 \mathrm{~s}$
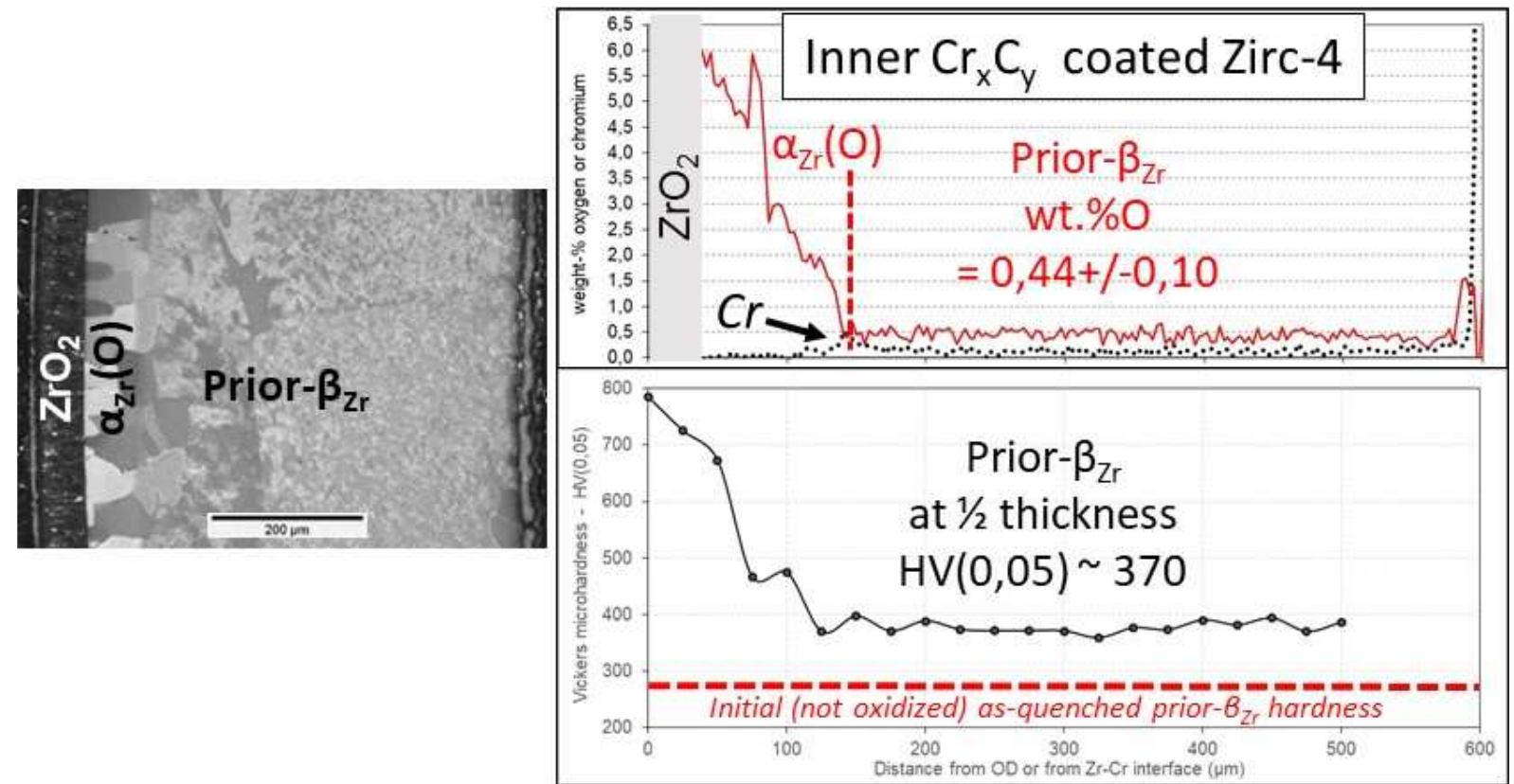

Figure 12 - Optical micrograph and through-thickness (from the outer diameter) oxygen (and chromium) diffusion profiles from EPMA and $\mu$-hardness profiles of inner-coated HSn-HO-Zirc-4 after two-sided steam oxidation at $1200^{\circ} \mathrm{C}$ for $600 \mathrm{~s}$ 

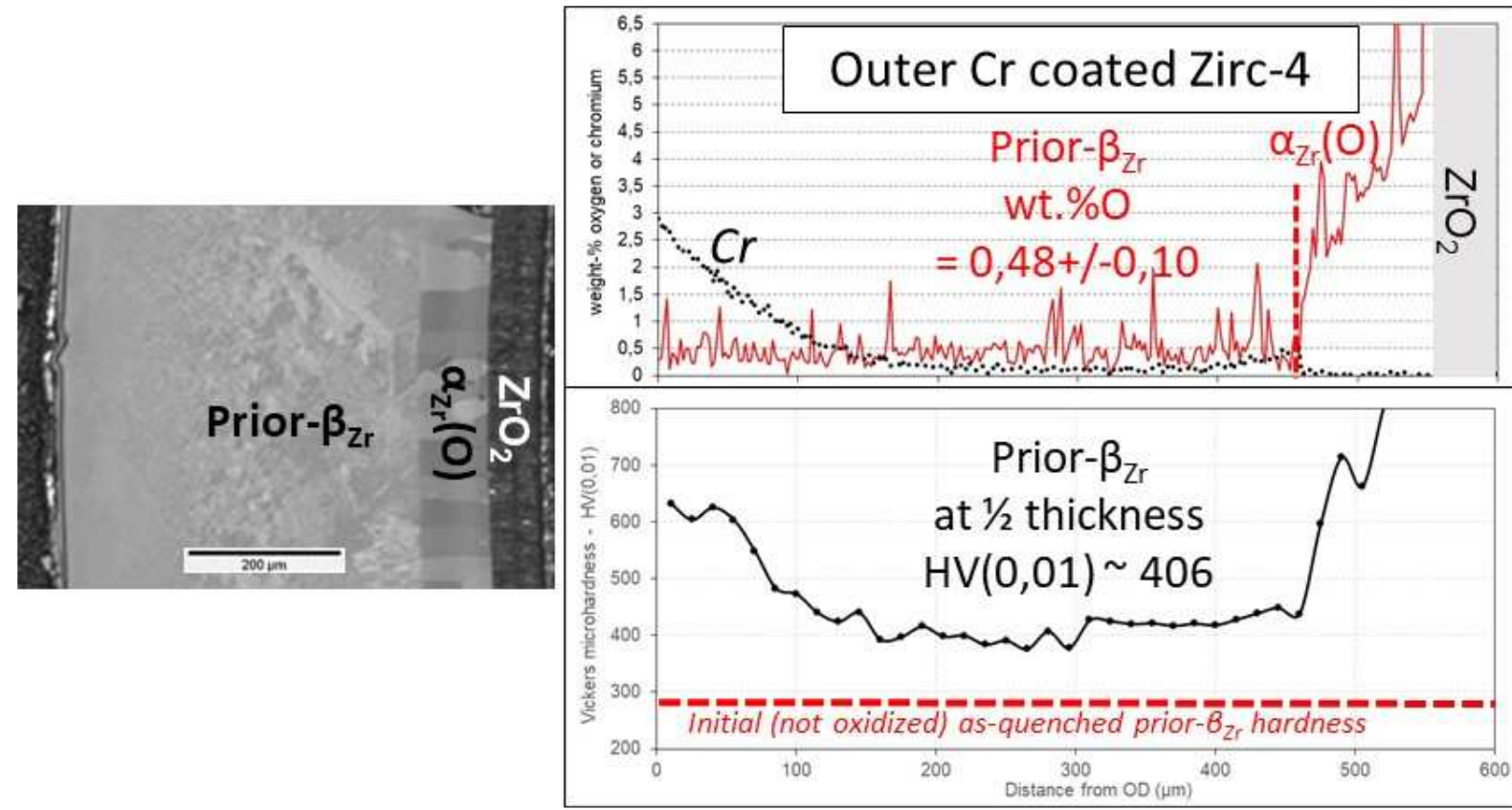

Figure 13 - Optical micrograph and through-thickness (from the outer diameter) oxygen (and chromium) diffusion profiles from EPMA and $\mu$-hardness profiles of outer-coated HSn-HO-Zirc-4 after two-sided steam oxidation at $1200^{\circ} \mathrm{C}$ for $600 \mathrm{~s}$
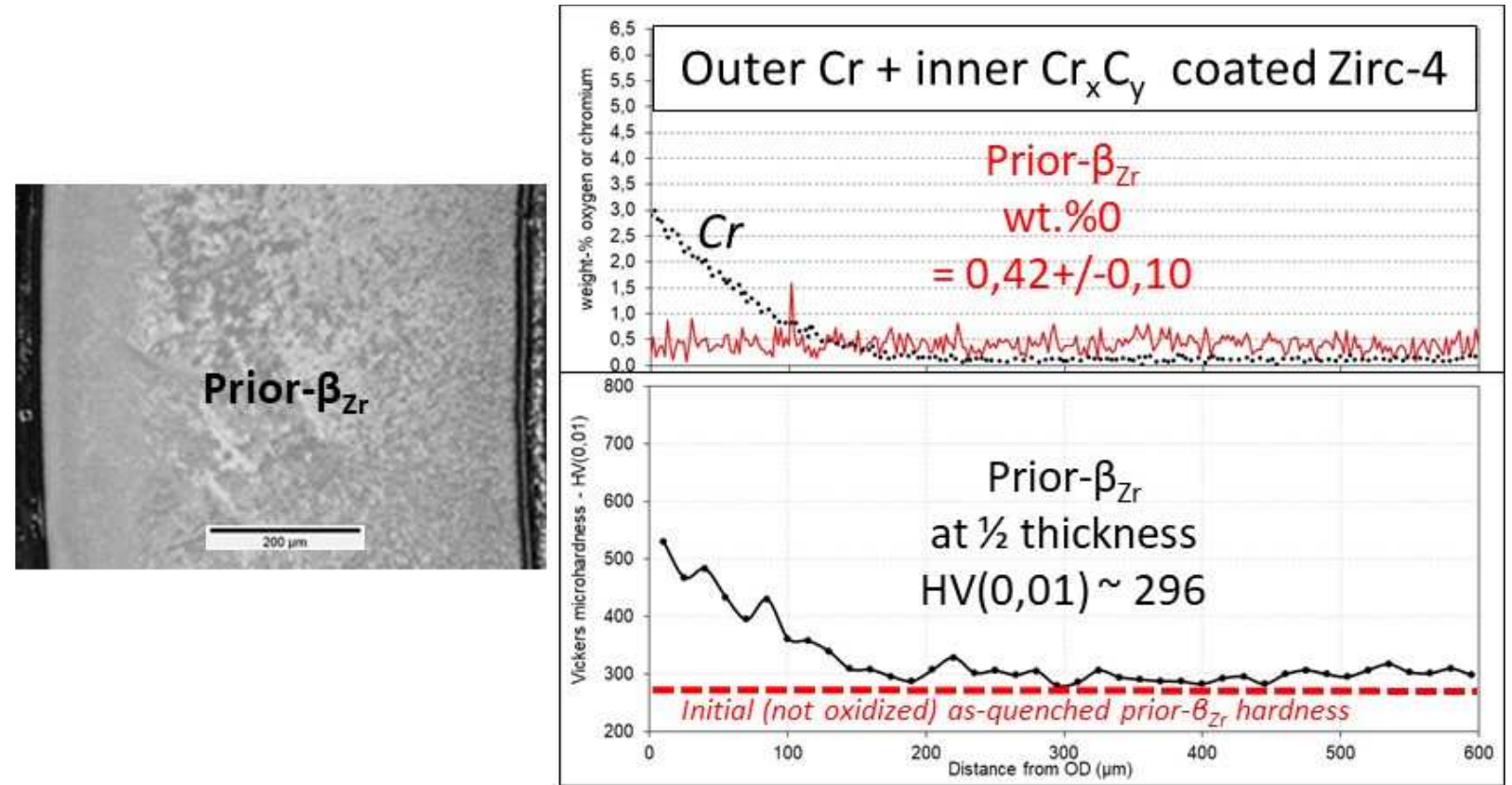

Figure 14 - Optical micrograph and through-thickness (from the outer diameter) oxygen (and chromium) diffusion profiles from EPMA and $\mu$-hardness profiles of two-sided coated HSn-HO-Zirc-4 after two-sided steam oxidation at $1200^{\circ} \mathrm{C}$ for $600 \mathrm{~s}$ 

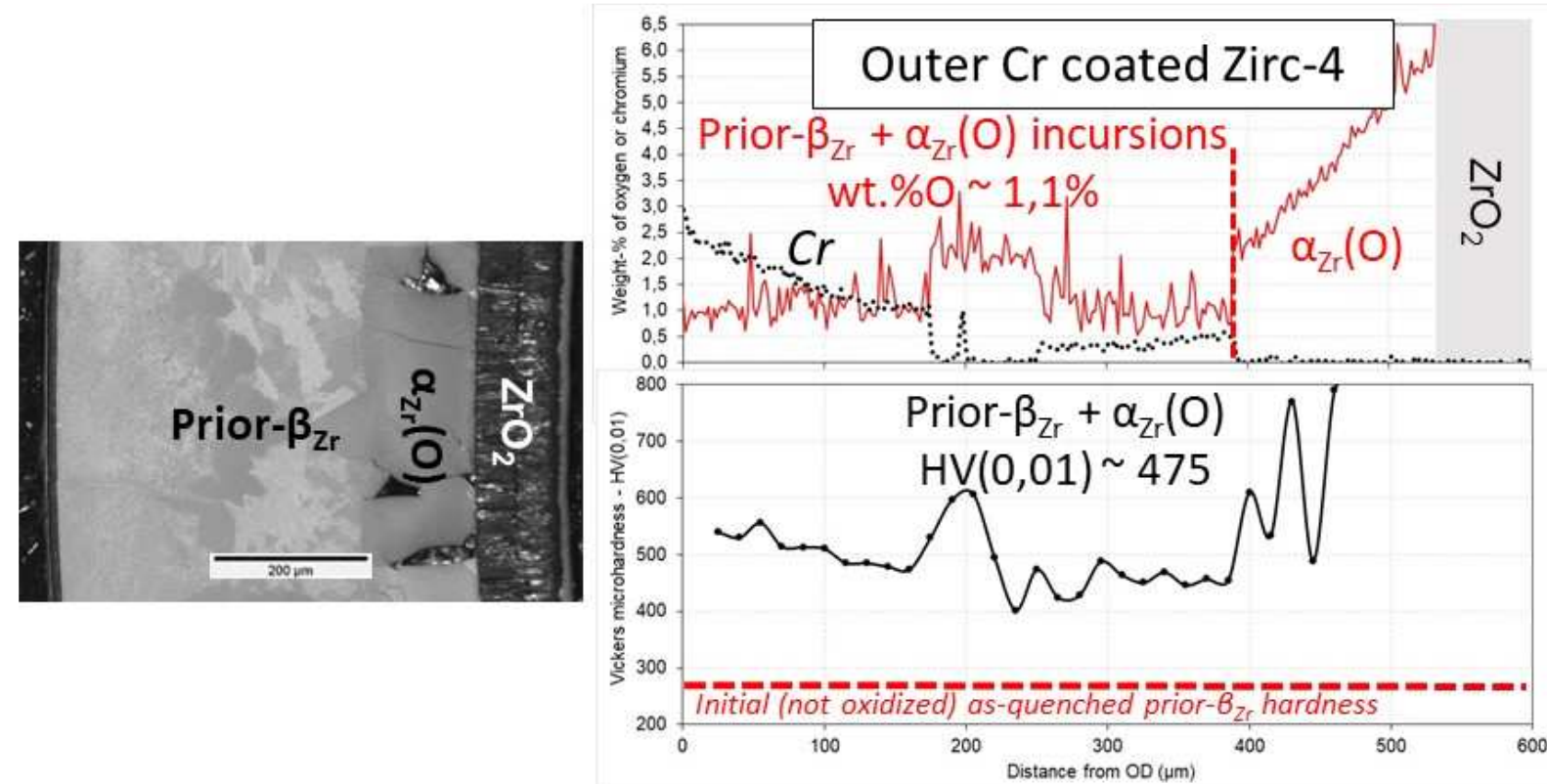

Figure 15 - Optical micrograph and through-thickness (from the outer diameter) oxygen (and chromium) diffusion profiles from EPMA and $\mu$-hardness profiles of outer-coated HSn-HO-Zirc-4 after two-sided steam oxidation at $1200^{\circ} \mathrm{C}$ for $1500 \mathrm{~s}$
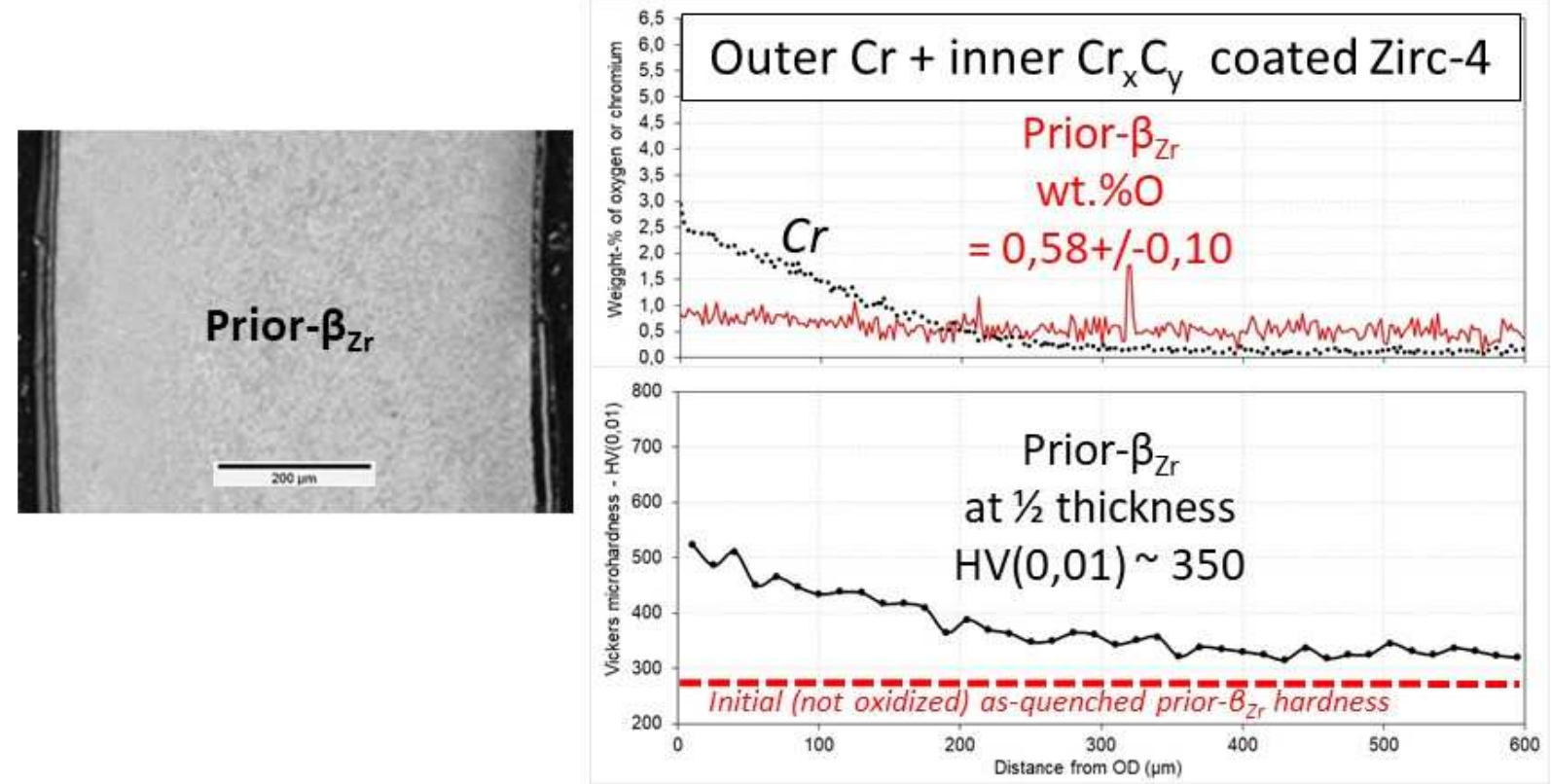

Figure 16 - Optical micrograph and through-thickness (from the outer diameter) oxygen (and chromium) diffusion profiles from EPMA and $\mu$-hardness profiles of two-sided coated HSn-HO-Zirc-4 after two-sided steam oxidation at $1200^{\circ} \mathrm{C}$ for $1500 \mathrm{~s}$ 


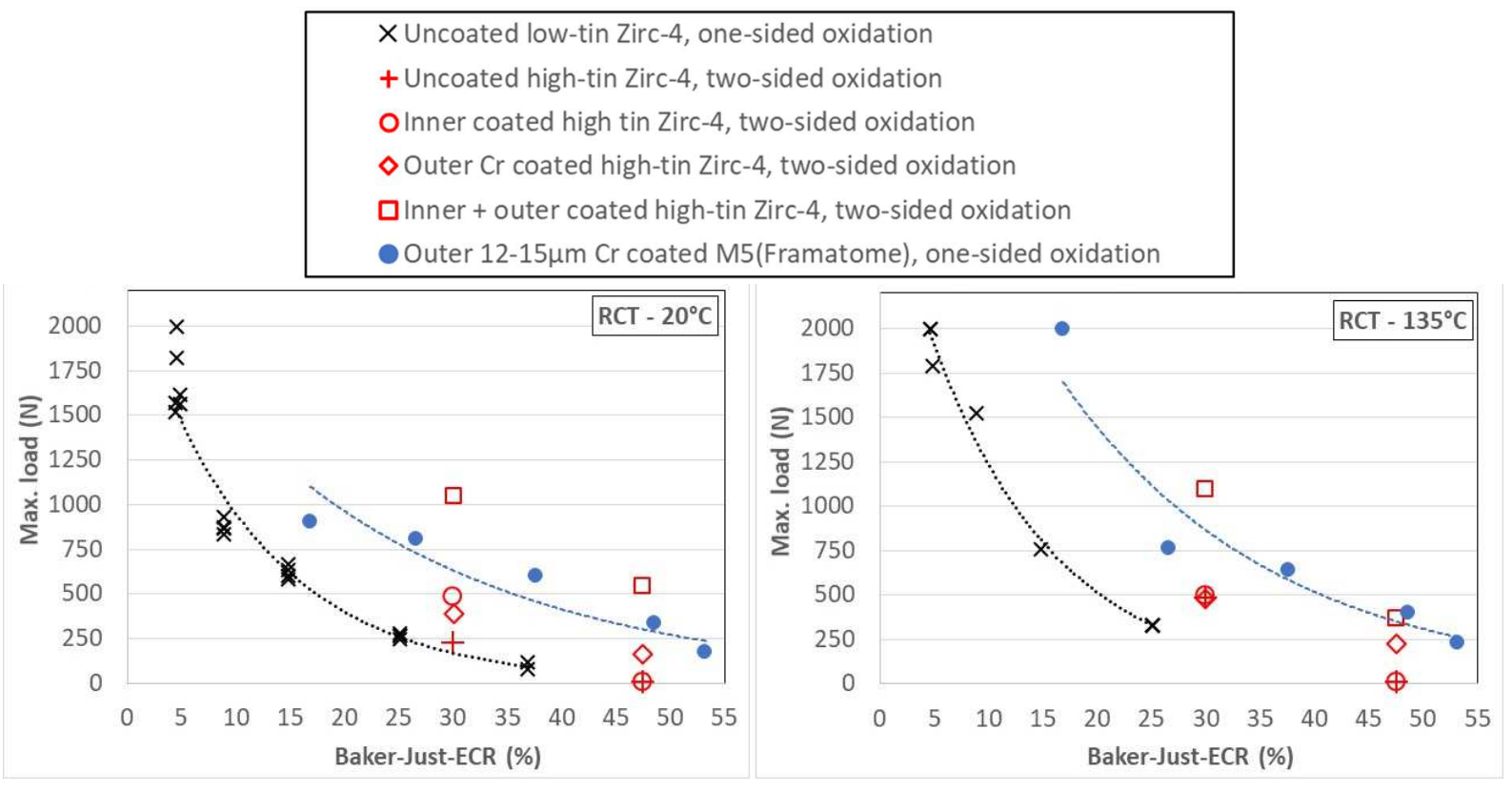

Figure 17 - Maximum load values derived from PQ RCTs after steam oxidation at $1200^{\circ} \mathrm{C}$ followed by direct quenching down to RT (on 1cm-long clad segments), plotted as a function of the Baker-Just ECR and compared with previous data obtained on uncoated [60] [79] and outer Cr-coated [21] cladding materials

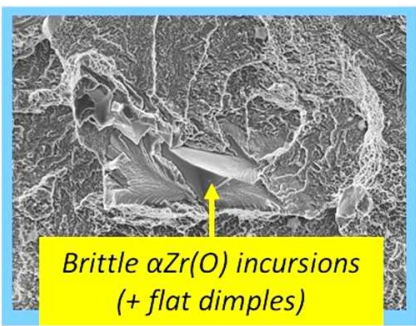

Uncoated Zirc-4
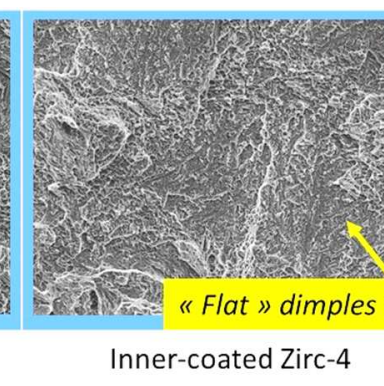

(a) two-sided oxidation for $600 \mathrm{~s}$ at $1200^{\circ} \mathrm{C}$

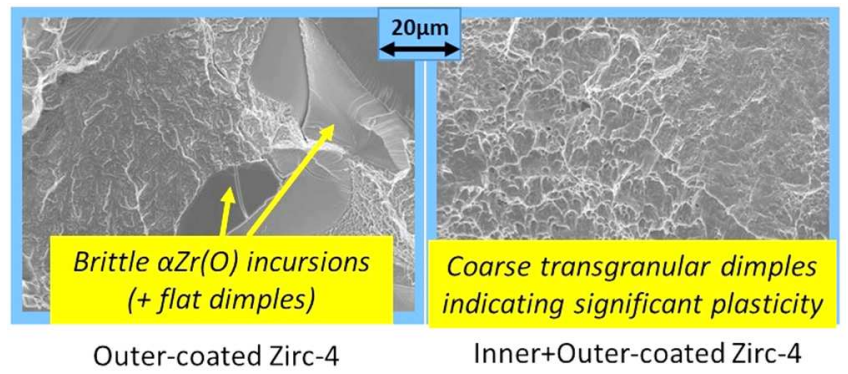

(b) two-sided oxidation for 1500 s at $1200^{\circ} \mathrm{C}$

Figure 18 - Typical fractographs showing the prior- $\beta_{z r}$ failure mode at mid clad thickness location, after PQ RCTs carried out at RT 


\section{$\diamond$ Uncoated LSn-Zirc-4, 1-sided oxidation \\ 6-15 $\mu \mathrm{m}$ outer $\mathrm{Cr}$-coated LSn-Zirc-4 or M5, 1-sided oxidation \\ * Inner and/or outer coated HSn-HO-Zirc-4, 2-sided oxidation (this study)}

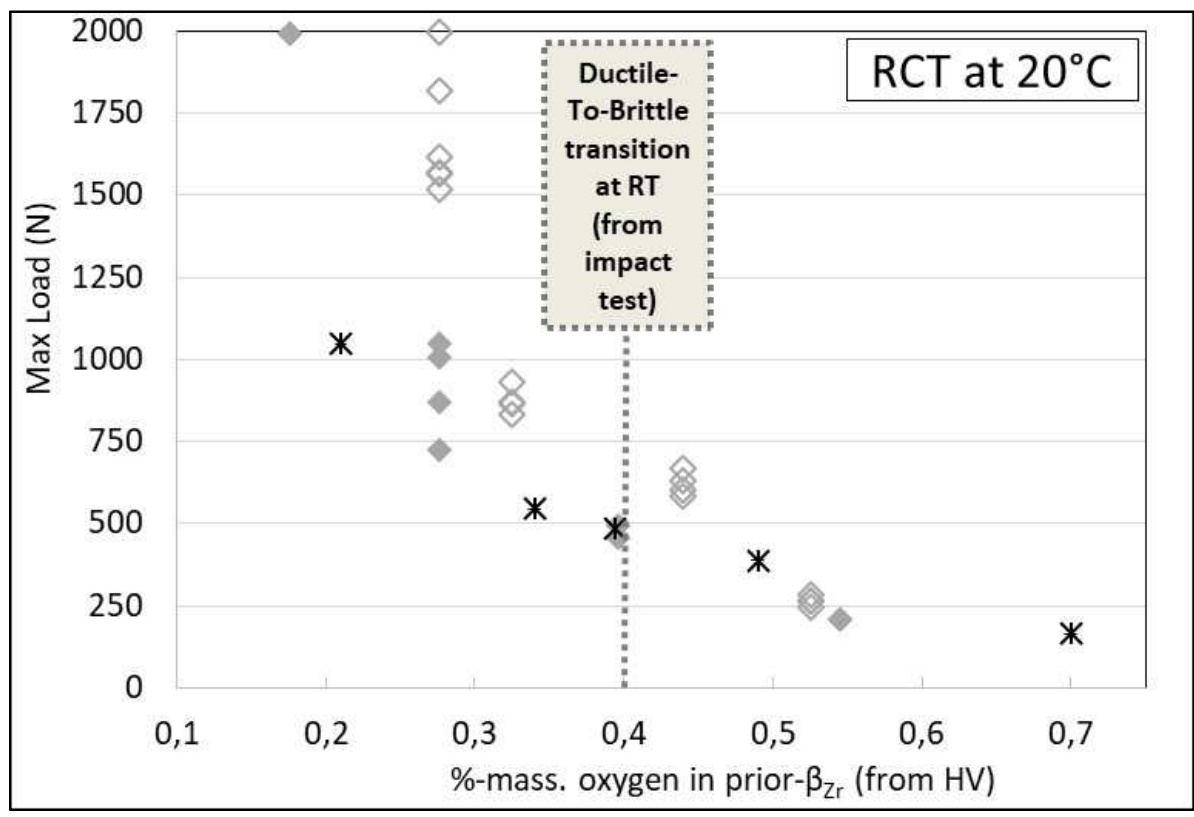

(a)

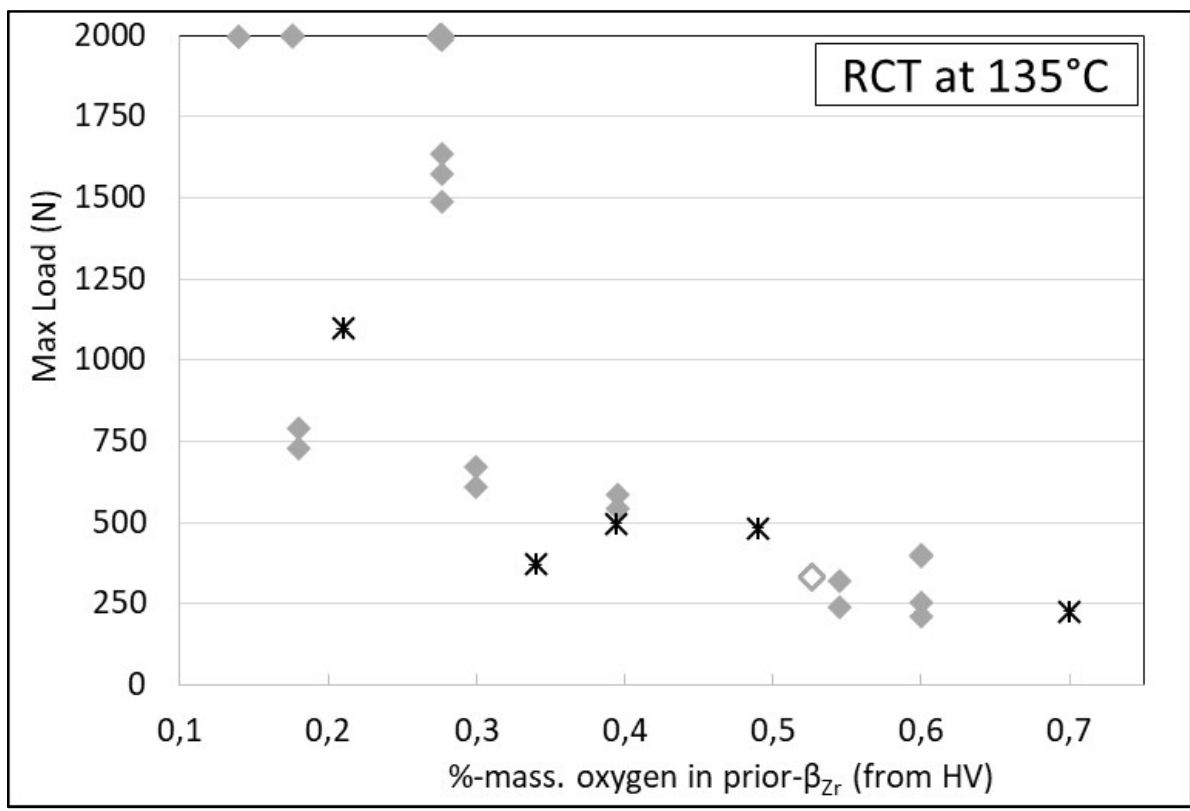

(b)

Figure 19 - Maximum load values derived from PQ RCTs after steam oxidation at $1200^{\circ} \mathrm{C}$ followed by direct quenching down to RT, plotted as a function of prior- $\beta_{z r}$ oxygen content derived from microhardness measurements (equation 1) and compared with previous data obtained on uncoated LowTin Zirc-4 [60] [79] and outer Cr-coated M5Framatome [21] cladding materials

Remark: due to the RCT maximum displacement available, the points corresponding to $2000 \mathrm{~N}$ are underestimated values (i.e., corresponding to un-failed samples) 


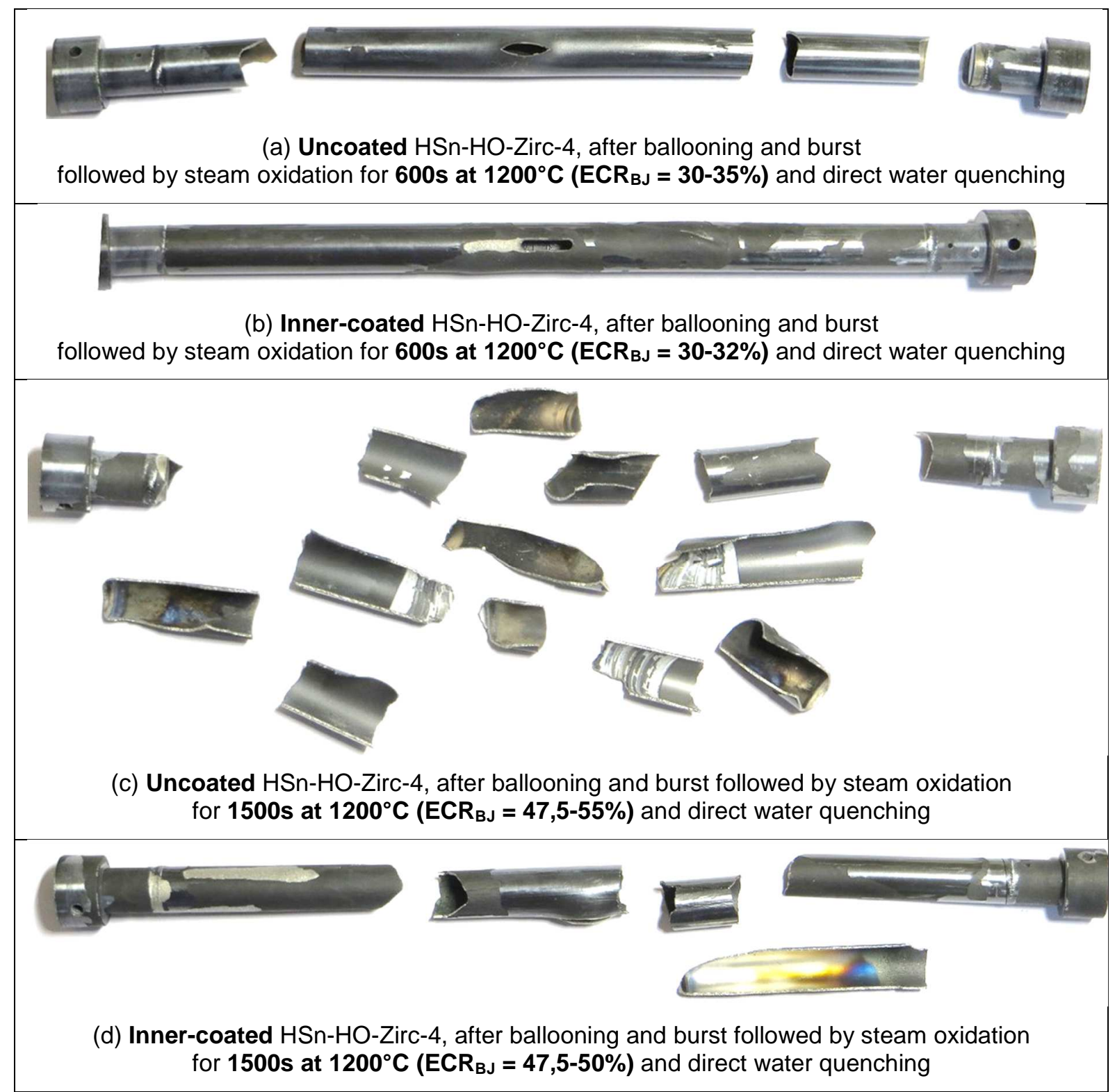

Figure 20 - Visual aspects of uncoated and inner-coated HSn-HO-Zirc-4 clad segments that have experienced internal pressure ballooning and burst temperature ramp tests and then subsequent HT steam oxidation and direct water quenching down to RT 


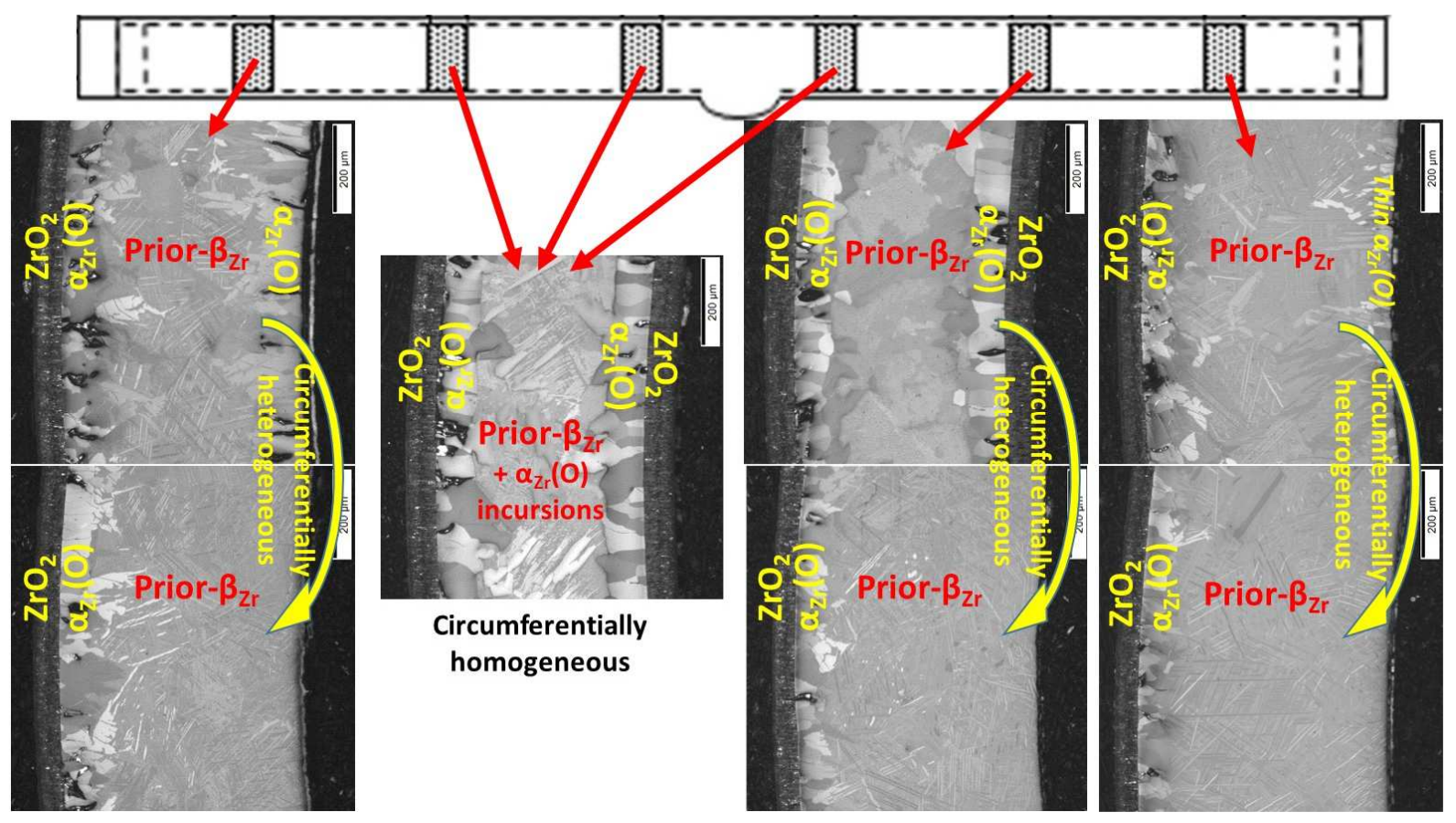

(a)

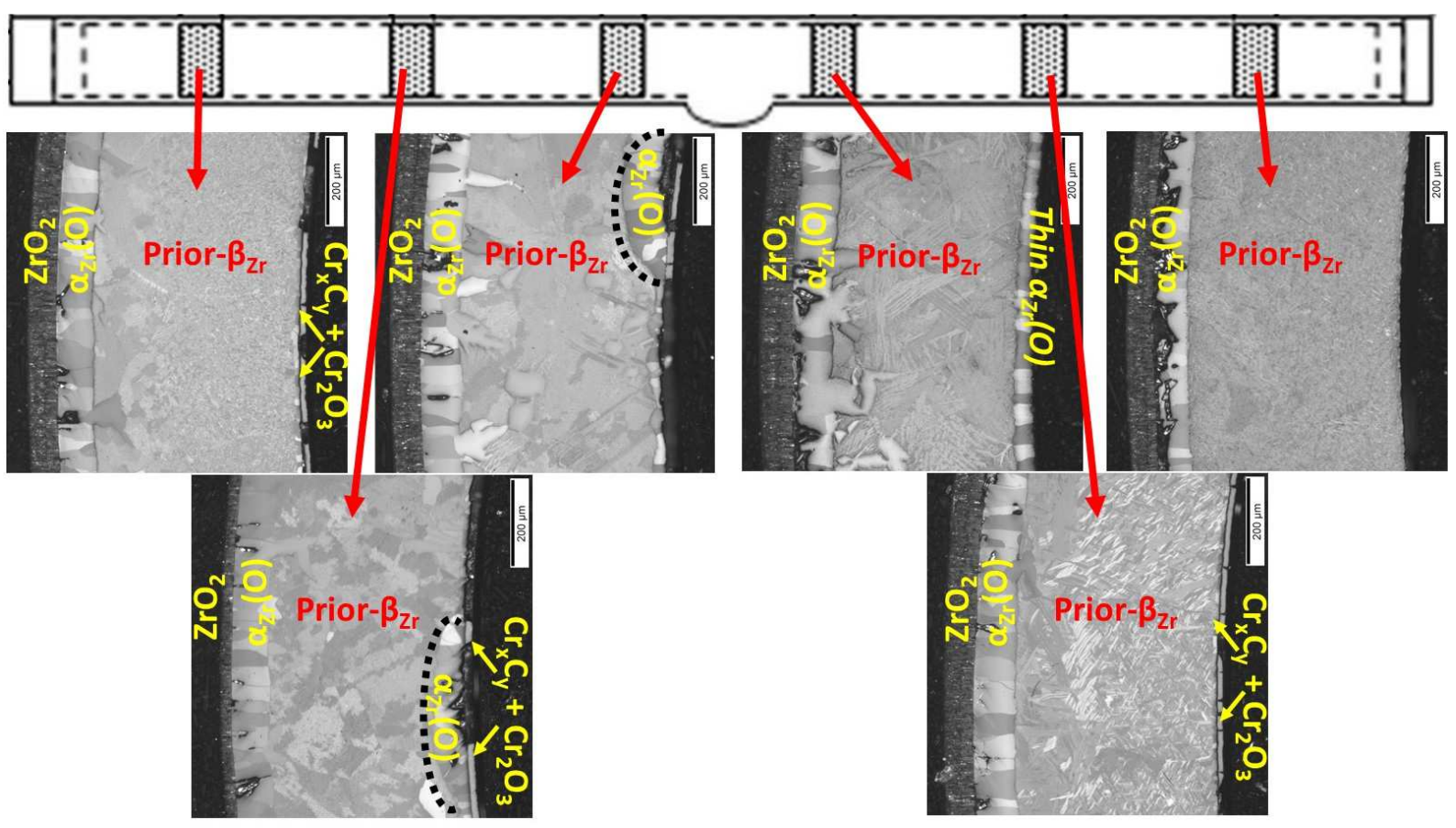

(b)

Figure 21 - Optical micrograph showing the $P Q$ microstructures of uncoated (a) and inner-coated (b) $\mathrm{HSn}$-HO-Zirc-4 clad segments that have experienced internal pressure ballooning and burst thermal ramp tests, and then subsequent $H T$ steam oxidation for 600 s at $1200^{\circ} \mathrm{C}$ 


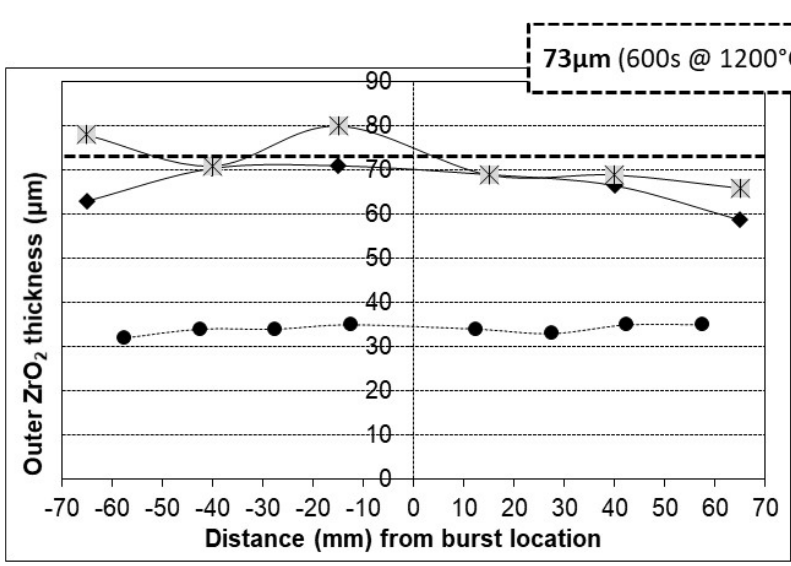

(a)

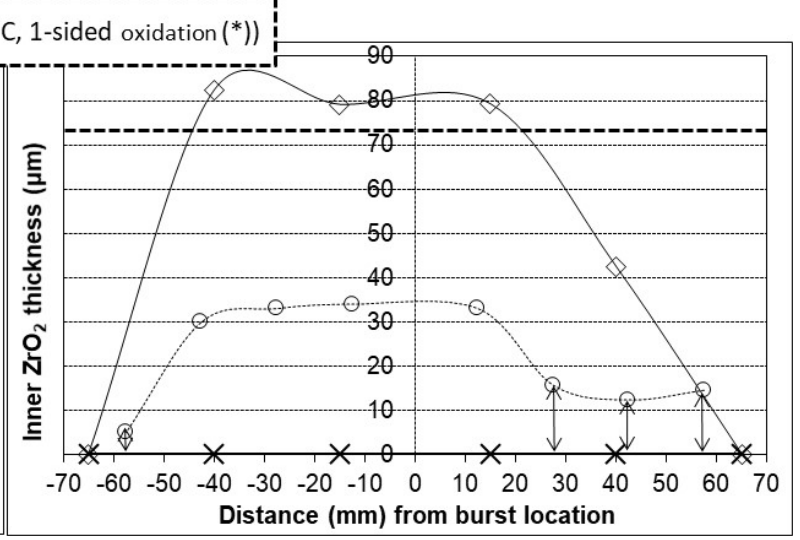

(b)

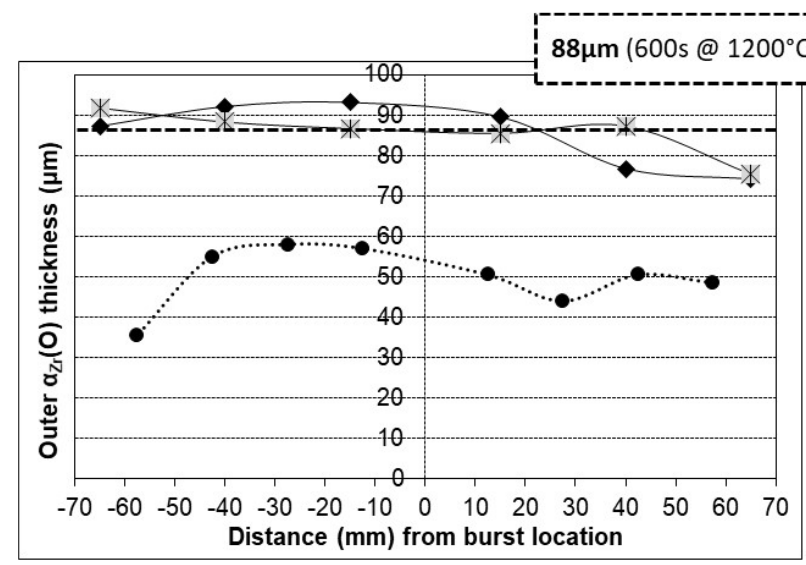

(c)

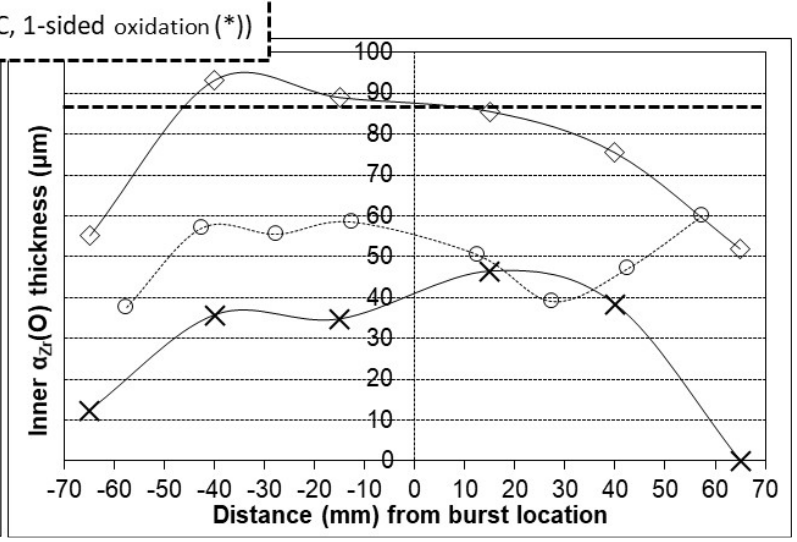

(d)

\footnotetext{
...•. Uncoated M5 -160 s at $1200^{\circ} \mathrm{C}\left({ }^{\star *}\right)$

$\longrightarrow$ Uncoated HSn-HO-Zirc-4 - 600s at $1200^{\circ} \mathrm{C}$

$-*$ - Inner-coated HSn-HO-Zirc-4 -600 s at $1200^{\circ} \mathrm{C}$
}

Figure 22 - Circumferentially averaged values of the thicknesses of the inner/outer $\mathrm{ZrO}_{2}$ and $\alpha_{\mathrm{zr}}(\mathrm{O})$ for uncoated and inner-coated HSn-HO-Zirc-4 clad segments that have experienced internal pressure ballooning and burst thermal ramp tests, and then subsequent $\mathrm{HT}$ steam oxidation for $600 \mathrm{~s}$ at $1200^{\circ} \mathrm{C}$

- Comparison with previous results obtained after one-sided steam oxidation of uncoated low-tin Zircaloy-4 [60] and using the same experimental methodology on uncoated M5 Framatome [47] 


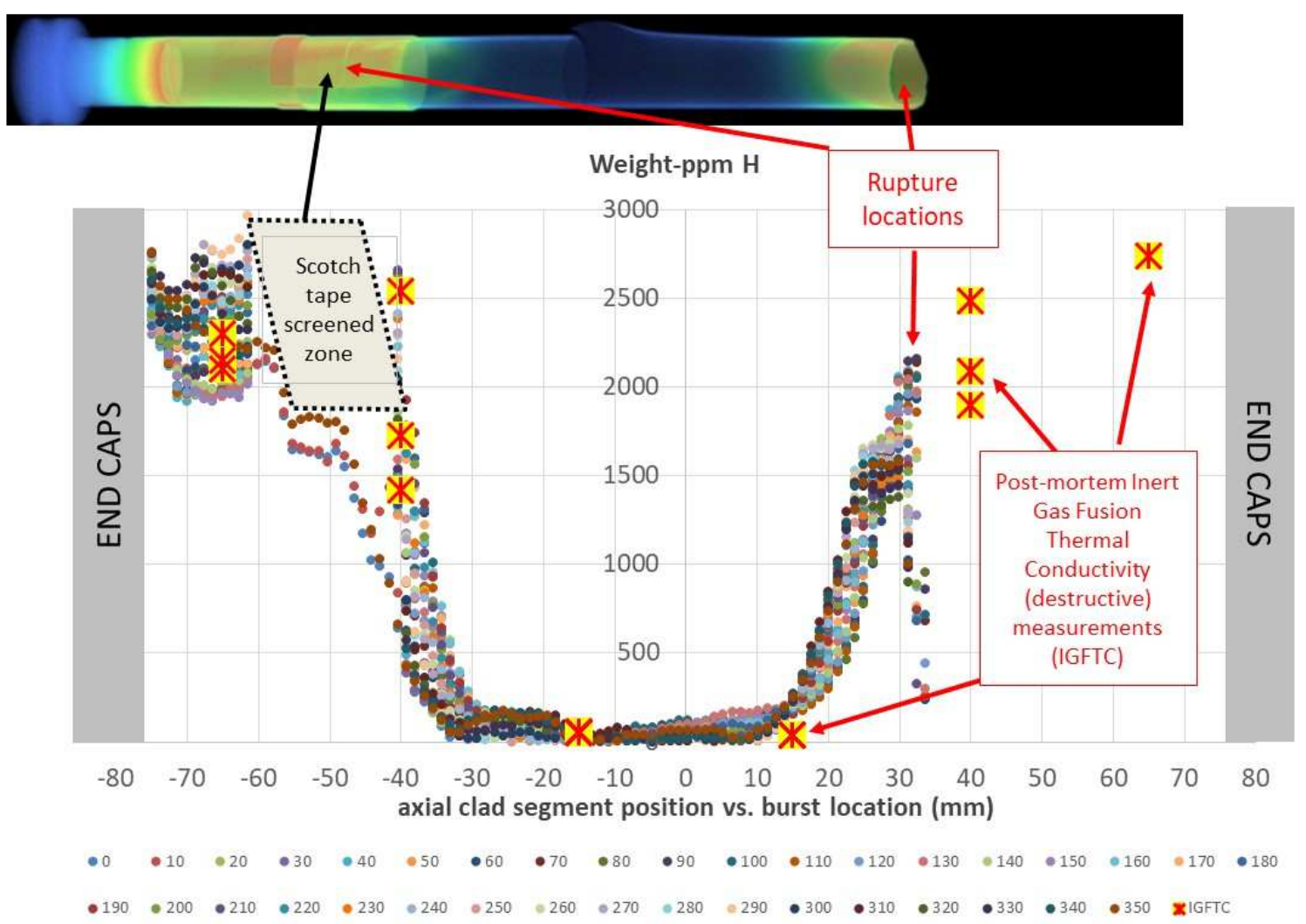

(a) Uncoated

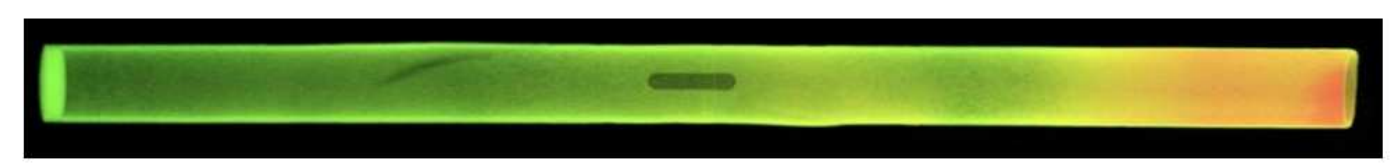

Weight-ppm H

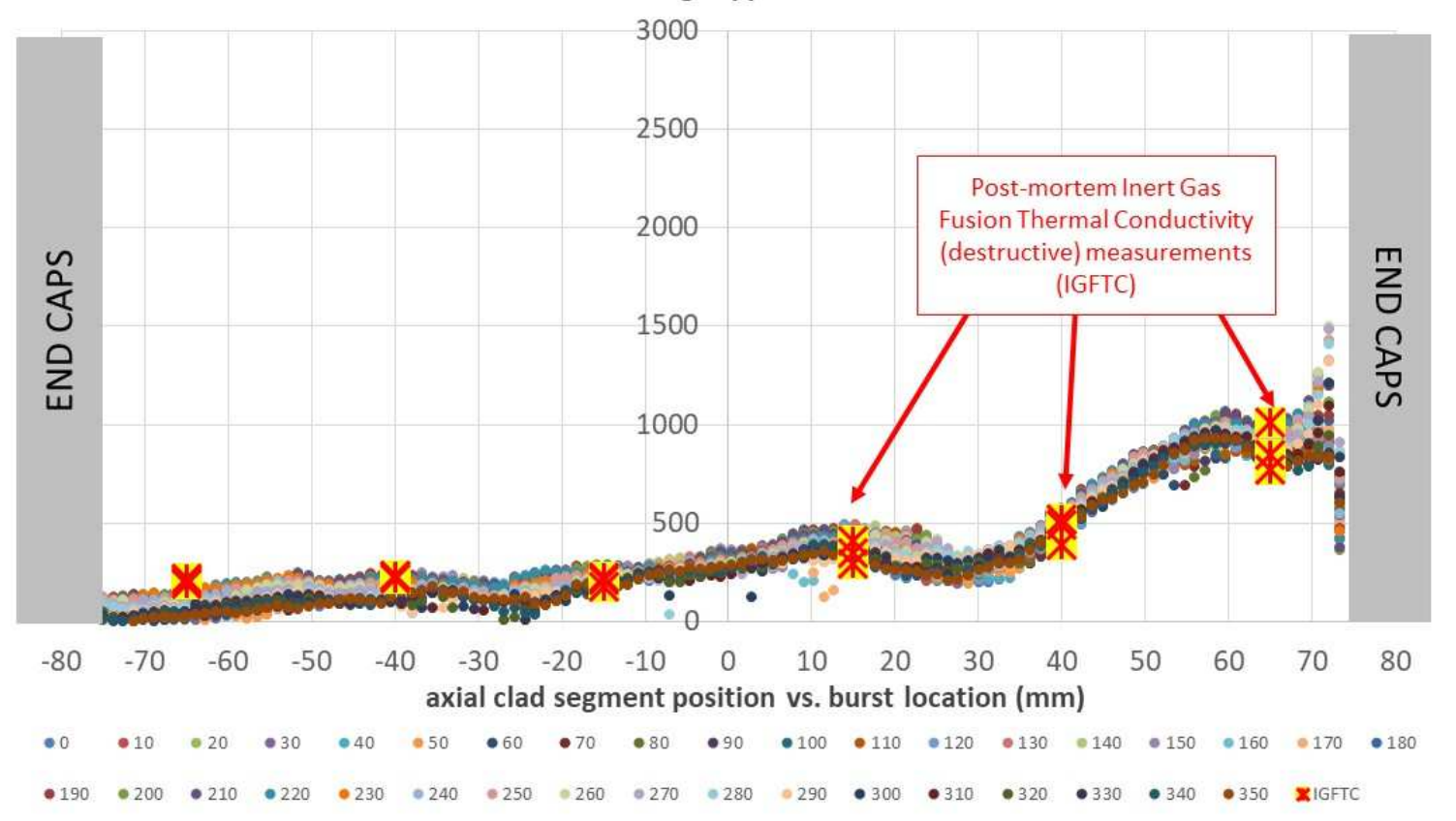

(b) Inner-coated

Figure 23 - PQ hydrogen contents measured by neutron tomography (3D-maps and results plotted every $10^{\circ}$ over the clad circumference) and by post-mortem IGFTC analysis of HSn-HO-Zirc-4 clad segments that have experienced internal pressure ballooning and burst thermal ramp tests, and then subsequent $H T$ steam oxidation for 600 s at $1200^{\circ} \mathrm{C}$ followed by direct water quenching down to $R T$ 


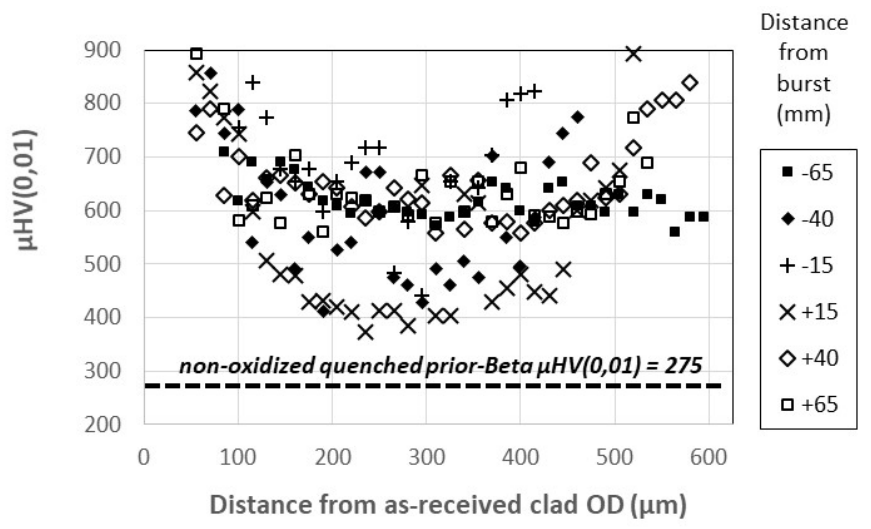

(a) uncoated

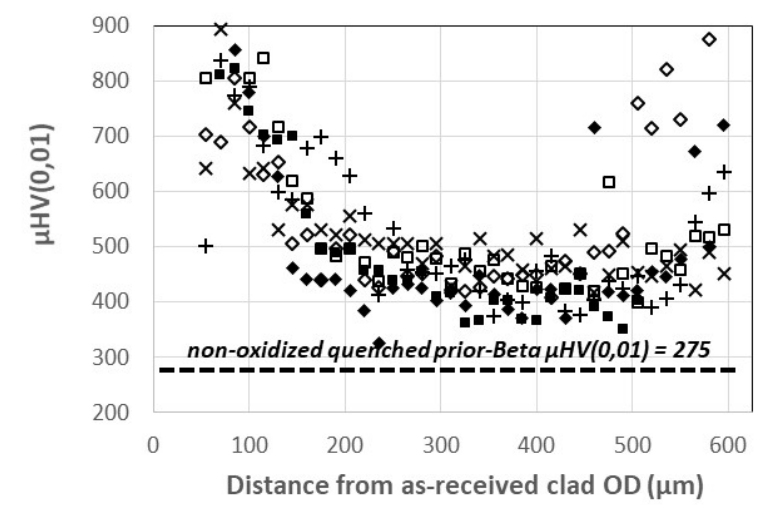

(b) inner coated

Figure 24 - Through-thickness micro-hardness profiles measured at different axial locations of uncoated and inner coated HSn-HO-Zirc-4 clad segments that have experienced internal pressure ballooning and burst thermal ramp tests, and then subsequent HT steam oxidation for 600 s at $1200^{\circ} \mathrm{C}$ + direct water quenching down to RT 


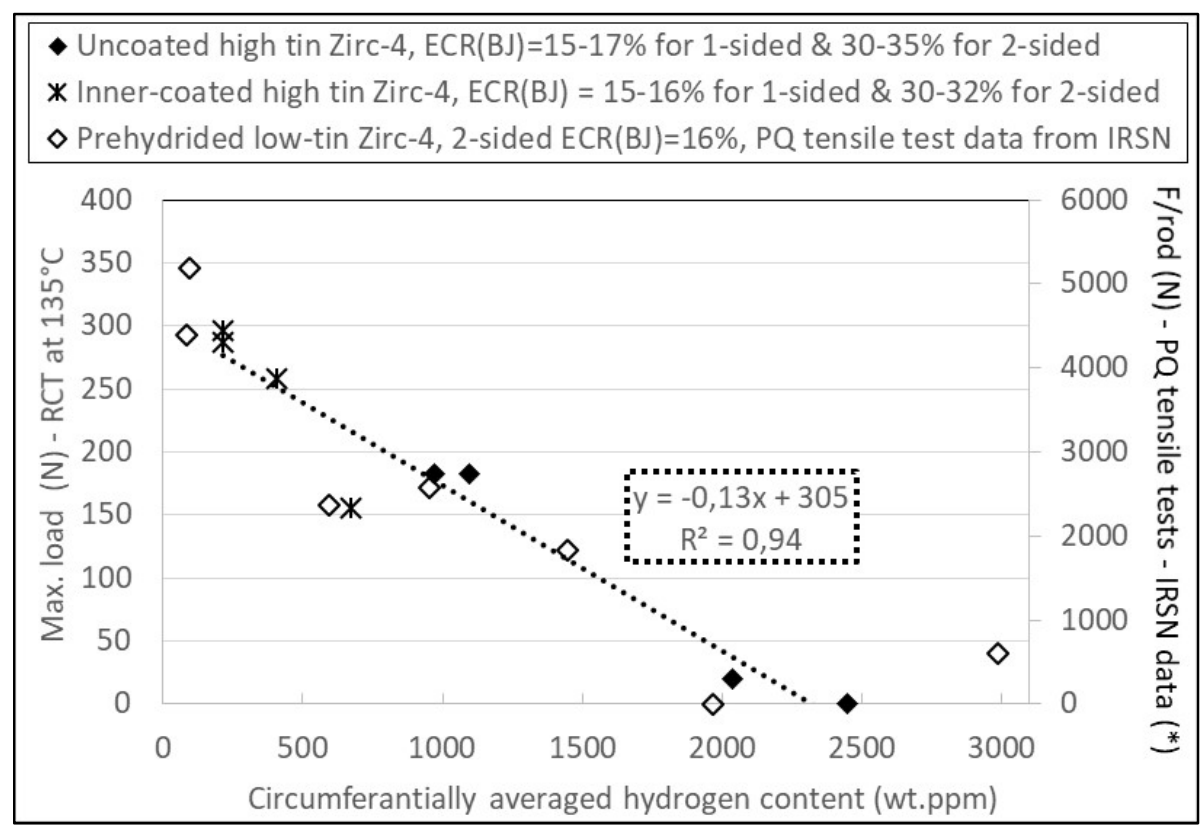

(a)

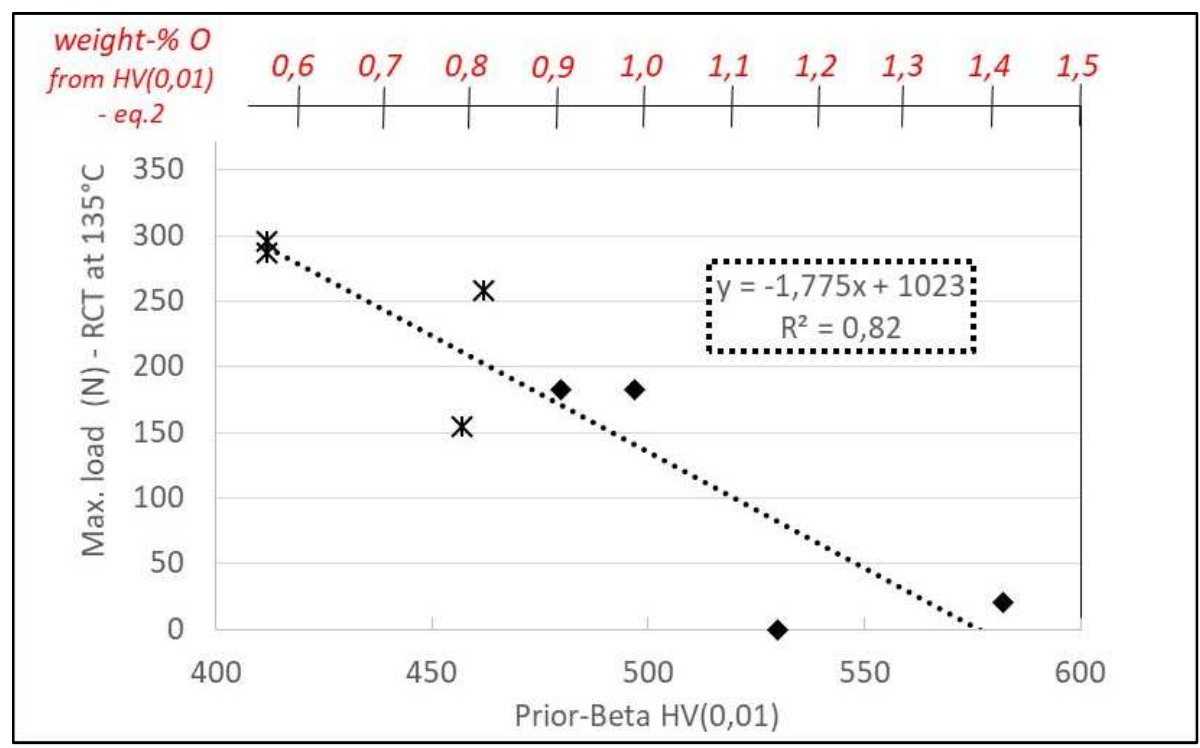

(b)

(*) F/rod: failure load measured upon PQ tensile test extrapolated to full clad section [82]

Figure 25 - Relationships between maximum loads derived from $P Q R C T s$ at $135^{\circ} \mathrm{C}$ and $P Q$ tensile data from IRSN obtained on pre-hydrided Zirc-4 [82]), and:

(a) circumferentially averaged measured (interpolated) hydrogen concentrations

(b) interpolated prior- $\beta$ zr micro-hardness and corresponding oxygen contents derived from equation 2 
口Uncoated \& 1-sided coated HSN-HO-Zirc-4, ECR(BJ) =30\%, 2-sided oxidation (no hydrogen), RCT at RT

O Uncoated \& 1-sided coated HSN-HO-Zirc-4, ECR(BJ) $=30 \%$, 2-sided oxidation (no hydrogen), RCT at $135^{\circ} \mathrm{C}$

- Uncoated HSn-HO-Zirc-4, ECR(BJ)=30-35\% for 2-sided oxidation - after ballooning \& burst, RCT at $135^{\circ} \mathrm{C}$

* Inner-coated HSn-HO-Zirc-4, ECR(BJ) $=30-32 \%$ for 2-sided oxidation - after ballooning\&burst, $\mathrm{RCT}$ at $135^{\circ} \mathrm{C}$

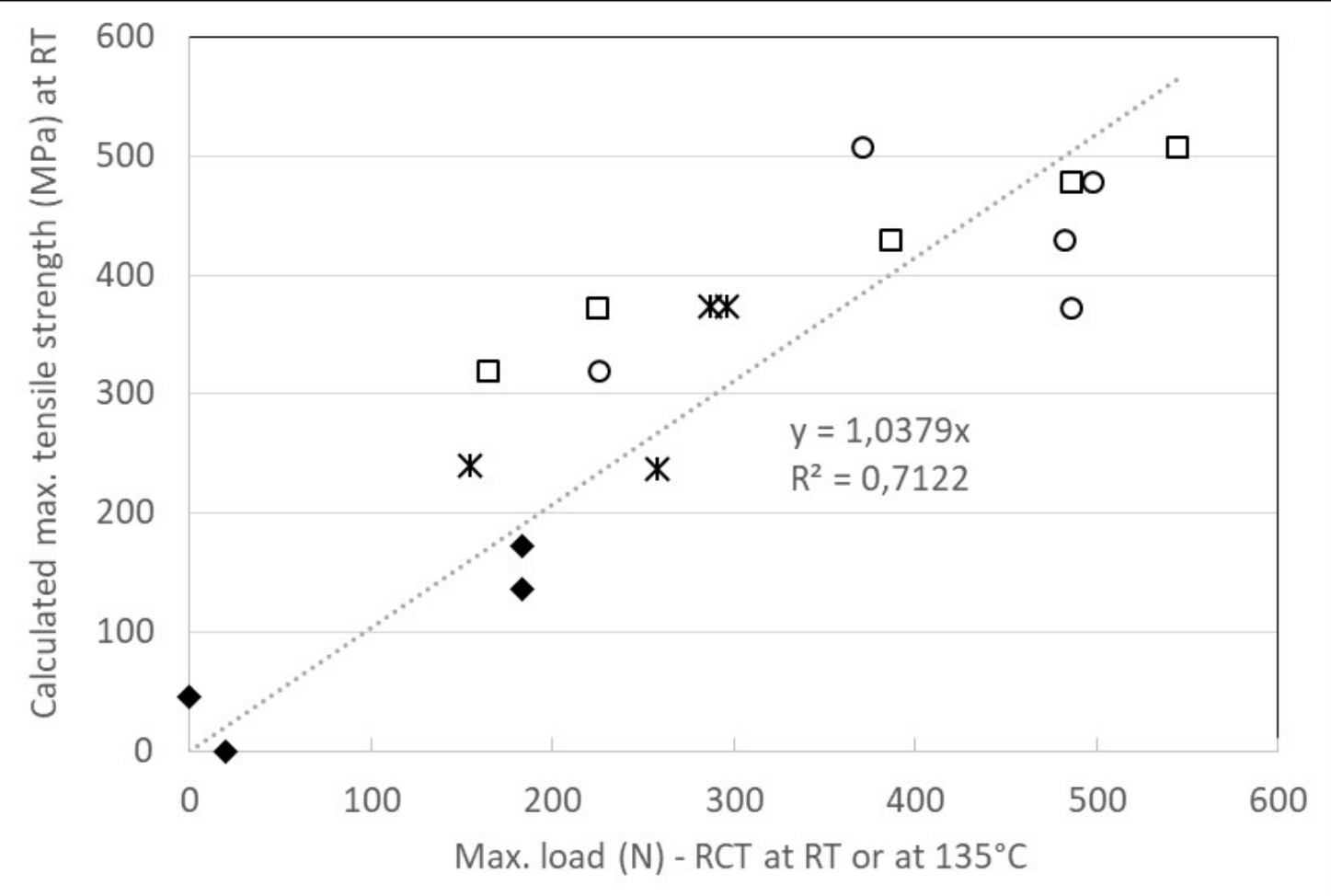

Figure 26 - Calculated PQ maximum tensile strength of prior- $\beta_{Z r}$ at $R T$, using Le Hong et al.' correlation [86] for low-tin Zirc-4 vs. oxygen $\left(^{*}\right)$ and hydrogen $\left(^{* *}\right)$ respective contents, plotted as a function of the maximum load derived from $P Q R C T$ s carried out at $R T$ or at $135^{\circ} \mathrm{C}$ on uncoated/coated HSn-HO-Zirc-4

$\left(^{*}\right)$ derived from prior- $\beta_{z r} H V(0.01)$ measurements

${ }^{* *}$ ) interpolated (averaged) values from IGFTC measurements 